\title{
Impulsivity in cue-elicited craving and appetitive learning
}

Citation for published version (APA):

Papachristou, H. (2013). Impulsivity in cue-elicited craving and appetitive learning. [Doctoral Thesis, Maastricht University]. Datawyse / Universitaire Pers Maastricht. https://doi.org/10.26481/dis.20131219hp

Document status and date:

Published: 01/01/2013

DOI:

10.26481/dis.20131219hp

Document Version:

Publisher's PDF, also known as Version of record

\section{Please check the document version of this publication:}

- A submitted manuscript is the version of the article upon submission and before peer-review. There can be important differences between the submitted version and the official published version of record.

People interested in the research are advised to contact the author for the final version of the publication, or visit the DOI to the publisher's website.

- The final author version and the galley proof are versions of the publication after peer review.

- The final published version features the final layout of the paper including the volume, issue and page numbers.

Link to publication

\footnotetext{
General rights rights.

- You may freely distribute the URL identifying the publication in the public portal. please follow below link for the End User Agreement:

www.umlib.nl/taverne-license

Take down policy

If you believe that this document breaches copyright please contact us at:

repository@maastrichtuniversity.nl

providing details and we will investigate your claim.
}

Copyright and moral rights for the publications made accessible in the public portal are retained by the authors and/or other copyright owners and it is a condition of accessing publications that users recognise and abide by the legal requirements associated with these

- Users may download and print one copy of any publication from the public portal for the purpose of private study or research.

- You may not further distribute the material or use it for any profit-making activity or commercial gain

If the publication is distributed under the terms of Article $25 \mathrm{fa}$ of the Dutch Copyright Act, indicated by the "Taverne" license above, 


\section{Impulsivity in cue-elicited craving and appetitive learning}


(C) Harilaos Papachristou, Maastricht 2013

Production: Datawyse | Universitaire Pers Maastricht

ISBN 9789461592675 


\title{
Impulsivity in cue-elicited craving and appetitive learning
}

\author{
DISSERTATION \\ to obtain the degree of Doctor at Maastricht University, \\ on the authority of the Rector Magnificus, Prof. dr. L.L.G. Soete \\ in accordance with the decision of the Board of Deans, \\ to be defended in public \\ on Thursday 19th December 2013 at 10.00 a.m. hours \\ by \\ Harilaos Papachristou
}

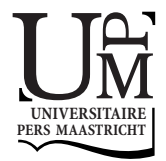




\section{Supervisors}

Prof. Dr. Anita Jansen

\section{Co-supervisor}

Dr. Chantal Nederkoorn

\section{Assessment Committee}

Prof. Dr. Jan Ramaekers (chairman)

Prof. Dr. Geert Dom, Antwerp University

Prof. Dr. Dike van de Mheen

Prof. Dr. Wim van den Brink, University of Amsterdam

Prof. Dr. Johan Vlaeyen

This thesis was partially funded by the U-Center clinic, Epen, The Netherlands. 


\section{Contents}

$\begin{array}{lll}\text { Chapter } 1 \text { General introduction } & 7\end{array}$

Chapter 2 Can't stop the craving: The effect of impulsivity on cue- 23 elicited craving for alcohol in heavy and light social drinkers

Chapter 3 The role of impulsivity and perceived availability on cueelicited craving for alcohol in social drinkers

Chapter 4 Dissection of appetitive conditioning: Does impulsivity play a role?

Chapter 5 Higher levels of trait impulsiveness and a less effective response inhibition are linked to more intense cue-elicited craving for alcohol in alcohol-dependent patients

Chapter 6 Cue reactivity during treatment, and not impulsivity, predicts relapse after treatment in alcohol use disorders

Chapter 7 General discussion

Summary

Acknowledgements

About the author 

CHAPTER 1

General introduction 
CHAPTER 1 


\section{General Introduction}

According to the World Health Organization, harmful use of alcohol is a serious worldwide problem that results in 1.8 millions deaths every year (WHO, 2004). Globally, hazardous alcohol consumption is a major risk factor for the development of medical problems, including cardiovascular disease, cirrhosis of the liver and cancers (WHO, 2004). Harmful alcohol use also disrupts the entire social fabric of a community because it is associated with a variety of public health and safety problems such as violence, fatal injuries, and road traffic accidents (WHO, 2004). Evidently, research on alcohol-drinking behaviour is essential because in order to decrease alcohol-induced mortality and morbidity, we must first understand how the behaviour develops and what maintains it.

Alcohol use can be conceptualized as a typical example of operant behaviour (Glautier \& Remington, 1995). Alcohol has both positive hedonic properties which sustain alcohol administration via positive reinforcement and a capacity to alleviate aversive states which maintains alcohol consumption through negative reinforcement (Drummond, Tiffany, Glautier, \& Remington, 1995). However, it appears that alcohol-drinking behaviour cannot be explained merely by its consequences. For example, in the laboratory, stimuli (or cues) that are repeatedly paired with alcohol administration and typically precede alcohol drinking influence alcohol-seeking behaviour in animals (Krank, 2003; Robbins, Everitt, \& Nutt, 2010). Clinical lore also suggests that alcohol and drug addicts relapse more often in the presence of substance-related cues (Carter \& Tiffany, 1999; Drummond, 2000; Jansen, 1998). Thus, it is not only the effects of alcohol on the central nervous system (CNS) but also alcohol-related stimuli that affect alcohol-drinking behaviour and relapse. Clearly, the role of cues in alcohol-drinking behaviour and relapse is worth investigating as it may be one of the factors that trigger and maintain alcohol-drinking behaviour (Drummond, 2000; Drummond et al., 1995).

\section{Cue-elicited craving as a component of cue reactivity}

One way that cues may influence alcohol-drinking behaviour and relapse is through the elicitation of craving. Although there has been controversy about its nature and definition, in general craving is regarded as the desire to use alcohol or other drugs (Drummond, 2001; Kozlowski \& Wilkinson, 1987; Sayette, Shiffman, Tiffany, Niaura, Martin, \& Shadel, 2000). Cue-elicited craving is typically conceptualized as a specific component of the more general concept of cue reactivity. In the field of addictive disorders, cue reactivity refers to the elicitation of a constellation of responses to alcohol- and drug-related cues (Drummond et al., 1995). These cueelicited responses can be subjective, cognitive-emotional (e.g., increases in craving, pleasure or anxiety), physiological (e.g., changes in heart rate, skin temperature), and behavioural (e.g., alcohol-seeking behaviour) (Carter \& Tiffany, 1999; Drum- 
mond, 2000). In the laboratory, this phenomenon is studied with a cue reactivity (or cue exposure) paradigm (Drummond et al., 1995). In a typical alcohol cue reactivity study, alcohol drinkers and a control group are exposed to control cues and alcohol-related cues and their cue-elicited reactions are observed and measured (Drummond, 2000; Carter \& Tiffany, 1999). A robust finding in the alcohol literature is that alcohol-dependent participants and heavy social alcohol drinkers often report an increase in craving for alcohol and demonstrate significant physiological reactivity (increased skin conductance) to alcohol-related vs. neutral stimuli (Carter \& Tiffany, 1999; Drummond 2000; Field \& Duka, 2002; Fox, Bergquist, Hong, \& Sinha, 2007; Greeley, Swift, Prescott, \& Heather, 1993; Rees \& Heather, 1995).

Although it would be wrong to restrict the explanation of cue reactivity merely to one mechanism, it is broadly assumed that it results from classical conditioning (Drummond, 2000; Robbins \& Erhman, 1992). There are three classic conditioning models of cue reactivity in the field of addictive disorders (Stewart, de Wit, \& Eikelboom, 1984; Siegel \& Ramos, 2002; Wikler, 1984). All of them assume that cues repeatedly paired with alcohol and drug administration become conditioned stimuli (CSs) that elicit conditioned responses (CRs) which in turn motivate drugand alcohol-seeking behaviour (Tiffany \& Conklin, 2000). Within this pavlovian cue reactivity framework, craving is one type of CR that could potentially trigger alcohol drinking (Tiffany, 1990). However, the nature of the craving CR and how it affects the operant alcohol-seeking behaviour differs between the three models. In Wikler's model, cues associated with withdrawal symptoms become CSs that elicit a conditioned withdrawal state (CR) (Wikler, 1984). As craving is part of the unconditioned withdrawal syndrome, it can also be conditioned and elicited as a component of the aversive CR (Drummond, 2001; Wikler, 1984). Similarly, Siegel argued that cues associated with drug administration become CSs that come to elicit compensatory withdrawal-like CRs opposite in direction to the initial positive hedonic drug and alcohol effects (Siegel \& Ramos, 2002). These aversive physiological CRs are translated into craving and alcohol/drug use, though the translational process is not clearly defined in the model (Drummond et al., 1995; Tiffany, 1990). In both models, craving has an aversive nature and motivates alcohol-seeking behaviour via negative reinforcement (Drummond et al., 1995). In an imaginary scenario, when a detoxified former alcohol-dependent patient encounters an alcohol-related cue (e.g., the sight of a drinking friend or a favourite pub), s/he experiences conditioned withdrawal-like symptoms including physiological responses (e.g., sweating) and craving and tries to escape from these aversive CRs by seeking the pleasant effects of alcohol (Tiffany \& Conklin, 2000). Unlike the negative reinforcement models, Stewart, de Wit, and Eikelboom's (1984) conditioned incentive model views alcohol- and drug-seeking as a result of positive reinforcement. In the model, craving is conceptualized as a central emotional or motivational state that mediates the positive reinforcing effects of alcohol (Stewart et al., 1984). The emotional state could be an UR to the alcohol itself and a CR to conditioned incentives or cues that 
have been paired with alcohol administration (Bindra, 1974; Hogarth \& Duka, 2006; Stewart et al., 1984; Tiffany \& Conklin, 2000). The central motivational state is expressed in the form of appetitive physiology (e.g., salivation), craving reports, alcohol-related thoughts, and behaviour associated with alcohol (operant alcoholseeking behaviour or approach behaviour to the alcohol CS similar to sign-tracking) (Drummond et al., 1995; Krank, 2003; Steward et al., 1984). In our imaginary scenario, the sight of a favourite pub (CS) elicits the central appetitive state (CR) and as a result, the detoxified former alcohol-dependent patient reports craving, remembers the pleasant effects of alcohol, salivates, and approaches the pub in order to find the reward promised by the conditioned emotional state. However, by approaching the pub, s/he runs the risk of being exposed to more alcohol-related stimuli that also elicit and perhaps potentiate the emotional state (e.g., an old drinking friend in the pub) (Tiffany \& Conklin, 2000). Finally, the activation of the central emotional state would prompt reinstatement of alcohol drinking via a positive reinforcement mechanism as a way to maintain and, even better, to augment the positive appetitive state (Hogarth \& Duka, 2006).

The common assumption in all three models that craving leads inevitably to alcohol drinking and relapse has been seriously criticized by some authors (Tiffany, 1990). Tiffany (1990) reported that the correlation between cue-elicited craving and behavioural measures of cue reactivity in alcohol and nicotine studies is usually low. Yet, the behavioural measures used in these studies may be poorly associated with real-life alcohol and nicotine use and relapse (Glautier \& Tiffany, 1995; Tiffany, 1990). In support of this argument, Drummond and Glautier (1994) illustrated that higher cue-elicited craving is associated with a shorter latency to relapse to alcohol dependence and with the amount of alcohol consumed during a 6-month follow-up period. Similarly, Abrams, Monti, Carey, Pinto, and Jacobus (1988) demonstrated that increased craving in response to smoking cues predicts relapse in abstinent smokers. Drummond, Litten, Lowman, and Hunt (2000) suggest that craving is related to alcohol drinking and relapse but only under certain conditions, for example, in combination with other variables that moderate craving or mediate its relationship with alcohol-drinking. The moderators of cue-elicited craving could also explain some of the variability in cue reactivity studies that cannot be easily explained by the monistic conditioning models (Rees \& Heather, 1995). For example, the magnitude of cue reactivity varies between people and in some laboratory studies participants do not always experience craving in response to alcoholrelated cues (Litt, Cooney, \& Morse, 2000; Rees \& Heather, 1995). The classic conditioning models can account for this variability and preserve their validity by arguing that the drinking histories of participants in cue reactivity studies differ in duration. A brief alcohol-drinking history offers fewer opportunities for the development of associative learning between alcohol-related cues and alcohol effects and results in a weaker craving CR. However, even among alcohol- and opiatedependent people with extensive alcohol-drinking and opiate-use histories, onethird does not respond to alcohol- and opiate-related cues (Litt et al., 2000; Rees \& 
Heather, 1995). Individual differences in the form of personality traits or genetic factors as well as cognitive-contextual variables may account for this heterogeneity of responses (Drummond et al., 2000). As regards personality factors, impulsivity is a possible candidate.

\section{Impulsivity}

\section{Impulsivity is a multidimensional construct}

The term impulsivity is used to describe a wide range of behaviours characterized by intolerance of uncertainty, impatience, difficulty withholding responses, and a tendency for unplanned and fast responses to salient stimuli without concern of the effects of one's behaviour on others or on the self (Dawe \& Loxton, 2004; de Wit, 2008; Dom, D’haene, Hulstijn, \& Sabbe, 2006; Evenden, 1999; Moeller, Barratt, Dougherty, Schmitz, \& Swann, 2001; Stanford, Mathias, Dougherty, Lake, Anderson, \& Patton, 2009; Verdejo-Garcia, Lawrence, \& Clark, 2008). Examples of impulsive behaviour can be seen in varying degrees in normal people (Evenden, 1999). Consequently, impulsivity is also regarded as a trait that varies along a continuum with higher levels of the trait linked to a higher incidence of psychopathology (Dawe \& Loxton, 2004; Evenden, 1999; Moeller et al., 2001; Stanford et al., 2009; VerdejoGarcia et al., 2008).

In general, impulsivity is measured with self-report scales and behavioural tasks (Dougherty, Bjork, Harper, Marsh, Moeller, Mathias, \& Swann, 2003; Dougherty, Mathias, Marsh, \& Jagar, 2005; Moeller et al., 2001; Lane, Cherek, Rhoades, Pietras, Tcheremissine, 2003). The former are typically used to measure long-term trait-dependent features of the concept, whereas the latter are more sensitive to temporal and situation-specific changes in impulsivity (Dougherty et al., 2003; Dougherty et al., 2005; Evenden, 1999; Moeller et al., 2001). Each type of measure has its own advantages and disadvantages. Self-report scales assess a wide range of day-to-day behaviours and integrate social aspects of the construct in the measurement, which provides them with good ecological validity (Moeller et al., 2001). However, they rely on the dubious assumptions that individuals have good insight of their own behaviour and are honest when they answer questions about it (Dougherty et al., 2003; Dougherty et al., 2005; Moeller et al., 2001). On the other hand, behavioural tasks are immune to such problems as demand effects or lack of insight, but they do not incorporate social aspects of behaviour (Moeller et al., 2001). Subsequently, performance on these tasks may not easily generalize to daily behaviour due to the artificial nature of the tasks (Dougherty et al., 2005; Evenden, 1999; Moeller et al., 2001).

The multitude of impulsivity scales and tasks and the wide spectrum of behaviours included in its definition imply that impulsivity is a multidimensional construct (Dougherty et al., 2003; Dougherty et al., 2005; Lane et al., 2003). In fact, it appears that behavioural measures correlate only weakly with self-report scales 
indicating that each type of measurement taps into somewhat different aspects of the construct (Dougherty et al., 2005; Lane et al., 2003; Reynolds, Ortengren, Richards, \& de Wit, 2006). Furthermore, although there is a stronger correlation between measures of the same type, factor analytic studies illustrate that there are distinct domains within each type (Dawe \& Loxton, 2004; Lane et al., 2003).

With the exception of Barratt Impulsiveness Scale (BIS-11), most widely used self-report measures of impulsivity are based on major personality theories proposed by Eysenck, Cloninger, Zuckerman, and Gray (Cloninger, 1994; Corr, Pickering, \& Gray, 1995; Eysenck, Pearson, Easting, \& Allsop, 1985; Patton, Stanford, \& Barratt, 1995; Pickering \& Gray, 1999; Stanford et al., 2009; Zuckerman, 1971). Although self-report measures usually correlate with each other, factor analytic studies discriminate between two distinct domains: rash impulsiveness and sensitivity to reward (Dawe, Gullo, \& Loxton, 2004; Dawe \& Loxton, 2004; Stanford et al., 2009; Zuckerman \& Cloninger, 1996). The former refers to unplanned spontaneous behaviour without regard to the consequences, while the latter refers to the predisposition to approach rewarding stimuli and experience positive affect from the interaction with them (Dawe \& Loxton, 2004). Measures like the Eysenck's Impulsiveness $\left(\mathrm{I}_{7}\right)$ questionnaire, Cloninger's Novelty Seeking (NS) scale of the Temperament and Character Inventory (TCI), Zuckerman's Sensation Seeking Scale (SSS), and BIS-11 load mostly on the rash impulsiveness factor (Cloninger, 1994; Dawe \& Loxton, 2004; Eysenck et al., 1985; Patton et al., 1995; Stanford et al., 2009; Zuckerman, 1971). On the other hand, measures that regard impulsivity as increased activity in Gray's Behavioural Activation System (BAS) load mainly on the reward sensitivity factor (Carver \& White, 1994; Corr et al., 1995; Dawe \& Loxton, 2004; Pickering \& Gray, 1999; Torrubia, Avila, Molto, \& Caseras, 2001).

Factor analytic studies reveal that behavioural measures of impulsivity can also be broadly divided into two categories: response inhibition and reward-directed tasks (Dougherty et al., 2003; Lane et al., 2003; Reynolds et al., 2006) Rewarddirected tasks usually measure the (in)ability to delay responding for reward (Dougherty et al., 2003). Response inhibition is an executive function that refers to the cognitive processes required to stop an automatic (prepotent) but inappropriate physical response (Aron, Robbins, Poldrack, 2004; Eagle, Bari, Robbins, 2008; Verdejo-Garcia et al., 2008). It is usually measured with one of two tasks: the go/no-go task and the stop signal task (Eagle et al., 2008). However, it appears that the tasks assess distinct psychological processes, each mediated by separate neurochemical systems (Eagle et al., 2008). The go/no-go task measures action-restraint, that is, the suppression of a physical response before that response has been initiated (Eagle et al., 2008). On the other hand, the stop signal task measures action cancellation, or the process of suppressing a prepotent physical response after it has been initiated and while being executed (Eagle et al., 2008). Aron et al. (2004) have illustrated that the stop signal task activates a cortical-subcortical network that includes the right inferior frontal cortex (rIFC), the subthalamic nucleus (STN) and the basal ganglia (BG). The authors further suggest that activation of this neural 
network may underlie voluntary suppression of inappropriate responses, regardless of response type (e.g., memory retrieval) (Aron et al., 2004).

Dawe et al. (2004) relate response inhibition to rash impulsiveness and they argue that both impulsivity components reflect prefrontal activity. In support of this idea, there is evidence that BIS-11 scores are also associated with various indices of executive functions and frontal activity (Stanford et al., 2009). Furthermore, Logan, Russel, Schachar, and Tannock (1997) demonstrated a positive relationship between response disinhibition measured with the stop signal task and the Extraversion scale of the Eysenck Personality Inventory in normal people. Moreover, Gorlyn, Keilp, Tryon, and Mann (2005) revealed an association between performance in the stop signal task and the Motor Impulsiveness subscale of BIS-11 in normal population. However, the results of a study with normal population by Enriccott, Ogloff, and Bradshaw (2006) did not replicate the latter finding. Finally, in abstinent alcohol-dependent people, measures of rash impulsiveness (BIS-11 and SSS) did not correlate with performance on a response inhibition task (go/no-go task) (Dom, Wilde, Hulstijn, \& Sabbe, 2007).

\section{Impulsivity and alcohol use disorders}

There is evidence from cross-sectional studies that heavy alcohol use and alcohol use disorders (AUDs) are associated with elevated levels of impulsivity measured with either self-report or behavioural measures (Dick, Smith, Olausson, Mitchell, Leeman, O’Malley, \& Sher, 2010; Verdejo-Garcia et al., 2008). For example, Nederkoorn, Baltus, Guerrieri, and Wiers (2009) revealed that heavy vs. light female social drinkers have a worse performance in the stop signal task. Similarly, in a community sample of male adolescents it was found that higher BIS-11 scores are linked to alcohol- and drug-related problems and may prompt a faster exposure to alcohol (Von Diemen, Bassani, Fuchs, Szobot, \& Pechansky, 2008). Moreover, a number of studies have found that a higher level of reward sensitivity is associated with hazardous alcohol drinking (Dawe \& Loxton, 2004; Kambouropoulos \& Staiger, 2007). Finally, alcohol-dependent drinkers have higher levels of impulsivity as measured with the BIS-11 and the go/no-go task than healthy controls (Lawrence, Luty, Bogdan, Sahakian, \& Clark, 2009).

However, there is controversy about the direction of the relationship between impulsivity and alcohol use disorders. Impulsivity may be a vulnerability factor to alcohol problems or a consequence of the neurotoxic effects of prolonged alcohol use (Dick et al., 2010; Jentsch \& Taylor, 1999; Lawrence et al., 2009; Verdejo-Garcia et al., 2008). Supporting evidence for the vulnerability account of impulsivity comes from prospective studies. Sher, Bartholow, and Wood (2000) demonstrated that in young adults elevated levels of rash impulsiveness predict the development of alcohol and drug use disorders after 6 years. Furthermore, Rubio, Jimenez, Rodriguez-Jimenez, Martinez, Avila, Ferre, Jimenez-Arriero, et al. (2008) revealed that in heavy social drinkers a poor performance on the stop signal task predicts the development of alcohol dependence 4 years later. Yet, these studies do not exclude 
the possibility that high impulsivity levels may also result from prolonged alcohol use. In fact, the two accounts are not mutually exclusive. Impulsivity can be a vulnerability factor for the development of alcohol use disorders but prolonged alcohol use may further exacerbate impulsivity deficits leading to a vicious cycle (Verdejo-Garcia, et al., 2008).

Although the studies described above implicate the concept of impulsivity in alcohol use disorders, they do not clarify how impulsivity affects alcohol-drinking behaviour. It is possible that various aspects of impulsivity are differentially involved in the initiation and maintenance of alcohol use disorders or explain different components of variance in alcohol-drinking behaviour (Dawe \& Loxton, 2004; Verdejo-Garcia et al., 2008). The latter idea is corroborated by a recent study that showed that while both rash impulsiveness (BIS-11) and response inhibition (go/no-go task) predict alcohol consumption in social drinkers, only response inhibition predicts binge drinking patterns (Henges \& Marczinski, 2012). Likewise, Christiansen, Cole, Goudie, and Field (2012) demonstrated that in social drinkers rash impulsiveness (BIS-11) and response inhibition (go/no-go task) explain unique variance in self-reported alcohol consumption and alcohol-related problems.

\section{Impulsivity and cue-elicited craving}

Reactivity to alcohol cues is a component of alcohol-drinking behaviour that appears to be involved in the maintenance of alcohol drinking. Thus, extending the idea described in the previous section, there might be some impulsivity traits that moderate this component in AUDs. As mentioned earlier, the involvement of impulsivity in cue reactivity could explain some of the variability in cue-elicited responses and could also help us identify individuals for whom cue-elicited craving is a high risk factor for relapse.

According to Stewart et al. (1984), cue-elicited craving is an index of the emotional state that motivates approach behaviour to alcohol and alcohol cues. Both Stewart et al.'s (1984) motivational state and Gray's BAS (Pickering \& Gray, 1999) share a common neurobiological substrate: the mesolimbic dopaminergic system. In both models, activation of the mesolimbic system results in dopamine release at the level of ventral striatum, which mediates reactivity to appetitive conditioned stimuli (Pickering \& Gray, 1999; Stewart et al., 1984). The difference between the two theories is that in Stewart et al.'s (1984) model the stimuli and the responses are perceived as alcohol- and drug-specific, while Gray's BAS activity generalizes to all appetitive stimuli (Kambouropoulos \& Staiger, 2001). Theoretically speaking, people with a hyperactive BAS would react more to appetitive stimuli including alcohol-related stimuli and experience stronger cue-elicited craving for alcohol (Kambouropoulos \& Staiger, 2001). In fact, evidence supporting this assumption comes from two studies with heavy social and alcohol-dependent drinkers where it was found that self-reported levels of reward sensitivity are positively associated 
with cue-elicited craving for alcohol (Franken, 2002; Kambouropoulos \& Staiger, 2001).

Neuroimaging studies demonstrate that the experience of cue-elicited craving in humans activates a frontolimbic circuit that includes the ventral striatum and the orbitofrontal (OFC) and anterior cingulated cortices (ACC) (Goldstein \& Volkow, 2002; Kalivas \& McFarland, 2003). However, prefrontal activity is also implicated in rash impulsiveness and response inhibition and there seems to be a degree of overlap between the prefrontal regions involved in cue-elicited craving and behaviour control (Dawe et al., 2004; Glodstein \& Volkow, 2002; Volkow, Fowler, \& Wang, 2003). As a result, the experience of cue-elicited craving may undermine behavioural control and vice versa; impaired prefrontal activity could result in disinhibition of a strong impulse or prepotent response such as cue-elicited craving for alcohol (Nederkoorn et al., 2009; Volkow et al., 2003). Thus, individuals with high levels of rash impulsiveness and/or weak response inhibition may experience stronger cue-elicited craving for alcohol than people with better performance on response inhibition and rash impulsiveness measures. This assumption was corroborated by two nicotine studies in which elevated BIS-11 scores were found to be associated with higher cue-elicited craving and physiological reactivity (Doran, McChargue, \& Spring, 2008; Doran, Spring, \& McChargue, 2007). However, no behavioural tasks of response inhibition were used in these studies. Most important, the relationship between cue-elicited craving and impulsivity components has never been investigated in alcohol cue reactivity studies.

\section{Outline of this thesis}

The main purpose of this thesis is to investigate whether higher cue-elicited craving for alcohol is associated with higher impulsivity levels in social and alcoholdependent drinkers. In order to achieve our purpose, we use a variety of behavioural and self-report measures of impulsivity but we mainly focus on response inhibition (stop signal task) and rash impulsiveness (BIS-11).

In the first study (Chapter 2), we investigate the involvement of response inhibition (stop signal task), reward sensitivity (CARROT), and trait impulsiveness (BIS-11) in cue-elicited craving for alcohol in heavy and light social drinkers. Unlike previous studies (Franken, 2002; Kambouropoulos \& Staiger, 2001), we use a behavioural measure of reward sensitivity in this experiment. Furthermore, the role of response inhibition and trait impulsiveness (BIS-11) is examined for the first time in alcohol cue reactivity. The inclusion of both heavy and light drinkers in the study is an additional advantage. It is expected that heavy vs. light drinkers will have a less efficient response inhibition and higher scores on measures of trait impulsivity and STR. Furthermore, it is hypothesized that a less efficient response 
inhibition and higher levels of STR and trait impulsiveness are associated with higher levels of cue-elicited craving for alcohol in social drinkers.

In the second study (Chapter 3), we take into account a factor that was ignored in our first study and in many other alcohol and drug cue reactivity studies in the literature (Wertz \& Sayette, 2001). This factor is the perceived availability of the substance and there is evidence from both laboratory and clinical studies that it may play a role in cue-elicited craving for alcohol and other drugs (Wertz \& Sayette, 2001). Thus, in the second experiment, we investigate the role of both response inhibition (stop signal task) and perceived availability of alcohol in moderate social drinkers. First of all, it is hypothesized that craving for alcohol is higher during alcohol than during water exposure and this increase in craving is stronger when alcohol is perceived as being available than when it is not. Additionally, it is expected that social drinkers with less efficient response inhibition experience higher cue-elicited craving for alcohol than social drinkers with more efficient response inhibition. Finally, it is hypothesised that the effects of perceived availability on cue-elicited craving for alcohol are stronger in social drinkers with less efficient response inhibition than in social drinkers with good response inhibition.

In Chapter 4, we try to go deeper and explore the mechanisms by which impulsivity modulates conditioned appetitive responses. One possibility is that impulsivity is involved in appetitive learning processes like acquisition and extinction. We test this idea with a pavlovian discriminative paradigm borrowed by Van Gucht et al.'s (2008) study. We examine the involvement of response inhibition (stop signal task), rash impulsiveness (short SSS), and reward sensitivity (BAS) in the acquisition and extinction of subjective appetitive responses for chocolate (craving/desire, expectancy, liking). First of all, in the present study we try to replicate the main findings in Van Gucht et al.'s (2008) study. It is hypothesised that there will a successful acquisition and a differential extinction of subjective appetitive responses (craving, expectancy, and liking). Specifically, it is expected that relative to the CS-, craving for chocolate in response to the CS+ and liking for the CS+ will remain unaffected after extinction, whereas expectancy for chocolate in the presence of the CS+ will be extinguished. Secondly, for each of the three measures of impulsivity (sensitivity to reward, sensation seeking, response inhibition), it is hypothesized that during the acquisition phase, more vs. less impulsive people will acquire a faster and stronger craving and expectancy response for chocolate to the $\mathrm{CS}+$ and a stronger liking for the $\mathrm{CS}+$, relative to the CS-. Furthermore, it is expected that there will be a differential extinction of these acquired subjective responses between more vs. less impulsive people. In particular, it is hypothesized that highly impulsive participants will not extinguish their subjective CRs, while less impulsive participants will extinguish them successfully.

In Chapter 5, we carry on our investigation in a clinical population. Participants were alcohol-dependent inpatients of the private clinic U-Center (Epen, the Netherlands) who took part in a cue reactivity study in which they were exposed to their favourite alcoholic drink in a real alcohol setting. The choice of stimuli and context 
made the alcohol exposure demanding for the participants but it also established a degree of similarity to real life drinking conditions. Two impulsivity measures were taken in that study: response inhibition (stop signal task) and trait impulsiveness (BIS-11). It is hypothesized that i) alcohol-dependent people experience stronger craving for alcohol when exposed to alcohol than to water cues, ii) a higher trait impulsiveness score is associated with higher cue-elicited craving for alcohol, and iii) a less effective response inhibition is linked to stronger cue-elicited craving for alcohol.

Finally, Chapter 6 consists of a small 3-month follow-up study in which we consider the role of impulsivity and cue-elicited craving in relapse. The participants in this study were former patients of the U-Center clinic who had been treated for alcohol use disorders and had an abstinent goal. All of them had participated in the cue-reactivity study described in Chapter 3. We tested the hypothesis that cueelicited craving for alcohol and rash impulsiveness (BIS-11) predict relapse in former patients.

\section{References}

Abrams, D. B., Monti, P. M., Carey, K. B., Pinto, R. P., \& Jacobus, S. I. (1988). Reactivity to smoking cues and relapse: two studies of discriminant validity. Behavior Research and Therapy, 26, 225-233.

Aron, A. R., Robbins, T. W, Poldrack, R. A. (2004). Inhibition and the right inferior frontal cortex. Trends in Cognitive Sciences, 8, 170-177.

Bindra, D. (1974). A motivational view of learning, performance, and behavior modification. Psychological Review, 81, 199-213.

Bouton, M. E. (2007). Learning and Behavior: A contemporary synthesis. Sunderland, Massachusetts: Sinauer Associates, Inc.

Carter, B. L., \& Tiffany, S. T. (1999). Meta-analysis of cue-reactivity in addiction research. Addiction, 94, 327-340.

Carver, C. S., \& White, T. L. (1994). Behavioral inhibition, behavioral activation, and affective responses to impending reward and punishment: the BIS/BAS scales. Journal of Personality and Social Psychology, 67, 319-333.

Christiansen, P., Cole, J. C., Goudie, A. J., \& Field, M. (2012). Components of behavioural impulsivity and automatic cue approach predict unique variance in hazardous drinking. Psychopharmacology, 219: 501-510.

Cloninger, C. R. (1994) Temperament and personality. Current Opinion in Neurobiology, 4, 266-273.

Corr, P. J., Pickering, A. D., \& Gray, J. A. (1995). Personality and reinforcement in associative and instrumental learning. Personality and Individual Differences, 19, 47-71.

Dawe, S., Gullo, M. J., \& Loxton, N. L. (2004). Reward drive and rash impulsiveness as dimensions of impulsivity: Implications for substance misuse. Addictive Behaviors, 29, 1389-1405.

Dawe, S., Loxton, N. J. (2004). The role of impulsivity in the development of substance use and eating disorders. Neuroscience and Biobehavioral Reviews, 28, 343-351.

De Wit, H. (2008). Impulsivity as a determinant and consequence of drug use: a review of underlying processes. Addiction Biology, 14, 22-31.

Dick, D. M., Smith, G., Olausson, O., Mitchell, S. H., Leeman, R. F., O’Malley, S. S., Sher, K. (2010). Understanding the construct of impulsivity and its relationship to alcohol use disorders. Addiction Biology, 15, 217-226. 
Dom, G., D’ haene, P., Hulstijn, W., \& Sabbe, B. (2006).Impulsivity in early- and late-onset alcoholics: differences in self-report measures and a discounting task. Addiction, 50-59.

Dom, G., De Wilde, B., Hulstijn, W., Sabbe, B. (2007). Dimensions of impulsive behaviour in abstinent alcoholics. Personality and Individual Differences, 42, 465-476.

Doran, N., McChargue, D., \& Spring, B. (2008). Effect of impulsivity on cardiovascular and subjective reactivity to smoking cues. Addictive Behaviors, 33, 167-172.

Doran, N., Spring, B., \& McChargue, D. (2007). Effects of impulsivity on craving and behavioural reactivity to smoking cues. Psychopharmacology, 194, 279-288.

Dougherty, D. M., Bjork, J. M., Harper, R. A., Marsh, D. M., Moeller, F. G., Mathias, C. W., \& Swann, A. C. (2003). Behavioural impulsivity paradigms: a comparison in hospitalized adolescents with disruptive behaviour disorders. Journal of Child Psychology and Psychiatry, 44, 1145-1157.

Dougherty, D. M., Mathias, C. W., Marsh, D. M., \& Jagar, A. A. (2005). Laboratory behavioral measures of impulsivity. Behavior Research Methods, 37, 82-90.

Drummond, D. C. (2000). Human models in craving research: What does cue-reactivity have to offer clinical research? Addiction, 95, S129-S144.

Drummond, D. C. (2001). Theories of drug craving, ancient and modern. Addiction, 96, 33-46.

Drummond, D. C., \& Glautier, S. (1994). A controlled trial of cue exposure treatment in alcohol dependence. Journal of Consulting and Clinical Psychology, 62, 809-817.

Drummond, D. C., Litten, R. Z., Lowman, C., \& Hunt, W. A. (2000). Craving research: future directions. Addiction, 95, S247-S255.

Drummond, D. C., Tiffany, S. T., Glautier, S., \& Remington, B. (1995). Addictive behaviour: cue exposure theory and practice. New York: John Wiley \& Sons.

Eagle, D. M., Bari, A., \& Robbins, T. W. (2008). The neuropsychopharmacology of action inhibition: crossspecies translation of the stop-signal and go/no-go tasks. Psychopharmacology, 199, 439-456.

Enticott, P. G., Ogloff, G. R. P., \& Bradshaw, J. L. (2006). Associations between laboratory measures of executive control and self-reported impulsivity. Personality and Individual Differences, 41, 285-294.

Evenden, J. (1999). Impulsivity: a discussion of clinical and experimental findings. Journal of Psychopharmacology, 13, 180-192.

Eysenck, S. B. G., Pearson, P. R., Easting, G., \& Allsopp, J. F. (1985). Age norms for impulsiveness and venturesomeness and empathy in adults. Personality and Individual Differences, 6, 613-619.

Field, M., \& Duka, T. (2002). Cues paired with a low dose of alcohol acquire conditioned incentive properties in social drinkers. Psychopharmacology, 159, 325-334.

Franken, I. H. A. (2002). Behavioural approach system (BAS) predicts alcohol craving. Personality and Individual Differences, 32, 349-355.

Fox, H. C., Bergquist, K. L., Hong, K., \& Sinha, R. (2007). Stress-induced and alcohol cue-induced craving in recently abstinent alcohol-dependent individuals. Alcoholism: Clinical and Experimental Research, 31, 395-403.

Glautier, S., \& Remington, B. (1995). The form of responses to drug cues. In D. C. Drummond, S. T. Tiffany, S. Glautier, \& B. Remington (Eds.), Addictive behaviour: cue exposure theory and practice (pp. 21-46). New York: John Wiley \& Sons.

Goldstein, R. Z., \& Volkow, N. D. (2002). Drug addiction and ist underlying neurobiological basis: neuroimaging evidence for the involvement of the frontal cortex. American Journal of Psychiatry, 159, 1642-1652.

Greeley, J. D., Swift, W., Prescott, J., \& Heather, N. (1993). Reactivity to alcohol-related cues in heavy and light drinkers. Journal of Studies on Alcohol, 54, 359-368.

Henges, A. L., Marczinski, C. A. (2012). Impulsivity and alcohol consumption in young social drinkers. Addictive Behaviors, 37, 217-220.

Hogarth, L., \& Duka, T. (2006). Human nicotine conditioning requires explicit contingency knowledge: is addictive behaviour cognitively mediated? Psychopharmacology, 184, 553-566.

Jansen, A. (1998). A learning model of binge eating: cue reactivity and cue exposure. Behaviour Research and Therapy, 36, 257-272. 
Jentsch, D. J., \& Taylor, J. R. (1999). Impulsivity resulting from frontostriatal dysfunction in drug abuse: implications for the control of behaviour by reward-related stimuli. Psychopharmacology, 146, 373390.

Kalivas, P. W., \& McFarland, K. (2003). Brain circuitry and the reinstatement of cocaine-seeking behavior. Psychopharmacology, 168, 44-56.

Kambouropoulos, N., \& Staiger, P. K. (2001). The influence of sensitivity to reward on reactivity to alcohol-related cues. Addiction, 96, 1175-1185.

Kambouropoulos N., \& Staiger, P. K. (2007). Personality, behavioural and affective characteristics of hazardous drinkers. Personality and Individual Differences, 42, 213-224.

Kozlowski, L. T., \& Wilkinson, D. A. (1987). Use and misuse of the concept of craving by alcohol, tobacco, and drug researchers. British Journal of Addiction, 82, 31-36.

Krank, M. D. (2003). Pavlovian conditioning with ethanol: sign-tracking (autoshaping), conditioned incentive, and ethanol self-administration. Alcoholism: Clinical and Experimental Research, 27, 15921598.

Lane, S. D., Cherek, D. R., Rhoades, H. M., Pietras, C. J., \& Tcheremissine, O. V., (2003). Relationships among laboratory and psychometric measures of impulsivity: implications in substance abuse and dependence. Addictive Disorders and Their Treatment, 2, 33-40.

Lawrence, A. J., Luty, J., Bogdan, N. A., Sahakian, B. J., \& Clark, L. (2009). Impulsivity and response inhibition in alcohol dependence and problem gambling. Psychopharmacology, 207, 163-172.

Litt, M. D., Cooney, N. L., \& Morse, P. (2000). Reactivity to alcohol-related stimuli in the laboratory and in the field: predictors of craving in treated alcoholics. Addiction, 95, 889-900.

Logan, G. D., Schachar, R. J., \& Tannock, R. (1997). Impulsivity and inhibitory control. Psychological Science, 8, 60-64.

Moeller, F. G., Barratt, E. S., Dougherty, D. M., Schmitz, J. M., \& Swann, A. C. (2001). Psychiatric aspects of impulsivity. American Journal of Psychiatry, 158, 1783-1793.

Nederkoorn, C., Baltus, M., Guerrieri, R., \& Wiers, R. W. (2009). Heavy drinking is associated with deficient response inhibition in women but not in men. Pharmacology Biochemistry and Behavior, 93, 331-336.

Patton, J. H., Stanford, M. S., \& Barratt, E. S. (1995). Factor structure of the Barratt Impulsiveness Scale. Journal of Clinical Psychology, 51, 768-774.

Pickering, A. D. \& Gray, J. A. (1999). The neuroscience of personality. In L. A. Pervin \& O. P. John (Eds.), Handbook of personality: Theory and research (pp. 277-299). New York: Guilford Press.

Rees, V. W., \& Heather, N. (1995). Individual differences and cue reactivity. In D. C. Drummond, S. T. Tiffany, S. Glautier, \& B. Remington (Eds.), Addictive behaviour: cue exposure theory and practice (pp. 99-118). New York: John Wiley \& Sons.

Reynolds, B., Ortengren, A., Richards, J. B., \& de Wit, H. (2006). Dimensions of impulsive behaviour: Personality and behavioural measures. Personality and Individual Differences, 40, 305-315.

Robbins, S. J., \& Ehrman, R. N. (1992). Designing studies of drug conditioning in humans. Psychopharmacology, 106, 143-153.

Robbins, T. W., Everitt, B. J., \& Nutt, D. J. (2010). The Neurobiology of addiction new vistas. New York: Oxford University Press Inc.

Rubio, G., Jimenez, M., Rodrigo-Jimenez, R., Martinez, I., Avila, C., Ferre, F., Jimenez-Arriero, M. A., Ponce, G., \& Palomo, T. (2008) The role of behavioural impulsivity in the development of alcohol dependence: A 4-year follow-up study. Alcoholism: Clinical and Experimental Research, 32, 1681-1687.

Sayette, M. A., Shiffman, S., Tiffany, S. T., Niaura, R. S., Martin, C. S., \& Shadel, W. G. (2000). Methodological approaches to craving research: the measurement of drug craving. Addiction, 95, S189-S210.

Siegel, S., \& Ramos, B. M. C. (2002). Applying laboratory research: Drug anticipation and the treatment of drug addiction. Experimental and Clinical Psychopharmacology, 10, 162-183.

Spinella, M. (2005). Self-rated executive function: Development of the executive function index. International Journal of Neuroscience, 115, 649-667.

Stanford, M. S., Mathias, C. W., Dougherty, D. M., Lake, S. L., Anderson, N. E., \& Patton, J. H. (2009). Fifty years of the Barratt Impulsiveness Scale: An update and review. Personality and Individual Differences, 47, 385-395. 
Stewart, J., de Wit, H., \& Eikelboom, R. (1984). Role of unconditioned and conditioned drug effects in the self-administration of opiates and stimulants. Psychological Review, 91, 251-268.

Tiffany, S. T. (1990). A cognitive model of drug urges and drug use behavior: role of automatic and nonautomatic processes. Psychological Review, 97: 147-168.

Tiffany, S. T. (1995). Potential functions of classical conditioning in drug addiction. In D. C. Drummond, S. T. Tiffany, S. Glautier, \& B. Remington (Eds.), Addictive behaviour: cue exposure theory and practice (pp. 47-71). New York: John Wiley \& Sons.

Tiffany, S. T., \& Conklin C. A. (2000). A cognitive processing model of alcohol craving and compulsive alcohol use. Addiction, S145-S153.

Torrubia, R., Avila, C., Molto, J., Caseras, X. (2001). The sensitivity to punishment and sensitivity to reward questionnaire (SPSRQ) as a measure of Gray's anxiety and impulsivity dimensions. Personality and Individual Differences, 31, 837-862.

Van Gucht, D., Vansteenwegen, D., Beckers, T., Van den Bergh, O. (2008). Return of experimentally induced chocolate craving after extinction in a different context: Divergence between craving for and expecting to eat chocolate. Behaviour Research and Therapy, 46, 375-391.

Verdejo-Garcia, A., Lawrence, A. J., \& Clark, L. (2008). Impulsivity as a vulnerability marker for substance-use disorders: Review of findings from high-risk research, problem gamblers and genetic association studies. Neuroscience and Behavioral Reviews, 32, 777-810.

Volkow, N. D., Fowler, J. S., \& Wang, G. J. (2003). The addicted human brain: insights from imaging studies. The Journal of Clinical Investigation, 111, 1444-1451.

Von Diemen, L., Bassani, D. G., Fuchs, S. C., Szobot, C. M., Pechansky, F. (2008). Impulsivity, age of first alcohol use and substance use disorders among male adolescents: a population based case-control study. Addiction, 103, 1198-1205.

Wertz, J. M., Sayette, M. A. (2001). A review of the effects of perceived drug use opportunity on selfreport urge. Experimental and Clinical Psychopharmacology, 9, 3-13.

WHO (2004). Global Status Report on Alcohol. Geneva.

Wikler, A. (1984). Conditioning factors in opiate addiction and relapse. Journal of Substance Abuse Treatment, 1, 279-285.

Zuckerman, M. (1971). Dimensions of sensation seeking. Journal of Consulting Psychology, 36, 45-52.

Zuckerman, M., \& Cloninger, C. R. (1996). Relationships between Cloninger's, Zuckerman's, and Eysenck's dimensions of personality. Personality and Individual Differences, 21, 283-285. 



\section{CHAPTER 2}

\section{Can't stop the craving: The effect of impulsivity on cue-elicited craving for alcohol in heavy and light social drinkers ${ }^{1}$}

${ }^{1}$ Papachristou, H., Nederkoorn, C., Havermans, R., van der Horst, M., \& Jansen, A. (2012). Can't stop the craving: The effect of impulsivity on cue-elicited craving for alcohol in heavy and light social drinkers. Psychopharmacology, 219, 511-518. 


\section{Abstract}

Rationale. A robust finding in the alcohol literature is that heavy and alcoholdependent drinkers show stronger reactions to alcohol-related cues than light drinkers. However, there are individual differences in the degree of cue-elicited craving. Personality factors appear to be involved in cue-reactivity and impulsivity is a possible candidate.

Objectives. The aim of the present study was to examine the role of different aspects of impulsivity in heavy drinking and alcohol cue-reactivity in social drinkers. Methods Participants were heavy $(\mathrm{n}=13)$ and light $(\mathrm{n}=29)$ social drinkers who were exposed to neutral and alcohol-related stimuli during a single laboratory session. Trait impulsivity, response inhibition, and sensitivity to reward (STR) were assessed with the Barratt Impulsiveness Scale (BIS-11), the Stop Signal Task (SST), and the Card Arranging Reward Responsivity Objective Test (CARROT) respectively.

Results. Heavy drinkers scored higher on trait impulsivity (BIS-11) than light drinkers. In addition, heavy drinkers reported elevated levels of craving for alcohol, but both in light and heavy drinkers, craving increased equally after exposure to alcohol cues. Impulsivity appeared to moderate this relation: heavy drinkers with ineffective response inhibition showed more craving to alcohol cues, compared to heavy drinkers with adequate response inhibition. In light drinkers, response inhibition did not influence craving to alcohol cues.

Conclusions. Different aspects of impulsivity are involved in heavy drinking and perhaps motivate alcohol consumption in a variety of ways. Having a deficient response inhibition appears to be a risk-factor for heavy drinkers because it is associated with increased craving to alcohol cues.

Keywords: Cue reactivity $\cdot$ Craving $\cdot$ Alcohol cue exposure $\cdot$ Impulsivity $\cdot$ Response Inhibition · Sensitivity to Reward 


\section{Introduction}

Cue reactivity has been discussed extensively in the field of drug and alcohol abuse. A robust finding is that alcohol-dependent people relative to healthy controls show enhanced subjective (craving) and physiological reactivity (e.g., salivation) when exposed to alcohol-related stimuli (Drummond, 2000). Although several theories have been proposed to explain cue reactivity, most evidence favours a positive incentive account (Carter \& Tiffany, 1999; Drummond, 2000). Regarding alcohol misuse/abuse, it is assumed that stimuli repeatedly paired with the reinforcing effects of alcohol acquire incentive value through classical conditioning and hence, elicit appetitive responses and promote drinking (Drummond, 2000; Robinson \& Berridge 1993; Stewart, de Wit, \& Eikelboom, 1984).

However, the relationship between cue reactivity and alcohol misuse/abuse seems to be more complicated than it was originally expected. After all, most people in western societies are frequently exposed to alcohol and alcohol-related cues and one would expect that anybody who ever drinks alcohol should come to display cue-elicited craving. Nevertheless, not all of us become heavy or dependent drinkers and not everyone who has ever drunk alcohol will feel intense craving in the presence of alcohol-related cues. Approximately a third of the participants in alcohol cue-reactivity studies does not react when exposed to alcohol-related cues (Litt, Cooney, \& Morse, 2000). Evidently, other factors mediate or moderate the relationship between cue reactivity and alcohol problem drinking. Some of these factors are conceptualized in terms of personality traits that may make someone vulnerable to substance misuse/abuse. A possible candidate is impulsivity.

Typically, impulsivity is conceptualized as a personality trait that leads to behaviour characterized by an inability to inhibit inappropriate action, lack of foresight or planning, and insensitivity to consequences (Dawe, Gullo, \& Loxton, 2004; Dawe \& Loxton, 2004; Dom, De Wilde, Hulstijn, \& Sabbe, 2006; Reynolds, Ortengren, Richards, \& de Wit, 2006). The concept of impulsivity has been incorporated into major personality theories including those by Eysenck (Eysenck \& Eysenck, 1977), Cloninger (1994), Zuckerman (1989), and Gray (1987), and many self-report instruments and behavioural tasks have been developed to measure it. However, the correlation between them is mostly weak (Dawe \& Loxton, 2004). Therefore, it seems that impulsivity is a multidimensional concept and different instruments and tasks assess different aspects of it.

There is wide agreement that there are at least two impulsivity dimensions. The first is related to response inhibition, while the second is concerned with motivation, in particular, sensitivity to reward (STR) (Dawe et al., 2004; Guerrieri, Nederkoorn, \& Jansen, 2008; Nederkoorn, Baltus, Guerrieri, \& Wiers, 2009). The former refers either to the failure to suppress a prepotent response or to early responding due to incomplete evaluation of all the relevant information (Dawe et al., 2004; Dom et al., 2007; Guerrieri et al., 2008). The latter refers to a predisposition 
to detect and approach rewarding stimuli perhaps because of their increased salience (Dawe et al., 2004; Gray, 1987; Guerrieri et al., 2008). Both impulsivity dimensions have been associated with alcohol problems.

As regards response inhibition, Noel, Van den Linden, d'Acremont, Bechara, Dan, Hanak et al. (2007) demonstrated that alcohol dependent individuals versus healthy controls display impaired performance on the Go/No Go task. Moreover, Nederkoorn et al. (2009) found that heavy drinking is associated with deficient performance on the Stop Signal Task, although only in women.

Regarding STR, Loxton and Dawe (2001) showed that increased STR is the best predictor of alcohol problems in adolescent girls. Similarly, Knyazev, Slobodskaya, Kharchenko, and Wilson (2004) found that self-reported STR predicts alcohol and substance use in adolescents and young adults. Finally, Kambouropoulos and Staiger (2007) reported that hazardous alcohol drinkers versus healthy controls score higher on self-report measures of STR.

Theoretically speaking, a high STR induces approach behaviour and increased cue reactivity to appetitive stimuli. In turn, these prepotent approach responses might not be inhibited in individuals with less effective response inhibition (Dawe et al., 2004). In particular, people high in STR may display intense craving to appetitive stimuli due to an overactive approach system, whereas people deficient in response inhibition may show increased craving to appetitive stimuli because they have difficulty inhibiting cue-elicited approach responses.

Very few studies in the field of drug and alcohol addiction have examined the relationship between impulsivity and cue reactivity. Most of them have used selfreport measures of impulsivity. Franken (2002) and Kambouropoulos and Staiger (2001) used the BAS scale and found that increased STR is associated with high levels of craving for alcohol in dependent and heavy drinkers. Additionally, Doran, McChargue, and Spring (2008) and Doran, Spring, and McChargue (2007) found that more impulsive smokers (impulsivity measured with the Barratt Impulsiveness Scale BIS-11) show higher levels of cue reactivity than less impulsive smokers.

The aim of the present study is to examine the relationship between different dimensions of impulsivity and cue-elicited craving for alcohol in heavy and light social drinkers. First of all, it is hypothesized that heavy drinkers are more impulsive than light drinkers. Specifically, it is expected that heavy drinkers will score higher on measures of trait impulsivity and STR and will display poorer response inhibition relative to light drinkers. Furthermore, it is expected that a less efficient response inhibition and higher levels of STR are associated with higher levels of cue-elicited craving for alcohol in social drinkers. 


\section{Methods}

\section{Participants}

Forty-two (32 women and 10 men) participants with a mean age of 26 years, (SD = 9.66) volunteered to participate in the study. All participants were Dutch native speakers recruited from the community and the University of Maastricht through telephone interviews, emails, and advertisements. During recruitment, special care was taken to recruit heavy social drinkers.

Exclusion criteria were (i) any prescribed psychoactive medication, (ii) any neurological, psychiatric, and/or substance abuse disorders except for smoking tobacco, (iii) being pregnant. None of the participants was excluded on the basis of the above criteria.

All participants had been asked before the experiment via an email or a brief telephone interview about their preferred type/brand of alcoholic beverage. University students were rewarded for their participation in the experiment with either course credits or a gift certificate of $7.5 €$. Participants from the community were rewarded with a gift certificate of $10 €$ (which included travel expenses).

\section{Measures}

Barratt Impulsiveness Scale version 11(BIS-11): The Dutch version of the BIS-11 (Patton, Stanford, \& Barratt, 1995) is a 30-item self-report questionnaire that assesses trait-impulsivity. Each item is reported on a 4-point scale. The total score varies from 30 (low impulsivity) to 120 (high impulsivity). The BIS-11 consists of three factors: Attentional Impulsiveness, Motor Impulsiveness, and Non-planning Impulsiveness. The original BIS-11 has been demonstrated to be reliable in both clinical and non-clinical populations (Patton et al., 1995).

\section{Response Inhibition}

The Stop-Signal Task (SST) was used to assess response inhibition (Logan, Schachar, \& Tannock, 1997). Each trial in this task begins with a 500ms fixation point in the centre of the computer screen. Then, a go trial follows. In each go trial participants are instructed to press as fast as possible either the right or the left "shift" button when a square pattern is presented either on the right or the left compartment of the screen respectively. In $25 \%$ of the trials an acoustic stop signal of $1000 \mathrm{~Hz}$ is heard after the go-signal indicating that the participants must withhold their response.

The stop signal delay is initially set at $250 \mathrm{~ms}$ but throughout the task is adjusted dynamically allowing the participants to successfully inhibit their responses at approximately $50 \%$ of the stop trials. When the participant fails to withhold the response, the next stop signal is presented $50 \mathrm{~ms}$ earlier thereby, making the task 
easier. On the other hand, when the participant inhibits the response successfully, the next stop-signal is presented $50 \mathrm{~ms}$ later, thereby making the task more difficult.

The dependent variable of interest in the task is the stop signal reaction time (SSRT), which is the difference between the mean Go reaction time and the mean stop signal delay, measured in milliseconds (ms). A higher SSRT is an index of impaired response inhibition.

In the present task, 3 practice blocks, of respectively 6, 12 and 24 trials were followed by 4 test blocks of 64 trials each. Between blocks, participants were allowed to have a short break.

\section{Sensitivity to Reward (STR)}

STR was measured with the Card Arranging Reward Responsivity Objective Test (CARROT) (Al-Adawi \& Powell, 1997; Powell, Al-Adawi, Morgan, \& Greenwood, 1996). The task involves four trials (T1-T4). During T1, participants have to sort 60 cards as fast as possible. Participants' performance time on T1 is a time limit for each of the following three trials (T2-T4) which involve the sorting of 100 cards each. Trials T2 and T4 contain no reward. However, in T3 participants are instantly rewarded with twenty cents for every fifth card sorted correctly. The dependent variable is the difference between the number of cards sorted in the rewarded trial and the average number of cards sorted in the two non-rewarded trials [T3$(\mathrm{T} 2+\mathrm{T} 4) / 2]$. Scores are converted to rates by dividing the number of cards sorted in each trial by the time taken to sort the 60 cards at $\mathrm{T} 1$.

\section{Craving}

Craving was measured with five items chosen from the shortened version of the Desires for Alcohol Questionnaire (DAQ) (Love, James, \& Willner, 1998). The fiveitem craving questionnaire consisted of those items with the highest loading on each of the following four factors: (1) strong desires and intentions to use alcohol (two items were chosen) (2) positive and negative reinforcement, (3) control over drinking, and (4) mild desires to drink (Love et al., 1998). The 5 -item questionnaire had a good internal consistency, with a Cronbach alpha coefficient of .79.

\section{AUDIT}

Alcohol problems were assessed with the Alcohol Use Disorders Identification Test (AUDIT) (Fleming, Barry, \& MacDonald, 1991; Saunders, Aasland, Babor, De La Fuente, \& Grant, 1993). This self-report instrument consists of ten multiple-choice items and is used to discriminate between people whose alcohol consumption is not harmful and those whose alcohol consumption reaches hazardous and problematic levels. A cut-off score of 11 was used in the present study (Fleming et al., 1991; Saunders et al., 1993). 
Time-line follow back questionnaire

Alcohol use was assessed with a self-report instrument based on the time-line follow back questionnaire (Sobell \& Sobell, 1990). Participants had to report how many alcohol drinks of different types they had consumed on each day for the last 30 days. The sum score in this questionnaire is the total amount of alcohol standard drinks consumed during the last 30 days.

\section{Procedure}

Ethical approval was sought and obtained from the Ethical Committee of the Psychology Faculty of Maastricht University. Participants took part in one individual testing session arranged between $11.00 \mathrm{am}$ and $18.00 \mathrm{pm}$. Participants first had to read and sign the informed consent form and then to complete a brief demographic questionnaire. Following this, STR and response inhibition were assessed with the CARROT and the SST respectively in a counterbalanced order. Having done this, participants were exposed first to water and later to their preferred type/brand of alcoholic beverage for three minutes respectively. The order of cue-exposure conditions was not counterbalanced to avoid carry-over effects (Rohsenow \& Niaura, 1999). There was a five-minute break between the cue-exposure conditions during which the participant was left alone in the laboratory to relax and to read some magazines (no alcohol advertisements were present) (Fig. 1).

At the beginning (before cues were present) and at the end of each cue exposure condition (while the cues were still present), participants rated their craving levels (Fig. 1). During the alcohol exposure session, participants were presented with a commercially labelled bottle of their preferred brand of alcoholic beverage and a proper (for the type of beverage) empty glass. Then, they were asked to open the bottle and pour the alcoholic beverage into the glass. Following this, they were instructed to pick up the glass and sniff the alcoholic beverage, stare at the glass and the bottle of alcohol, sniff the alcoholic beverage in the bottle, and finally immerse their fingers into the glass with the alcoholic beverage and touch their lips and tongue with their fingers. In this way, they could taste the alcoholic beverage without drinking it. The instructions were repeated throughout the three-minute period of the exposure. The water exposure was identical to the alcohol exposure but the cue was a commercially labelled bottle of spring water. Drinking alcohol or water was not allowed during the exposure.

At the end of the alcohol exposure period, the Timeline Alcohol Questionnaire, the AUDIT, and the BIS-11 were administered to the participants in a counterbalanced order (Fig. 1). Finally, they were thanked, debriefed, and received the reward for their participation in the experiment. 


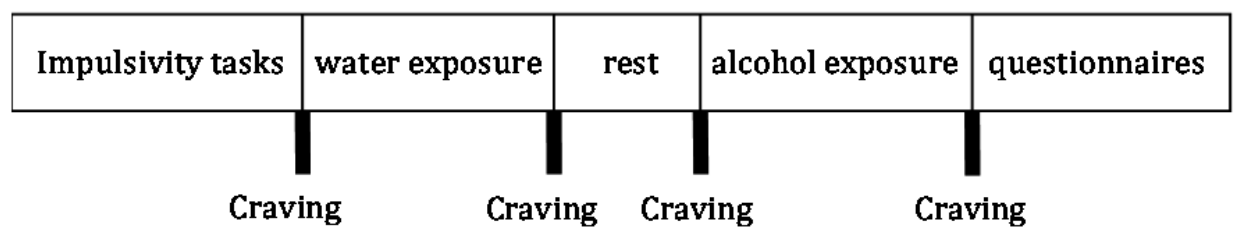

Fig. 1 Schematic representation of the experimental procedure.

\section{Statistical Analysis}

Based on their AUDIT scores with a cut-off score of 11, participants were divided into heavy ( $N=13)$ and light $(N=29)$ social drinkers. One-way independent analysis of variance (ANOVA) was used to compare the heavy and light drinking groups on craving and impulsivity measures. Moreover, a median split was conducted on the CARROT, SST and BIS-11 scores and participants were classified as high and low on each of these impulsivity measures, leading to three 2 (drinking group: heavy vs. light drinkers) x 2 (impulsivity: high vs. low in impulsivity) x 4 (cue exposure: baseline water, water exposure, baseline alcohol, alcohol exposure) different repeated-measures ANOVAs. The drinking group and the impulsivity level were the between-subjects factors, while cue exposure (four time points: baseline water, water exposure, baseline alcohol, and alcohol exposure) was the within-subject factor. Craving for alcohol was the dependent variable. Greenhouse-Geisser correction was applied when Mauchly's test of sphericity was significant.

\section{Results}

\section{General characteristics of the participants}

One-way independent ANOVA indicated that the two drinking groups differed significantly on the amount of alcohol consumed in the 30 days before participation, $\mathrm{F}$ $(1,40)=30.43, \mathrm{p}<.001$, with heavy drinkers $(\mathrm{M}=102.69, \mathrm{SD}=53.94)$ drinking more than light drinkers $(M=31.97, S D=29.34)$. Furthermore, there was a significant age difference between the two drinking groups, $F(1,40)=4.59$, p < .05, with heavy drinkers $(M=20.92, S D=2.06)$ being younger than light drinkers $(M=27.55$, $\mathrm{SD}=10.10$ ). Finally, the gender distribution (male/female ratio) for each drinking group was 6/23 and 4/9 for light and heavy drinkers respectively.

\section{Trait and behavioural impulsivity measures}

There was no significant difference in the SST (F $[1,40]<1$, n.s.) and CARROT (F $[1$, $40]<1$, n.s.) performances between the two drinking groups. Furthermore, there was no correlation between the three impulsivity measures in the present study. 
However, heavy drinkers scored significantly higher in trait impulsivity (BIS-11) than light drinkers $(F[1,40]=6.13, p<.02)$. Further analysis indicated that there was a significant difference in motor impulsiveness (BIS-11 Factor 2; F $[1,40]=$ $5.21, \mathrm{p}<.05$ ) and non-planning impulsiveness (BIS-11 Factor 3; $\mathrm{F}[1,40]=6.18, \mathrm{p}<$ .02 ) but not in attentional impulsiveness (BIS-11 Factor 1; F $[1,40]=3.22$, n.s.) between the two drinking groups. Table 1 shows the SST, CARROT, and BIS-11 mean scores and standard deviations for heavy and light drinkers respectively.

Table 1 Mean and Standard Deviation of impulsivity measures for heavy and light drinkers

\begin{tabular}{lcc}
\hline Impulsivity measures & Heavy drinkers $(\mathrm{n}=13)$ & Light drinkers $(\mathrm{n}=29)$ \\
\hline BIS-11 (Total) & $66.46(10.55) \mathrm{a}$ & $57.66(10.7)^{\mathrm{a}}$ \\
BIS-11 (Attention) & $18.92(4.07) \mathrm{a}$ & $16.41(4.24)^{b}$ \\
BIS-11 (Motor) & $22.23(3.63) \mathrm{a}$ & $19.45(3.66)^{\mathrm{a}}$ \\
BIS-11 (Non-planning) & $22.62(4.61) \mathrm{a}$ & $19.17(3.94)^{\mathrm{a}}$ \\
SST & $220.90(54.68) \mathrm{a}$ & $222.67(50.02)^{b}$ \\
CARROT & $.00(.07) \mathrm{a}$ & $-.02(.07)^{b}$ \\
\hline
\end{tabular}

Means sharing similar subscripts within a row differ at $\mathrm{p}<.05$

BIS-11 Barratt Impulsiveness Scale version 11, SST Stop Signal Task,

CARROT Card Arranging Reward Responsivity Objective Test

\section{The effects of response inhibition (SST) on craving during cue-exposure in heavy and light drinkers}

A three-way repeated measures ANOVA showed that there was a significant main effect of drinking group on craving levels $(F[1,38]=7.1, p<.05$, Fig. 2). Inspection of Fig. 2 shows that heavy vs. light drinkers had higher craving levels at each time point of the cue-exposure. 


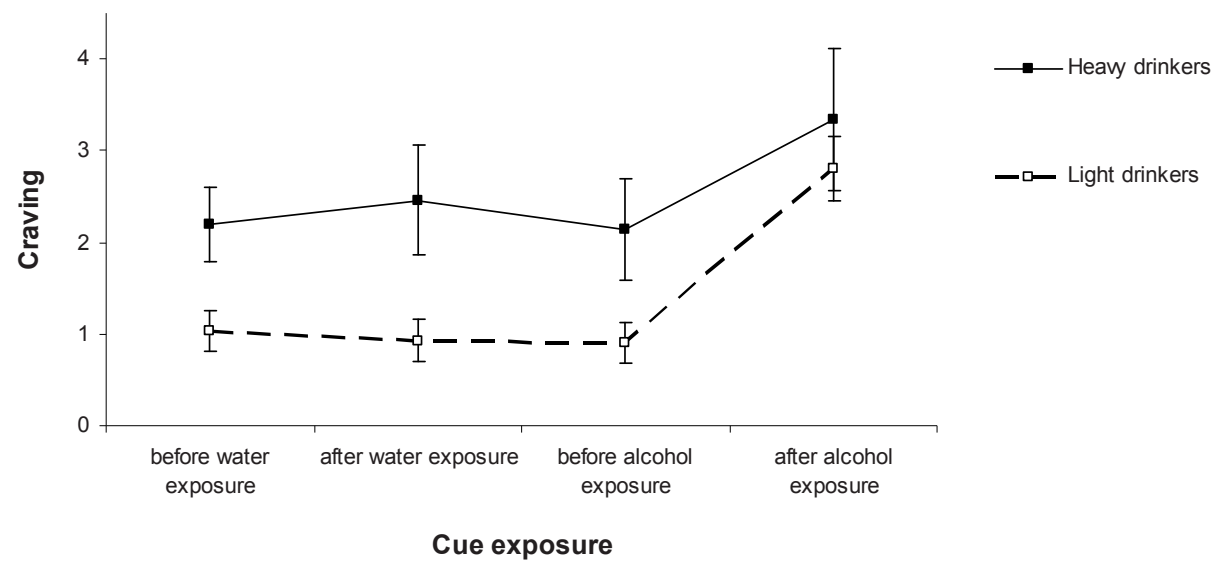

Fig. 2 Mean craving scores and S.E.M. of the two drinking groups (light vs. heavy drinkers) during the two cue-exposure conditions (water vs. alcohol)

The cue exposure had a significant main effect on craving, $(\mathrm{F}[1.76,67]=22.96, \mathrm{p}<$ .001). Within-subjects simple contrasts showed that craving levels after the alcohol cue exposure were significantly higher than craving levels at each of the three previous time points of the cue exposure, (alcohol exposure vs. water baseline, F [1, $38]=22.81, \mathrm{p}<.001$; alcohol exposure vs. water exposure, $\mathrm{F}[1,38]=26.23, \mathrm{p}<$ .001; alcohol exposure vs. alcohol baseline, F [1, 38] = 35.4, p <.001), (Fig. 2).

However, there was no difference between the two drinking groups in their reactivity to the alcohol cues. The interaction between drinking group and cue exposure was not significant $(\mathrm{F}[1.76,70]=1.1$, n.s.). This means that the heavy drinkers did not report more cue-induced craving after the alcohol exposure than the light drinkers.

There appeared to be no significant main effect of response inhibition on craving $(\mathrm{F}[1,38]=1.76$, n.s.). This means that, in general, participants high and low in response inhibition did not have different craving levels throughout the cue exposure procedure.

More importantly, the analysis showed that response inhibition did influence reactivity to alcohol cues differently in heavy and light drinkers: there was a significant interaction between response inhibition, cue exposure, and drinking group, on craving $(\mathrm{F}[1.76,67]=4.2, \mathrm{p}<.05)$. Within-subjects simple contrasts (alcohol exposure was used as reference) indicated that the interaction was marginally significant for alcohol exposure vs. baseline alcohol $(\mathrm{F}[1,38]=3.91, \mathrm{p}=.055)$ and significant for alcohol exposure vs. baseline water ( F $[1,38]=5.75, p<.05)$.

To further investigate this relationship, an ANOVA was performed between response inhibition and increase in craving (craving after alcohol exposurecraving before alcohol exposure) for each drinking group separately. The analysis showed that the interaction was marginally significant for the heavy drinkers ( $\mathrm{F}$ [1, 11 ] $=2.26, p=.065$ ) but not for the light drinkers (Fig. 3). In other words, during 
the exposure to the alcohol cues, light drinkers with different response inhibition levels did not experience significantly different craving levels. On the other hand, heavy drinkers who were deficient in response inhibition experienced significantly higher craving than heavy drinkers with effective response inhibition. Therefore, the analysis demonstrated that ineffective response inhibition was associated with augmented cue-elicited craving in heavy drinkers but not in light drinkers. ${ }^{2}$

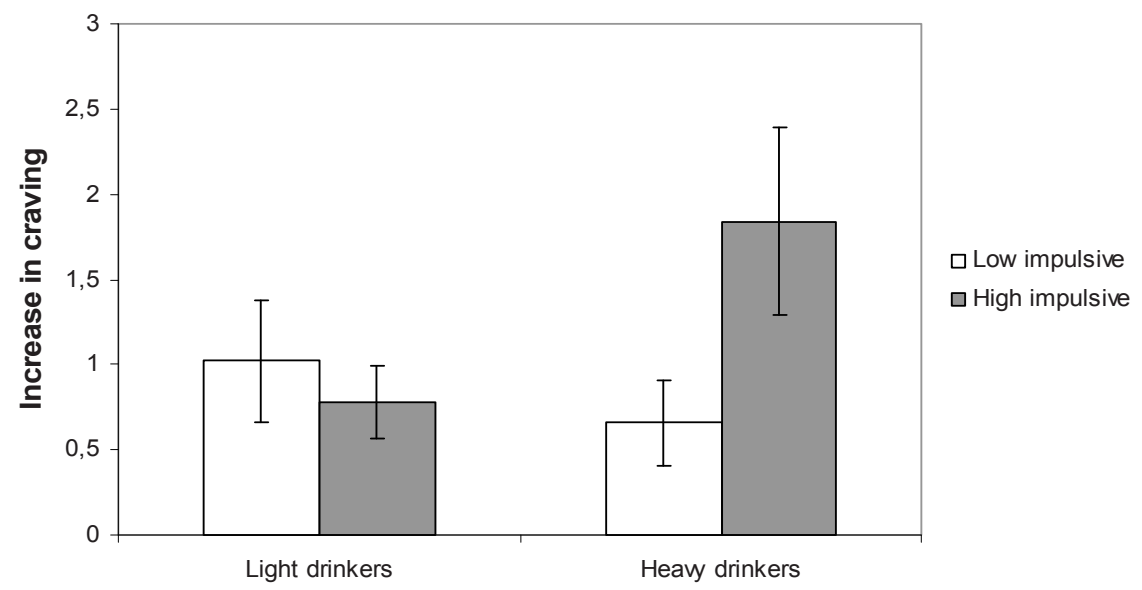

Fig. 3 Mean increase in craving and S.E.M. of the heavy and light drinkers according to their response inhibition levels (as measured with the SST) during the alcohol cue-exposure condition.

\section{The effects of reward sensitivity and trait impulsivity on craving during cue- exposure in heavy and light drinkers}

The same repeated measures ANOVA was used, with groups based on the median score on the CARROT (high and low STR), heavy and light drinkers, and four time points during the cue exposure. The same significant main effects of drinking status, $(F[1,38]=5.98, p<.05)$ and of cue exposure $(F[1.72,65.26]=19.26, p<.001)$ were found as described above. However, neither the main effect of STR, nor any interaction effect appeared to be significant.

In addition, the 2 (heavy vs. light drinkers) 22 (low vs. high in trait impulsivity, based on median score on BIS-11) x 4 (four time points during cue exposure) repeated measures ANOVA showed again a marginally significant main effect of drinking status $(F[1,38]=4.02, p=.052)$ and a highly significant main effect of cue

\footnotetext{
${ }^{2}$ Based on a median split on monthly alcohol use, we can divide participants into equal groups of heavy $(\mathrm{N}=21)$ and light $(\mathrm{N}=21)$ drinkers. When using the median split the heavy drinking group is larger $(21$ vs. 13) and therefore the analysis has more power. When the same analysis is conducted, we find the same pattern of results with an even higher level of significance for the within-subjects simple contrasts (alcohol exposure vs. baseline alcohol, $\mathrm{F}[1,38]=5.17, \mathrm{p}<.05$ ) and for the two-way interaction between response inhibition and alcohol cue exposure on the increase in craving for each drinking group separately, $\mathrm{F}[1,19]=5.05, \mathrm{p}<.05$.
} 
exposure $(\mathrm{F}[1.72,65.18]=16.33, \mathrm{p}<.001)$ on craving. Neither the main effects of trait impulsivity nor any interaction effects were significant. ${ }^{3}$

\section{Discussion}

The primary aim of the present study was to investigate (i) whether there are differences in impulsivity between heavy and light social drinkers, (ii) whether impulsivity moderates cue-elicited craving for alcohol in social drinkers. The results confirmed both of the above hypotheses.

First of all, heavy drinkers had higher impulsivity scores on the BIS-11 than light drinkers. Previous studies using the BIS-11 have also shown that heavy and dependent drinkers are more impulsive than healthy controls (Carlson, Johnson, \& Jacobs, 2010; Lawrence, Luty, Bogdan,, Sahakian, \& Clark, 2009; Rubio, Jimenez, Rodrigo-Jimenez, Martinez, Avila, Ferre, et al., 2008). As the BIS-11 is thought to be a measure of trait impulsivity, the present results imply that impulsivity, as a personality characteristic, may predispose an individual to develop heavy drinking. Specifically, the Non-planning Impulsiveness subscale assesses lack of reflection and self-control as well as a tendency to focus on the present, while the Motor Impulsiveness subscale reflects the tendency to act on the spur of the moment without consideration of the negative consequences of one's own behaviour (Carlson et al., 2010; Stanford, Mathias, Dougherty, Lake, Anderson, \& Patton, 2009). These attitudes may predispose an individual to heavy drinking perhaps in order to experience the immediate positive reinforcing qualities of alcohol without consideration of the future negative consequences of heavy drinking (e.g., dangers of binge drinking). Individuals high on these traits may have greater difficulty refraining from alcohol, once they find themselves in a situation where alcohol is available.

An alternative explanation could be that heavy drinking causes or exacerbates impulsive characteristics in an individual (Jentsch \& Taylor, 1999). In support of this argument, Scaife and Duka (2009) have shown that binge drinking is related to prefrontal cortex dysfunction in young social binge drinkers. Furthermore, Spinella (2005) found a negative correlation between the BIS-11 Non-planning Impulsiveness scale and a self-report index of the dorsolateral prefrontal cortex (DLPFC) and striatum activity (Spinella, 2005; Stanford et al., 2009). Similarly, a negative correlation was reported between the BIS-11 Motor Impulsiveness subscale and a selfreport index of orbitofrontal cortex (OFC) activity (Spinella, 2005; Stanford et al., 2009). It could be argued that heavy drinking patterns affect prefrontal cortex function and this was reflected on the higher BIS-11 scores of the heavy drinkers as compared to the scores of the light drinkers.

\footnotetext{
${ }^{3}$ When we add age as a covariate, the pattern of all results remained the same and age was never significant as a covariate.
} 
As regards the second hypothesis of the present study, the results showed that response inhibition, as measured with the SST, is associated with cue reactivity (craving) in heavy but not light social drinkers. It was found that heavy drinkers who were deficient in response inhibition had higher craving levels for alcohol than heavy drinkers who were efficient in response inhibition. Thus, a poorer response inhibition was associated with a difficulty to overcome strong appetitive conditioned responses (e.g., cue-elicited craving for alcohol) in the presence of alcoholrelated cues (e.g., a bottle of one's favourite alcoholic beverage). However, in our sample of young social drinkers we found no evidence for the assumptions that heavy drinking results necessarily in impaired response inhibition or that response inhibition leads inevitably to heavy drinking. Therefore, it appears that a deficient response inhibition is a predisposing tendency or a risk-factor that in combination with a heavy drinking pattern and in the right context (e.g., in the presence of alcohol-related cues) leads to an inability to inhibit a conditioned appetitive response like craving.

Response inhibition is a prefrontal executive function and performance on the SST relies heavily on the right inferior prefrontal cortex and the frontostriatal pathway (Aron \& Poldrack, 2006; Aron, Robbins, \& Poldrack, 2004). From a psychological point of view, response inhibition, as measured with the SST, is concerned with the inhibition and cancellation of a well-learned motor response. However, evidence is accumulating that the same inhibitory mechanism may be involved in the inhibition of memories and affective responses (Aron et al., 2004). Cue-elicited craving for alcohol is such an affective response that also relies on prefrontal activity. Neuroimaging studies show activation of a variety of prefrontal cortical areas and frontal subcortical structures in alcohol-dependent individuals during exposure to alcohol-related stimuli (Li, Luo, Yan, Bergquist, \& Sinha, 2009). As such, cueelicited craving and response inhibition may rely on common prefrontal neural pathways and interact with each other. Our results suggest that such an interrelationship is plausible. Further support for this assumption comes from the findings of a recent neuroimaging fMRI study with alcohol-dependent individuals who performed the SST (Li et al., 2009). Although also in this study there was no difference between the SSRTs of patients and healthy controls, effective inhibitors in the healthy control group showed stronger activation of the left DLPFC than effective inhibitors in the patient group (Li et al., 2009). More importantly, within the patient group, those with higher craving levels showed more impaired DLPFC activation than those patients with lower craving levels (Li et al., 2009). Despite these preliminary results, more research is needed in order to understand this relationship at a psychological and neuropsychological level.

The current finding that heavy drinkers did not differ as a group in their SST performance from the light drinkers may result from the characteristics of the present sample and/or a moderate sample size. It is also possible that chronic alcohol abuse and dependence exacerbate inhibitory impairments in alcohol-dependent 
individuals and make it easier for these impairments to be detected by the SST in clinical populations.

Regarding reward sensitivity, the heavy drinkers did not differ in their CARROT performance from the light drinkers and no interaction was found between craving and reward sensitivity. At first glance, these findings appear to be in contrast with the results of previous studies (Franken, 2002; Kambouropoulos \& Staiger, 2001). However, in earlier alcohol studies STR was measured with a self-report scale (BAS), while in the present study we used the CARROT, which is a behavioural measure of STR (Franken, 2002; Kambouropoulos \& Staiger, 2001). Although there is evidence for a relationship between trait reward sensitivity and CARROT performance, it may be that behavioural and self-report measures assess somewhat different aspects of STR (Dawe et al., 2004; Kambouropoulos \& Staiger, 2007). Therefore, in the present study we cannot draw any definite conclusion regarding reward sensitivity because our measures may not have been sensitive enough or appropriate to detect any differences between the drinking groups or any relationship between craving and reward sensitivity.

In sum, our results show that different aspects of impulsivity are involved in heavy drinking and perhaps motivate alcohol consumption in a variety of ways. High trait impulsivity, as measured with the BIS-11, appears to be a personality characteristic of heavy social drinkers and may result in/from heavy drinking patterns in young social drinkers. More importantly, response inhibition, as measured with the SST, appears to be a risk-factor for some heavy drinkers because it affects their craving and perhaps their alcohol consumption in the presence of alcoholrelated cues. This, in turn, may lead to the development of more serious alcohol problems for some heavy drinkers.

It remains of course to investigate empirically if response inhibition affects not only the craving but also the drinking behaviour of social drinkers in the presence of alcohol-related cues. Moreover, it would be interesting to examine whether the same mechanisms apply to clinical populations. Finally, if response inhibition is a risk factor for heavy drinking then training response inhibition would lead to less craving and perhaps less drinking for some heavy alcohol and problem drinkers. Indeed, evidence supporting this idea comes from a recent study by Houben, Nederkoorn, Wiers, and Jansen (2010) who reported a decrease in heavy drinkers' alcohol consumption after a week of response inhibition training with a Go/No-Go task. Therefore, the early detection of response inhibition problems and the incorporation of response inhibition training techniques in therapeutic programs may be of great value for some problem drinkers. 


\section{References}

Al-Adawi, S., \& Powell, J. H. (1997). The influence of smoking on reward responsiveness and cognitive functions: a natural experiment. Addiction, 92, 1773-1782.

Aron, A. R., \& Poldrack, R. A. (2006). Cortical and subcortical contributions to stop-signal response inhibition: Role of the subthalamic nucleus. The Journal of Neuroscience, 26, 2424-2433.

Aron, A. R., Robbins, T. W., \& Poldrack, R. A. (2004). Inhibition and the right inferior frontal cortex. Trends in Cognitive Science, 8, 170-177.

Carlson, S. R., Johnson, S. C., \& Jacobs, P. C. (2010). Disinhibited characteristics and binge drinking among university student drinkers. Addictive Behaviors, 35, 242-251.

Carter, B. L., \& Tiffany, S. T. (1999). Meta-analysis of cue-reactivity in addiction research. Addiction, 94: 327-340.

Cloninger, C. R. (1994). Temperament and personality. Current Opinion in Neurobiology, 4, 266-273.

Dawe, S., Gullo, M. J., Loxton, N. L. (2004). Reward drive and rash impulsiveness as dimensions of impulsivity: Implications for substance misuse. Addictive Behaviors, 29, 1389-1405.

Dawe, S., \& Loxton, N. J. (2004). The role of impulsivity in the development of substance use and eating disorders. Neuroscience \& Biobehavioral Reviews, 28, 343-351.

Dom, G., De Wilde, B., Hulstijn, W., Sabbe, B. (2007). Dimensions of impulsive behaviour in abstinent alcoholics. Personality and Individual Differences, 42, 465-476.

Doran, N., McChargue, D., \& Spring, B. (2008). Effect of impulsivity on cardiovascular and subjective reactivity to smoking cues. Addictive Behaviors, 33, 167-172.

Doran, N., Spring, B., \& McChargue, D. (2007). Effects of impulsivity on craving and behavioural reactivity to smoking cues. Psychopharmacology, 194, 279-288.

Drummond, D. C. (2000). Human models in craving research: What does cue-reactivity have to offer clinical research? Addiction, 95, S129-S144.

Eysenck, S. B. G., \& Eysenck, H. J. (1977). The place of impulsiveness in a dimensional system of personality description. The British Journal of Social and Clinical Psychology, 16, 57-68.

Fleming, M. F., Barry, K. L., MacDonald, R. (1991). The Alcohol Use Disorders Identification Test (AUDIT) in a college sample. International Journal of the Addictions, 26, 1173-1185.

Franken, I. H. A. (2002). Behavioural approach system (BAS) predicts alcohol craving. Personality and Individual Differences, 32, 349-355.

Gray, J. A. (1987). Perspectives on anxiety and impulsivity: A commentary. Journal of Research in Personality, 21, 493-509.

Guerrieri, R., Nederkoorn, C., Jansen, A. (2008). The effect of an impulsive personality on overeating and obesity: Current state of affairs. Psychological Topics, 17, 265-286.

Houben, K., Nederkoorn, C., Wiers, R. W., \& Jansen, A. (2010). Running Head: Resisting temptation by training inhibition. Manuscript submitted for publication.

Jentsch, D. J., \& Taylor, J. R. (1999). Impulsivity resulting from frontostriatal dysfunction in drug abuse: implications for the control of behaviour by reward-related stimuli. Psychopharmacology, 146, 373390.

Kambouropoulos, N., \& Staiger, P. K. (2001). The influence of sensitivity to reward on reactivity to alcohol-related cues. Addiction, 96, 1175-1185.

Kambouropoulos, N., \& Staiger, P. K. (2007). Personality, behavioural and affective characteristics of hazardous drinkers. Personality and Individual Differences, 42, 213-224.

Knyazev, G. G., Slobodskaya, H. R., Kharchenko, I. I., \& Wilson, G. D. (2004). Personality and substance use in Russian youths: The predictive and moderating role of behavioural activation and gender. Personality and Individual Differences, 37, 827-843.

Lawrence, A. J., Luty, J., Bogdan, N. A., \& Sahakian, B. J., \& Clark, L. (2009). Impulsivity and response inhibition in alcohol dependence and problem gambling. Psychopharmacology, 207, 163-172.

Li, C. R., Luo, X., Yan, P., Bergquist, K., \& Sinha, R. (2009). Altered impulse control in alcohol dependence: Neural measures of stop signal performance. Alcoholism: Clinical and Experimental Research, 33, 740-750. 
Litt, M. D., Cooney, N. L., \& Morse, P. (2000). Reactivity to alcohol-related stimuli in the laboratory and in the field: predictors of craving in treated alcoholics. Addiction, 95, 889-900.

Logan, G. D., Schachar, R. J., Tannock, R. (1997). Impulsivity and inhibitory control. Psychological Science, 8, 60-64.

Love, A., James, D., Willner, P. (1998). A comparison of two alcohol craving questionnaires. Addiction, 93, 1091-1102.

Loxton, N. L., Dawe, S. (2001). Alcohol abuse and dysfunctional eating in adolescent girls: The influence of individual differences in sensitivity to reward and punishment. International Journal of Eating Disorders, 29, 455-462.

Nederkoorn, C., Baltus, M., Guerrieri, R., \& Wiers, R. W. (2009). Heavy drinking is associated with deficient response inhibition in women but not in men. Pharmacology Biochemistry and Behavior, 93, 331-336.

Noel, X., Van den Linden, M., d'Acremont, M., Bechara, A., Dan, B., Hanak, C., et al. (2007). Alcohol cues increase cognitive impulsivity in individuals with alcoholism. Psychopharmacology, 192, 291-298.

Patton, J. H., Stanford, M. S., \& Barratt, E. S. (1995). Factor structure of the Barratt Impulsiveness Scale. Journal of Clinical Psychology, 51, 768-774.

Powell, J. H., Al-Adawi, S., Morgan, J., \& Greenwood, R. J. (1996). Motivational deficits after brain injury: effects of bromocriptine in 11 patients. Journal of Neurology, Neurosurgery, and Psychiatry, 60, 416421.

Reynolds, B., Ortengren, A., Richards, J. B., de Wit, H. (2006). Dimensions of impulsive behaviour: Personality and behavioural measures. Personality and Individual Differences, 40, 305-315.

Rieger, M., Gauggel, S., Burmeister, K. (2003). Inhibition of ongoing responses following frontal, nonfrontal, and basal ganglia lesions. Neuropsychology, 17, 272-282.

Robinson, T. E., Berridge, K. C. (1993). The neural basis of drug craving: an incentive-sensitization theory of addiction. Brain Research Reviews, 18, 247-291.

Rohsenow, D. J., Niaura, R. S. (1999). Reflections on the state of cue-reactivity theories and research. Addiction, 94, 341-351.

Rubio, G., Jimenez, M., Rodrigo-Jimenez, R., Martinez, I., Avila, C., Ferre, F., et al. (2008). The role of behavioural impulsivity in the development of alcohol dependence: A 4-year follow-up study. Alcoholism: Clinical and Experimental Research, 32, 1681-1687.

Saunders, J. B., Aasland, O. G., Babor, T. F., De La Fuente, J. R., Grant, M. (1993). Development of the Alcohol Use Disorders Identificatication Test (AUDIT): WHO collaborative project on early detection of persons with harmful alcohol consumption-II. Addiction, 88, 791-804.

Scaife, J. C., \& Duka, T. (2009). Behavioural measures of frontal lobe function in a population of young social drinkers with binge drinking pattern. Pharmacology Biochemistry and Behavior, 93, 354-362.

Sobell, L. C., \& Sobell, M. B. (1990). Self-reports across addictive behaviours: Issues and future directions in clinical and research settings. Behavioural Assessment, 12, 77-90.

Spinella, M. (2005). Self-rated executive function: Development of the executive function index. International Journal of Neuroscience, 115, 649-667.

Stanford, M. S., Mathias, C. W., Dougherty, D. M., Lake, S. L., Anderson, N. E., \& Patton, J. H. (2009). Fifty years of the Barratt Impulsiveness Scale: An update and review. Personality and Individual Differences, 47, 385-395.

Stewart, J., de Wit, H., \& Eikelboom, R. (1984). Role of unconditioned and conditioned drug effects in the self-administration of opiates and stimulants. Psychological Review, 91, 251-268.

Zuckerman, M. (1989). Personality in the third dimension: A psychobiological approach. Personality and Individual Differences, 10, 391-418. 


\section{CHAPTER 3}

\section{The role of impulsivity and perceived availability on cue-elicited craving for alcohol in social drinkers ${ }^{4}$}

${ }^{4}$ Papachristou, H., Nederkoorn, C., Corstjens, J., Jansen, A. (2012). The role of impulsivity and perceived availability on cue-elicited craving for alcohol in social drinkers. Psychopharmacology, 224, 145-153. 


\section{Abstract}

Rationale. Previous research has demonstrated a role for impulsivity and perceived availability of the substance in cue-elicited craving. However, their effects on cue-elicited craving for alcohol are still ambiguous. Most important, there has been no empirical evidence for the potential interaction of these factors on alcohol craving.

Objectives. The aim of the present study was to examine the effects of response inhibition and perceived availability on cue-elicited craving for alcohol in social drinkers.

Methods. Participants were light-to-moderate social drinkers ( $n=75)$ who were exposed to neutral- and alcohol-related stimuli during a single laboratory session. Response inhibition was assessed with the Stop Signal Task. Participants were randomly assigned to one of two perceived availability groups $(n=37$, expecting alcohol; $\mathrm{n}=38$, not expecting alcohol).

Results. Overall craving for alcohol was higher in participants who expected alcohol than in those who did not. This finding was statistically significant only in the alcohol condition. Most important, there was a significant interaction between response inhibition, perceived availability, and time on cue-elicited craving. Regardless of cue type, impulsive people who expected alcohol experience a significant increase in cue-elicited craving relative to impulsive people who did not expect alcohol. This effect was not observed in the non-impulsive groups.

Conclusions. The results clearly show that perceived availability alone and in combination with response inhibition can modulate alcohol cue reactivity. Theoretical explanations and clinical implications of these findings are discussed.

Keywords: Cue reactivity · Craving · Alcohol cue exposure $\cdot$ Impulsivity $\cdot$ Response Inhibition - Perceived availability 


\section{Introduction}

Cue reactivity is a robust phenomenon in the alcohol literature. Alcohol-dependent and heavy social drinkers often report an increase in subjective craving and demonstrate significant physiological reactions to alcohol-related cues (Drummond, 2000; Field \& Duka, 2002; Fox, Bergquist, Hong, Sinha, 2007). However, there is still controversy about the origins and nature as well as the factors involved in this phenomenon. For example, cue reactivity has been conceptualized as being either a drug-like appetitive, or a withdrawal-like, or finally a homeostatic response that opposes the unconditioned drug effect (Siegel, 2001; Stewart, de Wit, \& Eikelboom , 1984; Wikler, 1948;). Although there is supportive evidence for all the aforementioned models, most evidence suggests that stimuli associated with alcohol consumption become conditioned incentives, thus, eliciting appetitive responses and motivating drinking (Carter \& Tiffany 1999; Drummond, 2000; Field \& Duka 2002).

However, not everybody who drinks alcohol experiences the same levels of cueelicited craving. Even among alcohol-dependent people there is evidence that approximately a third does not report craving when exposed to alcohol-related cues (Litt, Cooney, \& Morse, 2000). Apparently, the relationship between cue-elicited craving and alcohol misuse/abuse is complex and it appears that personality and cognitive factors are involved in it (Papachristou, Nederkoorn, Havermans, van der Horst, \& Jansen, 2012; Wertz \& Sayette, 2001).

Regarding personality factors, impulsivity seems to be a possible candidate. Impulsivity is typically associated with a lack of planning, a difficulty in inhibiting inappropriate behaviour and insensitivity to consequences (Dawe, Gullo, \& Loxton, 2004; Dawe \& Loxton, 2004; Dom, De Wilde, Hulstijn, \& Sabbe, 2007; Reynolds, Ortengren, Richards, \& de Wit, 2006). However, most impulsivity measures correlate weakly to each other, which implies that impulsivity is not a unidimensional concept (Dawe \& Loxton, 2004). A line of research suggests that response inhibition, the ability to inhibit a prepotent response, is a distinct psychological process under the general concept of impulsivity (Dawe et al., 2004; Nederkoorn, Baltus, Guerrieri, \& Wiers, 2009; Papachristou et al., 2012).

A line of research has shown that heavy and dependent drinkers exhibit deficiencies in response inhibition (Christiansen, Cole, Goudie, \& Field, 2012), though the findings are not always consistent across studies (Fernie, Cole, Goudie, \& Field, 2010; Kamarajan, Porjesz, Jones, Choi, Chorlian, Padmanabhapillai, Rangaswamy, Stimus, \& Begleiter, 2005). For example, Colder and O'Connor (2002) reported that high levels of alcohol consumption are associated with deficiencies in response inhibition. Additionally, Rubio, Jimenez, Rodriguez-Jimenez, Martınez, Avila, Ferre, Jimenez-Arriero, Ponce, and Palomo (2008) conducted a 4-year follow-up study and reported that performance on the stop signal task, a behavioural measure of response inhibition, predicts the development of alcohol use disorders. 
In theory, an impaired response inhibition system could lead to strong cue-elicited craving for alcohol via a difficulty in inhibiting an appetitive response to a stimulus with strong incentive properties (e.g., an alcohol cue) (Dawe \& Loxton, 2004; Papachristou et al., 2012). Although there is a scarcity of empirical studies in the field, there is some evidence to support the above assumption. Papachristou et al. (2012) reported that response inhibition moderates cue-elicited craving for alcohol in heavy but not light social drinkers.

Apart from personality factors, cognitive variables appear also to influence cueelicited craving. One possible candidate here is the perceived availability of the substance. In the present study, this term is identical to what Wertz and Sayette define as "perceived drug use opportunity" or "drug availability, intention to use the drug, and the expectation of experiencing the drug's effects, assuming at least a minimal desire for drug use" (Wertz \& Sayette, 2001, cited in p. 4). Among several explanations, the authors propose that the perceived availability of the substance may be an integral component of the conditioned stimulus (e.g., alcohol-related cue). Consequently, substance-related cues may elicit less or even no craving when the substance is perceived to be unavailable because the stimulus complex is not complete (Wertz \& Sayette, 2001). An alternative explanation could be that throughout the course of substance use/abuse, information regarding drug use opportunity is becoming a distinct conditioned stimulus, which elicits cue reactivity even when physical drug cues are not present (Wertz \& Sayette, 2001). Consistent with a conditioning account, Field and Cox (2008) also suggest that drug-related cues first elicit an expectation for the use of the substance, which in turn leads to craving. In their opinion, cue-elicited craving is mediated by the perceived availability of the substance (Field \& Cox, 2008).

Supportive (though tentative) evidence for the role of perceived availability in cue-elicited craving comes from the fact that treatment-seeking inpatients usually report lower levels of cue-elicited craving than continuing substance users (Wertz \& Sayette, 2001). One reason for this weak response to the substance-related cues could be the perceived unavailability of the substance for the inpatients in the treatment centers (Wertz \& Sayette, 2001). Additionally, stronger supportive evidence comes from laboratory studies with nicotine-dependent smokers (Field \& Cox, 2008). Most dependent smokers show an increased craving when exposed to smoking-related cues, while self-reported craving significantly decreases when smokers perceive no opportunity to smoke in the near future (Droungas, Ehrman, Childress, \& O’Brien, 1995; Juliano \& Brandon, 1998).

Nevertheless, in the field of alcohol the findings are not as consistent as in the field of nicotine. Davidson, Tiffany, Johnston, Flury, and Li (2003) found that perceived availability does not have an effect on craving for alcohol in non-treatment seeking alcohol-dependent people. Furthermore, MacKillop and Lisman (2005) reported that when heavy drinkers are exposed to alcohol cues it is the unavailability and not the availability of alcohol that is associated with higher craving. However, the same authors also reported that in heavy drinkers unavailability information 
leads to higher craving for alcohol regardless of the type of cue exposure (alcohol vs. water cues) (MacKillop \& Lisman, 2007). Clearly, there is a need for more research on the role of perceived availability on cue-elicited craving for alcohol in social and dependent drinkers.

The aim of the present study is to examine the role of perceived availability and response inhibition on cue-elicited craving for alcohol in social drinkers. First of all, it is hypothesized that craving for alcohol is higher during alcohol than during water exposure. The increase in craving is expected to be stronger when alcohol is perceived to be available than when it is not. Additionally, it is hypothesized that social drinkers with impaired response inhibition experience higher cue-elicited craving for alcohol than social drinkers with good response inhibition. Finally, it is expected that the effects of perceived availability may be stronger in those social drinkers with impaired response inhibition than in social drinkers with good response inhibition. Patterson and Newman (1993) argue that disinhibited people, even under aversive conditions, focus more and respond more forcefully to salient and rewarding stimuli in the environment than normal people. As mentioned above, perceived availability is considered to be either a salient component of the stimulus-complex or a distinct salient CS on its own. Therefore, for those social drinkers with impaired response inhibition availability information may be an additional cue (or cue component) to attend and to respond. Consequently, their craving response to this cue may be stronger than the craving response of social drinkers with adequate response inhibition. This interaction may also be able to explain some of the inconsistent findings in the alcohol literature.

\section{Methods}

\section{Participants}

Seventy five participants ( 25 men and 50 women) with a mean age of 23.29 (SD = $5.20)$ volunteered to participate in the study. All of them were recruited from Maastricht University via emails and advertisements placed in the university premises. Only participants who were able and willing to consume alcohol were invited to take part in the study. Participants who did not wish to consume alcohol for personal, health, cultural, religious, or other reasons could not participate in this experiment. Other exclusion criteria were: (a) having a hepatic disease, (b) being pregnant, (c) receiving any medication that could interact with alcohol. None of the participants had been diagnosed with any substance abuse disorder (apart from smoking tobacco). All participants had to specify their typical type/brand of alcoholic beverage before being invited to the laboratory. At the end of the experiment, participants were rewarded with either a $20 €$ gift certificate or course credits to fulfil academic requirements. 


\section{Measures}

\section{Response inhibition}

The Stop Signal Task (SST) was used to assess response inhibition (Logan, Schachar, \& Tannock, 1997). The task begins with a 500ms fixation cross presented in the centre of a computer screen. Then a go trial follows. In each go trial a square pattern appears either on the left or the right compartment of the screen and participants are required to push as quickly as possible the left or right "shift" button, respectively. However, in $25 \%$ of the go trials, an acoustic stop signal $(1000 \mathrm{~Hz}$ tone) is heard after the go-signal, indicating that the participants must withhold their response. The stop signal delay (SSD) initially occurs at $250 \mathrm{~ms}$ after the go signal presentation but throughout the task it changes according to the participant's performance. These adjustments enable the participants to successfully inhibit their responses at approximately $50 \%$ of the stop trials.

First, participants performed 3 practice blocks of respectively 6, 12 and 24 trials. Next, 4 test blocks of 64 trials each followed. The intertrial interval was $1000 \mathrm{~ms}$. The dependent variable of interest is the stop signal reaction time (SSRT). A higher SSRT means that it takes more time for a participant to inhibit a prepotent response and, thus, it is an index of impaired response inhibition.

\section{Craving}

Craving was assessed with two $100-\mathrm{mm}$ visual analogue scales (VAS). Participants were asked to indicate (a) their desire to consume alcohol: "How much do you feel like drinking alcohol right now?", and (b) their urge to drink alcohol: "How strong is your urge to drink alcohol right now?". Visual analogue scales have been used in many alcohol-related studies and have been found to be valid and reliable indicators of craving for alcohol (Juliano \& Brandon, 1998; Kozlowski, Pillitteri, Sweeney, Whitfield, \& Graham, 1996).

\section{Alcohol Use Identification Test (AUDIT)}

The AUDIT is a reliable screening tool for identifying those people whose alcohol consumption is excessive and reaches problematic levels (Saunders, Aasland, Babor, De La Fuente, \& Grant, 1993). It consists of 10 multiple-choice items which assess hazardous alcohol consumption, alcohol-dependence symptoms, and harmful alcohol use (Saunders et al., 1993).

\section{Timeline follow-back questionnaire}

Alcohol use was also assessed with the Timeline follow-back questionnaire. When completing this questionnaire, participants are required to provide a detailed description of the frequency and quantity of their alcohol consumption (expressed in standard units or drinks) over the last 30 days (Sobell \& Sobell, 1990). The sum score of standard drinks was used as an index of each participant's alcohol consumption. 


\section{Procedure}

Ethical approval was obtained from the Ethical Committee of the Psychology Faculty of Maastricht University. Participants took part in one individual testing session arranged between $12.30 \mathrm{pm}$ and $19.00 \mathrm{pm}$. After signing the informed consent form, participants had to complete a brief demographic questionnaire. Having done this, they were presented with the Timeline Alcohol Questionnaire and the AUDIT and then they were instructed to perform the SST. Following this, participants were first offered a small amount of water to control for thirst and then were explicitly told that they had been randomly allocated to either the "expecting alcohol" or the "not expecting alcohol" conditions. Unlike the latter group, the former would be offered a glass of their typical alcoholic beverage at the end of the experiment. Participants were explicitly asked if they had understood the implications of this allocation (e.g., "I would like to know if you have understood the condition in which you are in. Are you going to have a drink of alcohol at the end of the experiment or not?"). When the participants confirmed that they had understood the condition they were in, they were told that they would be exposed first to water and then to alcohol cues. As Rohsenow and Niaura (1999) recommend, the order of the cue exposure conditions was not counterbalanced to avoid carry-over effects.

At the beginning of the water exposure, participants were presented with a tray containing a commercially labelled bottle of spring water, an empty glass for water, and a small glass containing $1.5 \mathrm{ml}$ of water. After the water exposure, a 5-min break followed during which the participants were offered some magazines to read (without alcohol-related advertisements) and left alone to relax. Immediately after the break, participants were again offered a small amount of water to control for thirst and were once more asked to report the drinking condition they were in. Then, the alcohol cue exposure started. Like the water exposure, participants were confronted with a commercially labelled bottle of their typical alcoholic beverage, a proper glass for the alcoholic beverage, a small glass containing $1.5 \mathrm{ml}$ of this alcoholic beverage and, if necessary, a bottle opener.

Each cue exposure condition lasted 20 minutes. Participants had to sit down in front of a table facing the wall. The experimenter first ensured that the lab was quiet and the lights dimmed and then sat down on a chair behind the participant and instructed them what to do with the cues. During each cue exposure condition, craving was assessed five times, once at the beginning (baseline) and then every five minutes. The complexity of the cue exposure increased across time (Greeley, Swift, \& Heather, 1993). For example, during the first five minutes participants were exposed only to imagery and visual cues. However, in the next five minutes, they were also exposed to olfactory cues. Following this, taste was also included by having participants immerse their fingers into the beverage (water or alcohol) and touch their mouth and tongue with those fingers. Finally, during the last 5 minutes they had also to drink $1.5 \mathrm{ml}$ of either water or alcohol (most intense exposure). 
After the alcohol cue exposure, half the participants were offered a glass of their typical alcoholic beverage ("expecting alcohol" condition), while the other half were not offered alcohol ("not expecting alcohol" condition). For safety reasons, the blood alcohol level of the former group was monitored with a breath analyzer before they left the laboratory. All participants signed up on a debriefing list in order to receive a debriefing email after the experiment had ended. Finally, they were thanked and rewarded for their participation in the experiment.

\section{Statistical analysis}

Participants were divided into two perceived availability groups (expecting alcohol: $\mathrm{N}=37$; not expecting alcohol: $\mathrm{N}=38$ ). Perceived availability condition was the between-subjects factor in the analysis. The SSRT and AUDIT were centered and entered as covariates into the analysis. Craving for alcohol was the dependent variable and was calculated by averaging the scores in the two visual analogue scales for each participant. For the purpose of the present analysis, only the last time point of the cue exposure was chosen (most intense cue exposure). A three-way 2 (Cue: water vs. alcohol) x 2 (Time: baseline vs. exposure) x 2 (Perceived Availability: expecting vs. not expecting alcohol) mixed ANCOVA was performed on craving for alcohol. In addition, interactions with the covariates (SSRT and AUDIT) were tested. When further analysis was required, a median split was conducted on the SSRTs in order to classify social drinkers as being either good or impaired in response inhibition. Greenhouse-Geisser correction was used when Mauchly's test of sphericity was significant.

\section{Results}

\section{General characteristics of the sample}

Participants had consumed on average 47.8 (SD $=44.57$ ) standard alcoholic drinks in the 30 days before participation in the experiment and their mean AUDIT score was $7.72(\mathrm{SD}=4.16)$.

\section{Differences between perceived availability conditions}

There was no significant difference in baseline craving levels, AUDIT scores, amount of standard drinks/month, and SSRTs between people who expected and people who did not expect alcohol in the present experiment (Table 1). Table 2 depicts correlations between SSRT, AUDIT scores, craving scores after alcohol cue exposure, and Standard drinks/month for each perceived availability condition. 
Table 1 Differences (Mean and Standard Deviation) between perceived availability conditions

\begin{tabular}{lcc}
\hline Variables & Expecting alcohol $(\mathrm{n}=37)$ & Not expecting alcohol $(\mathrm{n}=38)$ \\
\hline Craving levels at water baseline & $2.51(1.67)^{\mathrm{a}}$ & $2.20(1.87)^{\mathrm{b}}$ \\
SSRT & $203.84(32.03)^{\mathrm{a}}$ & $202.97(33.22)^{b}$ \\
AUDIT & $7.76(4.13)^{\mathrm{a}}$ & $7.68(4.24)^{b}$ \\
Standard drinks/month & $46.08(46.04)^{\mathrm{a}}$ & $49.47(43.66)^{b}$ \\
\hline
\end{tabular}

Means sharing similar subscripts within a row differ at $\mathrm{p}<.05$

SSRT Stop Signal Reaction Time, AUDIT Alcohol Use Identification Test

Table 2 Correlations between after SSRT, AUDIT, Standard drinks/month and craving after alcohol cue exposure for each perceived availability condition

\begin{tabular}{|c|c|c|c|c|c|}
\hline $\begin{array}{l}\text { Perceived Availability } \\
\text { condition }\end{array}$ & & SSRT & AUDIT & $\begin{array}{l}\text { Standard } \\
\text { drinks/month }\end{array}$ & $\begin{array}{l}\text { Craving after alcohol } \\
\text { cue exposure }\end{array}$ \\
\hline \multirow{4}{*}{$\begin{array}{l}\text { Expecting alcohol } \\
(\mathrm{N}=37)\end{array}$} & SSRT & & .11 & .26 & $.33^{*}$ \\
\hline & AUDIT & .11 & & $.78^{* *}$ & .23 \\
\hline & Standard drinks/month & .26 & $.78^{* *}$ & & .28 \\
\hline & $\begin{array}{l}\text { Craving after alcohol cue } \\
\text { exposure }\end{array}$ & $.33^{*}$ & .23 & .28 & \\
\hline \multirow{4}{*}{$\begin{array}{l}\text { Not expecting alcohol } \\
(\mathrm{N}=38)\end{array}$} & SSRT & & -.17 & -.15 & -.22 \\
\hline & AUDIT & -.17 & & $.72^{* *}$ & $.49^{* *}$ \\
\hline & Standard drinks/month & -.15 & $.72^{* *}$ & & $.34^{*}$ \\
\hline & $\begin{array}{l}\text { Craving after alcohol cue } \\
\text { exposure }\end{array}$ & -.22 & $.49^{* *}$ & $.34^{*}$ & \\
\hline
\end{tabular}

**. Correlation is significant at the .01 level (two-tailed)

*. Correlation is significant at the .05 level (two-tailed)

SSRT Stop Signal Reaction Time, AUDIT Alcohol Use Identification Test

\section{The effect of cue exposure}

There was a main effect of the type of cue (water, alcohol) on the overall craving for alcohol (baseline + exposure), F (1,67) = 21.82, p <.001 (Fig. 1). Craving for alcohol is higher in the alcohol than in the water condition (Fig. 1). Moreover, a significant effect of time was found, $\mathrm{F}(1,67)=28.83, \mathrm{p}<.001$. Overall, craving for alcohol is higher after cue exposure than at baseline (Fig. 1). Finally, there was a significant 2way interaction of the type of cue (water, alcohol) x time (baseline, exposure) on craving, $F(1,67)=81.24, p<.001$. Inspection of Fig. 1 indicates that the pattern of change in craving levels across time differs between the water and the alcohol conditions. After the water exposure, craving for alcohol is significantly reduced com- 
pared to baseline levels, $\mathrm{t}(74)=-4.38, \mathrm{p}<.001$. On the other hand, craving for alcohol significantly increases after exposure to alcohol cues relative to baseline levels, $t(74)=9.68, p<.001$. Finally, there was a main effect of AUDIT on craving, F $(1,67)$ $=12,62, \mathrm{p}=.001$. However, none of the interactions with AUDIT was significant (Cue type $\mathrm{x}$ Time $\mathrm{x}$ AUDIT, F $(1,67)=.01$, ns; Cue $\mathrm{x}$ AUDIT, F $(1,67)=1.57$, ns.; Time $x$ AUDIT, F $(1,67)=2.09$, ns.).

\section{The effect of the perceived availability}

A significant main effect of perceived availability (expecting vs. not expecting alcohol) on craving for alcohol was found, $\mathrm{F}(1,67)=5.33, \mathrm{p}<.05$. Overall, social drinkers who expected to consume alcohol at the end of the experiment experience higher craving (baseline + exposure) during both the water and the alcohol conditions than those participants who perceived alcohol to be unavailable in the laboratory. The effect of availability was qualified by a significant 2-way interaction between the type of cue (water, alcohol) and perceived availability (expecting vs. not expecting alcohol) on craving for alcohol, $\mathrm{F}(1,67)=5.55, \mathrm{p}<.05$. Independent-samples ttests indicated that craving levels during the water condition (baseline + exposure) do not differ significantly between the two perceived availability groups, t (73) = 1.35, n.s. However, during the alcohol condition (baseline + exposure), social drinkers who expected alcohol experience significantly higher craving than those participants who did not expect alcohol, t (73) $=2.48, \mathrm{p}<.05$, (Fig. 1). Finally, none of the interactions with AUDIT was significant (perceived availability $x$ AUDIT, $F(1,67)=$ .81 , ns.; cue type x perceived availability x AUDIT, $\mathrm{F}(1,67)=.57$, ns.).

\section{Effect of response inhibition}

There was no significant main effect of response inhibition on craving, $F(1,67)=$ .00 , n.s. Furthermore, there was no significant interaction between response inhibition and perceived availability on craving, $F(1,67)=2.8, \mathrm{p}=.099$. Similarly, the interactions response inhibition $\mathrm{x}$ AUDIT $(\mathrm{F}(1,67)=.00$, ns) and response inhibition $\mathrm{x}$ perceived availability $\mathrm{x}$ AUDIT $(\mathrm{F}(1,67)=.16$, ns.) on craving were not significant. However, there was a significant 3-way interaction between time (baseline, exposure) $\mathrm{x}$ response inhibition $\mathrm{x}$ perceived availability (expecting, not expecting alcohol) on craving for alcohol, $\mathrm{F}(1,67)=5.51, \mathrm{p}<.05$. Yet, the 4-way interaction time $\mathrm{x}$ response inhibition $\mathrm{x}$ perceived availability $\mathrm{x}$ AUDIT on craving was not significant, $F(1,67)=.062$, ns. To analyze the 3 -way interaction further, a median split was conducted on SSRTs and participants were divided into good and impaired in response inhibition. A two-way ANCOVA time x perceived availability with AUDIT as covariate was performed on craving for each response inhibition group, respectively. The analysis showed that the interaction time x perceived availability on craving was not significant for those participants with good response inhibition, $F$ $(1,34)=.29$, ns. (Fig. 1). On the other hand, the same interaction was significant for 
those social drinkers with impaired response inhibition, $F(1,35)=6.99, p<.05$ (Fig. 1). Only in the latter group, the difference in craving between exposure to any cue (water or alcohol) and baseline was different between the two perceived availability conditions (expecting vs. not expecting alcohol). Further analysis within the impaired response inhibition group (and while controlling for AUDIT) showed that the main effect of time (baseline, exposure) was significant for those social drinkers who were expecting to consume alcohol at the end of the experiment, $F(1,18)=$ $11.76, \mathrm{p}=.003$, but non-significant for those social drinkers who could not drink at the end of the experiment, $F(1,16)=.23$, ns. (Fig. 1). Inspection of Fig. 1 shows that regardless of cue type, social drinkers with impaired response inhibition who expected to consume alcohol experience their highest craving during exposure (i.e. higher increase in craving during alcohol exposure and less decrease of craving during water exposure).

The 3-way interaction between cue (water, alcohol) $\mathrm{x}$ response inhibition $\mathrm{x}$ perceived availability (expecting vs. not expecting alcohol) was non-significant, $\mathrm{F}$ $(1,71)=2.14$, n.s. Similarly, the 4-way interaction cue (water, alcohol) $\mathrm{x}$ time (baseline, exposure) $\mathrm{x}$ response inhibition $\mathrm{x}$ perceived availability (expecting vs. not expecting alcohol) on craving was not significant, $F(1,71)=.18$, n.s. Finally, the 4way interaction cue type $\mathrm{x}$ response inhibition $\mathrm{x}$ perceived availability $\mathrm{x}$ AUDIT on craving $(\mathrm{F}(1,67)=.27, \mathrm{~ns}$.) and the 5 -way interaction cue type $\mathrm{x}$ time $\mathrm{x}$ response inhibition x perceived availability x AUDIT on craving $(F(1,67)=2.99$, ns.) were not significant.

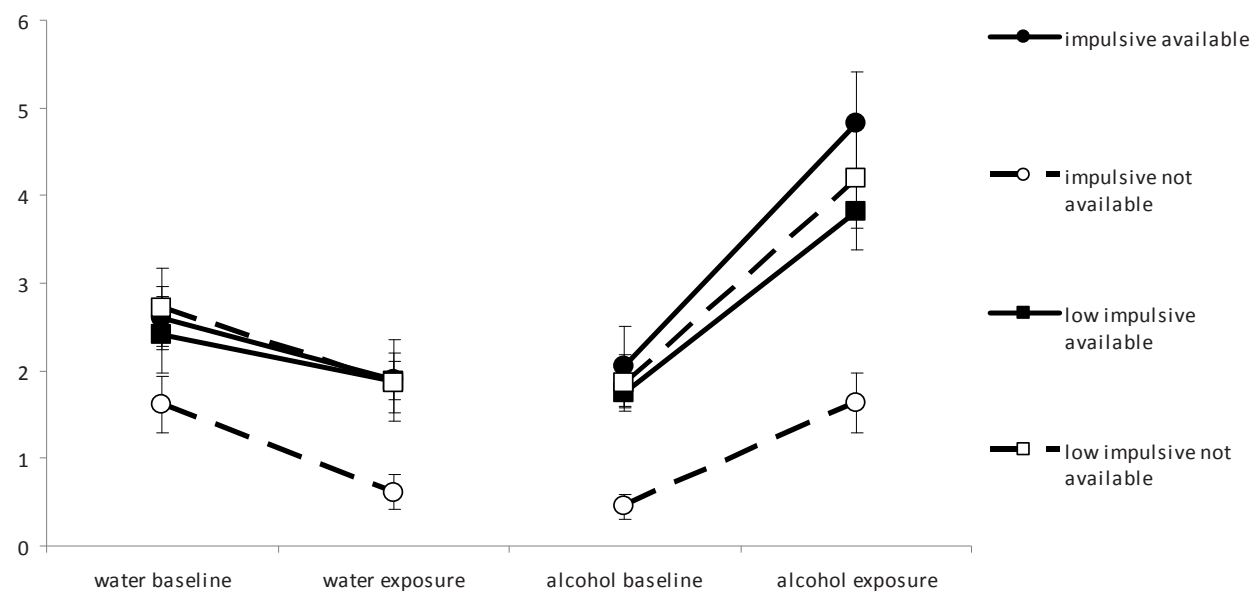

Fig. 1 Craving levels across time during the water and alcohol conditions when alcohol was perceived available or not available and when people were impaired (+ 1 SD above the mean) or good (-1 SD below the mean) in response inhibition. 


\section{Discussion}

The aim of the present study was to investigate the effects of response inhibition and perceived availability on cue-elicited craving for alcohol in social drinkers. It was hypothesized that cue-elicited craving for alcohol is higher during the alcohol than during the water cue exposure and that this difference in craving levels is larger in participants who expect to consume alcohol relative to those who do not. Additionally, it was assumed that people with impaired versus good response inhibition react more to alcohol cues. Finally, it was expected that the effects of perceived availability are more intense in social drinkers with impaired versus unimpaired response inhibition. The results confirmed most of the above hypotheses.

First of all, it was found that alcohol cues elicit stronger craving than neutral (water) cues. This finding verifies our first hypothesis and is in line with the cuereactivity literature (Carter \& Tiffany, 1999; Drummond, 2000). Most important, a significant interaction between response inhibition, perceived availability, and time on craving for alcohol was reported, independent of cue type (water or alcohol). When response inhibition levels are sufficient, perceived availability has no effect on craving for alcohol. However, when response inhibition mechanisms are impaired, participants who perceive alcohol to be available experience a significant increase in cue-elicited craving relative to participants who do not expect alcohol. The craving of the latter impulsive group does not change significantly from baseline levels. This is a totally new finding in the cue-reactivity literature and therefore awaits further replication. However, it is of primary theoretical and clinical importance because it demonstrates the impact of the combination of personality and cognitive factors on alcohol cue reactivity.

This finding partially affirms our last hypothesis that people with impaired response inhibition are more reactive to their environment when they consider alcohol to be available than unavailable. Disinhibited people may be more sensitive to salient cues (Dawe et al., 2004; Dawe \& Loxton, 2004; Patterson \& Newman, 1993) and, as the present results also illustrate, to the absence of these cues. For these participants, perceived availability may be a salient cue to respond and therefore, their craving for alcohol would be stronger when this cue is present than when it is absent.

It could also be argued that for impulsive people perceived availability is not part of the physical alcohol stimulus (CS) because it affects craving during both the water and the alcohol cue exposure. Rather, it seems to act as a distinct CS (Juliano \& Brandon, 1998; Wertz \& Sayette, 2001). It is possible, for example, that availability knowledge always precedes a drinking episode. As a result of the association with the rewarding effects of alcohol, availability information may itself become a CS that triggers craving for alcohol regardless of the presence of proximal alcohol cues (Juliano \& Brandon, 1998). Further evidence supporting this idea comes from the fact that specific reactions to alcohol-related cues do not differ between impul- 
sive and non-impulsive participants in the two perceived availability groups because the interaction between cue type, time, perceived availability, and response inhibition on craving is not significant. The lack of interaction excludes alternative explanations, such as perceived availability being a necessary component of the CS complex or an occasion setter (Juliano \& Brandon, 1998; Wertz \& Sayette, 2001).

The significant main effect of perceived availability may also indicate that the knowledge that alcohol is available may serve as a distinct CS (Juliano \& Brandon 1998; Wertz \& Sayette 2001). However, the main effect of availability in the present study is qualified by the significant interaction between cue type and perceived availability, which demonstrates that the difference in overall craving (baseline + exposure) between the two groups reaches statistical significance only during the alcohol condition. Nevertheless, it could still be argued that perceived availability serves as a weak CS that causes the non-significant difference in overall craving between the two perceived availability groups during the water condition. In the alcohol condition, however, the combination of the physical alcohol cues with perceived availability may result in the significant difference in overall craving between the groups. This explanation appears to be consistent with Drummond's (2000, cited in p. 132) concept of a "cue cascade ... in which each cue increases ... the salience of the next cue".

Therefore, it appears that perceived availability of the substance may serve as a more distal and distinct CS that acts in combination with other factors to increase craving. For example, it may have a weak effect on craving when presented with neutral stimuli, but a stronger effect when followed by alcohol-related cues because it amplifies their salience (Drummond, 2000). Additionally, it may increase craving independent of cue type but only in combination with high impulsivity levels.

Nevertheless, alternative explanations cannot be excluded. For example, one methodological limitation of the present study was that the water and the alcohol conditions were not counterbalanced in order to avoid transfer of reactivity to the water cues. The alcohol condition was always presented second in order; hence it was always closer to the end of the experiment, which in turn signals temporal proximity to alcohol drinking for those social drinkers who expected alcohol. Consequently, it is possible that the main effect of availability becomes more pronounced as the time to delivery of the alcohol draws closer. According to this interpretation, availability is an independent cue that does not interact with the alcohol cue.

The clinical significance of the present results should not be underestimated. Alcohol is readily available in most places in western countries except for the addiction clinics. People with alcohol problems do not have access to the substance when they undergo inpatient treatment. Moreover, craving/desire for alcohol is often used as an index of the treatment progress of the patient. However, the present study reveals that personality aspects in combination with cognitive factors can modulate craving for alcohol and present a faulty image of the progress of the patient in the clinic. For example, it could be that the more impulsive inpatients who 
perceive alcohol to be unavailable in the clinic demonstrate no significant craving while being in treatment. However, the same people when being outside the clinic could experience serious craving for alcohol even in the absence of physical alcohol cues only because they know that alcohol is available. The present data have also consequences for cue exposure treatment in which patients are exposed to alcohol cues. The goal of this treatment is to have participants crave as much as possible, while the drinking response is prevented. This procedure should extinguish the craving response to the drinking cues (Conklin \& Tiffany, 2002). However, if the patient knows that there is no opportunity to drink, their craving might be lower and extinction is less likely to happen. In addition, the present data suggest that it is important for impulsive people to expose themselves also to the availability of alcohol. When not extinguished, this cue, which is very salient after leaving an inpatient clinic, might induce strong feelings of craving and possibly trigger relapse in impulsive drinkers.

In the present study, we did not find a modulating effect of response inhibition in cue-elicited craving for alcohol, which seems to be in disagreement to our hypothesis and the results of our earlier study (Papachristou et al., 2012). In our previous study we reported a modulating effect of response inhibition on cue-elicited craving for alcohol in heavy (mean AUDIT score $=12.1$ ) but not in light drinkers (mean AUDIT score $=5.81$ ) (Papachristou et al., 2012). In the present study our sample consists of light-to-moderate social drinkers (mean AUDIT score $=7.72$ ), and this difference in the drinking status of the samples could be a reason for the discrepancy in the findings between the two studies.

The drinking status is also one of the major methodological differences between the present study and earlier alcohol studies on perceived availability (MacKillop \& Lisman, 2005, 2007). In both studies by MacKillop and Lisman (2005, 2007) participants were heavy drinkers who had to consume at least 20+/14+ standard drinks per week for men/women respectively (MacKillop \& Lisman, 2005, 2007). In the present study, we did not include such a criterion for participation. Perhaps, the effects of availability are different for different types of drinkers but only empirical research can investigate this hypothesis.

The drinking status (light-to-moderate drinkers) and the gender differences (the majority of the present sample consisted mostly of female rather than male participants) in our sample limit the generalization of these findings. Therefore, the results should be considered to be preliminary and more research should be conducted on the same topic perhaps with different types of drinkers (heavy, people with alcohol use disorders) and samples with different gender proportions. In any case, the present findings are more in agreement with earlier nicotine studies in which perceived availability of tobacco was found to increase craving (Carter \& Tiffany, 2001; Droungas et al., 1995; Field \& Cox, 2008; Juliano \& Brandon, 1998). Unlike the earlier nicotine studies, however, the present data illustrate that perceived availability serves as a distinct CS that acts in combination with personality aspects such as impulsivity to increase craving. Although this is an entirely new 
finding and should be subject to replication, its clinical implications should not be ignored. More important, the results clearly show that a variety of factors and their combination affect cue reactivity, which may partly explain the lack of and the variability in cue reactivity observed in clinical and non-clinical populations (Carter \& Tiffany, 1999; Litt et al., 2000).

\section{References}

Carter, B. L., \& Tiffany, S. T. (2001). The cue-availability paradigm: the effects of cigarette availability on cue reactivity in smokers. Experimental and Clinical Psychopharmacology, 9, 183-190.

Carter, B. L., \& Tiffany, S. T. (1999). Meta-analysis of cue-reactivity in addiction research. Addiction, 94, 327-340.

Christiansen, P., Cole, J. C., Goudie, A. J., \& Field, M. (2012). Components of behavioural impulsivity and automatic cue approach predict unique variance in hazardous drinking. Psychopharmacology, 219, 501-510.

Colder, C. R., \& O’Connor, R. (2002). Attention biases and disinhibited behavior as predictors of alcohol use and enhancement reasons for drinking. Psychology of Addictive Behaviors, 16, 325-332.

Conklin, C. A., \& Tiffany, S. T. (2002). Applying extinction research and theory to cue-exposure addiction treatments. Addiction, 97, 155-167.

Davidson, D., Tiffany, S. T., Johnston, W., Flury, L., Li, T. K. (2003). Using the cue-availability paradigm to assess cue reactivity. Alcoholism: Clinical and Experimental Research, 27, 1251-1256.

Dawe, S., Gullo, M. J., \& Loxton, N. L. (2004). Reward drive and rash impulsiveness as dimensions of impulsivity: Implications for substance misuse. Addictive Behaviors, 29, 1389-1405.

Dawe, S., \& Loxton, N. J. (2004). The role of impulsivity in the development of substance use and eating disorders. Neuroscience and Biobehavioral Reviews, 28, 343-351.

Dom, G., De Wilde, B., Hulstijn, W., Sabbe, B. (2007). Dimensions of impulsive behaviour in abstinent alcoholics. Personality and Individual Differences, 42, 465-476.

Droungas, A., Ehrman, R. N., Childress, A. R., \& O’Brien, C. P. (1995). Effect of smoking cues and cigarette availability on craving and smoking behavior. Addictive Behaviors, 20, 657-673.

Drummond, D. C. (2000). Human models in craving research: What does cue-reactivity have to offer clinical research? Addiction, 95, S129-S144.

Fernie, G., Cole, J. C., Goudie, A. J., Field, M. (2010). Risk-taking but not response inhibition or delay discounting predict alcohol consumption in social drinkers. Drug and Alcohol Dependence, 112, 54-61.

Field, M., \& Cox, W. M. (2008). Attentional bias in addictive behaviors: a review of its development, causes, and consequences. Drug and Alcohol Dependence, 97, 1-20.

Field, M., \& Duka, T. (2002). Cues paired with a low dose of alcohol acquire conditioned incentive properties in social drinkers. Psychopharmacology, 159, 325-334.

Fox, H. C., Bergquist, K. L., Hong, K., Sinha, R. (2007). Stress-induced and alcohol cue-induced craving in recently abstinent alcohol-dependent individuals. Alcoholism: Clinical and Experimental Research, 31, 395-403.

Greeley, J. D., Swift, W., Heather, N. (1993). Reactivity to alcohol-related cues in heavy and light drinkers. Journal of Studies on Alcohol and Drugs, 54, 359-368.

Juliano, L. M., Brandon, T. H. (1998). Reactivity to instructed smoking availability and environmetal cues: evidence with urge and reaction time. Experimental and Clinical Psychopharmacology, 6, 45-53.

Kamarajan, C., Porjesz, B., Jones, K. A., Choi, K., Chorlian, D. B., Padmanabhapillai, A., Rangaswamy, M., Stimus, A. T., Begleiter, H. (2005). Alcoholism is a disinhibitory disorder: neurophysiological evidence from a Go/No-Go task. Biological Psychology, 69,353-373.

Kozlowski, L. T., Pillitteri, J. L., Sweeney, C. T., Whitfield, K. E., Graham, J. W. (1996). Asking questions about urges or craving for cigarettes. Psychology of Addictive Behaviors, 10, 248-260. 
Litt, M. D., Cooney, N. L., Morse, P. (2000). Reactivity to alcohol-related stimuli in the laboratory and in the field: predictors of craving in treated alcoholics. Addiction, 95, 889-900.

Logan, G. D., Schachar, R. J., Tannock, R. (1997). Impulsivity and inhibitory control. Psychological Science, 8, 60-64.

MacKillop, J., \& Lisman, S. A. (2005). Examining the effects of perceived availability on craving for alcohol: a quasi-experimental approach. Addiction Research and Theory, 15, 231-245.

MacKillop, J., \& Lisman, S. A. (2007). Reactivity to alcohol cues: isolating the role of perceived availability. Experimental and Clinical Psychopharmacology ,13, 229-237.

Nederkoorn, C., Baltus, M., Guerrieri, R., \& Wiers, R. W. (2009). Heavy drinking is associated with deficient response inhibition in women but not in men. Pharmacology Biochemistry and Behavior, 93, 331-336.

Papachristou, H., Nederkoorn, C., Havermans, R., van der Horst, M., \& Jansen, A. (2012). Can't stop the craving: The effect of impulsivity on cue-elicited craving for alcohol in heavy and light social drinkers. Psychopharmacology, 219, 511-518.

Patterson, C. M., \& Newman, J. P. (1993). Reflectivity and learning from aversive events: Toward a psychological mechanism for the syndromes of disinhibition. Psychological Review, 100, 716-736.

Reynolds, B., Ortengren, A., Richards, J. B., \& de Wit, H. (2006). Dimensions of impulsive behaviour: Personality and behavioural measures. Personality and Individual Differences, 40, 305-315.

Rohsenow, D. J., Niaura, R. S. (1999). Reflections on the state of cue-reactivity theories and research. Addiction, 94, 341-351.

Rubio, G., Jimenez, M., Rodriguez-Jimenez, R., Martınez, I., Avila, C., Ferre, F., Jimenez-Arriero, M. A., Ponce, G., Palomo, T. (2008). The Role of Behavioral impulsivity in the development of alcohol dependence: A 4-Year follow-up study. Alcoholism: Clinical and Experimental Research, 32, 1681-1687.

Saunders, J. B., Aasland, O. G., Babor, T. F., De La Fuente, J. R., Grant, M. (1993). Development of the Alcohol Use Disorders Identification Test (AUDIT): WHO collaborative project on early detection of persons with harmful alcohol consumption-II. Addiction, 791-804.

Siegel, S. (2001). Pavlovian conditioning and drug overdose: when tolerance fails. Addiction Research and Theory, 9, 503-513.

Sobell, L. C., \& Sobell, M. B. (1990). Self-reports across addictive behaviours: Issues and future directions in clinical and research settings. Behavioral Assessement, 12, 77-90.

Stewart, J., de Wit, H., Eikelboom, R. (1984). Role of unconditioned and conditioned drug effects in the self-administration of opiates and stimulants. Psychological Review, 91, 251-268.

Tiffany, S. T. (1990). A cognitive model of drug urges and drug use behavior: role of automatic and nonautomatic processes. Psychological Review, 97, 147-168.

Wertz, J. M., Sayette, M. A. (2001). A review of the effects of perceived drug use opportunity on selfreport urge. Experimental and Clinical Psychopharmacology, 9, 3-13.

Wikler, A. (1948). Recent progress in research on the neurophysiologic basis of morphine addiction. American Journal of Psychiatry, 105, 329-338. 


\section{CHAPTER 4}

\section{Dissection of appetitive conditioning: Does impulsivity play a role? ${ }^{5}$}

${ }^{5}$ Papachristou, H., Nederkoorn, C., Beunen, S., \& Jansen, A. (2013). Dissection of appetitive conditioning: Does impulsivity play a role? Appetite, 69, 46-53. 


\section{Abstract}

Rationale. It is generally assumed that cue-reactivity results from appetitive pavlovian learning. This is the reason for applying cue exposure with response prevention interventions in the treatment of substance and eating disorders. However, not all appetitive conditioned responses are equally sensitive to extinction. Additionally, impulsivity traits appear to moderate cue-reactivity. Nevertheless, there has been little research on the role of impulsivity traits in the learning of different appetitive response systems.

Objectives. The purpose of the present study was i) to replicate Van Gucht et al.'s (2010) findings, in particular, the acquisition and the differential extinction of appetitive learned responses and ii) to investigate the role of impulsivity traits in appetitive learning.

Methods. Participants $(\mathrm{n}=50)$ took part in a single laboratory session. Impulsivity traits (reward sensitivity, response inhibition, sensation seeking) were measured at the beginning of the session. A paradigm similar to Van Gucht et al.'s (2010) was used for the acquisition and extinction of subjective conditioned responses for milk chocolate (craving, expectancy, and liking).

Results. The acquisition of appetitive responses was successful. Unlike craving and liking, the extinction of expectancy was fully successful. Impulsivity traits played no role in the acquisition and extinction of appetitive conditioning.

Conclusions. The results support the differential sensitivity of different appetitive response systems to extinction. The lack of findings for the role of impulsivity traits in appetitive learning shows that the question of how impulsivity affects appetitive behaviour still remains open. Theoretical and methodological issues and clinical implications of the findings are discussed.

Keywords: Pavlovian appetitive learning - Cue reactivity - Craving - Expectancy • Liking · Impulsivity $\cdot$ Response Inhibition · Sensitivity to Reward · Sensation Seeking 


\section{Introduction}

Cue reactivity is a well-researched phenomenon in substance abuse and eating disorders (Drummond, 2001; Jansen, 1998). When addicts, binge eaters or overweight participants are faced with drug-related cues, they often exhibit changes in physiology and increases in self-reported craving (Carter \& Tiffany, 1999; Ferriday \& Brunstrom, 2009; Jansen, 1998). It has been argued that learning mechanisms are involved in cue reactivity. According to this view, arbitrary cues repeatedly paired with the reinforcing and rewarding effects of drugs/food become conditioned stimuli (CS+) and elicit conditioned responses (CR: e.g., craving) as a result of pavlovian learning (Drummond, 2001; Jansen, 1998). Most important, there is empirical evidence that cue reactivity motivates drug- and food-seeking behaviour, precipitates relapse in abstinent substance users, and may be involved in the maintenance of an overweight body (Birch et al., 1989; Cornell et al., 1989; Drummond, 2001; Tetley et al., 2009).

Assuming that cue reactivity is a learned response, learning procedures such as acquisition and extinction could be applied to it (Bouton, 2007). In classical conditioning, an extinction procedure refers to the presentation of the CS+ in the absence of the unconditioned stimulus (US), which diminishes or abolishes the CR (Bouton, 2007). This is the main principle behind the use of the cue exposure with response prevention interventions in many treatment programs for addiction and eating disorders (Conklin \& Tiffany 2002; Jansen, 1998; Toro et al., 2003). The goal is to expose the patient to drug/food-related cues and elicit a robust conditioned response (e.g., a strong craving response), while drug/food-taking is prevented. This procedure should extinguish the learned responses (e.g., craving) to these cues (Conklin \& Tiffany 2002; Jansen, 1998). However, the effectiveness of this intervention in treatment is not always successful (Conklin \& Tiffany, 2002).

Among many reasons for its reduced effectiveness (Conklin \& Tiffany, 2002), one could be that there are considerable individual differences in cue reactivity. Personality factors may explain some of the variability in cue-elicited responses (Papachristou, Nederkoorn, Corstjens, \& Jansen, 2012; Papachristou, Nederkoorn, Havermans, van der Horst, \& Jansen, 2012). For example, it has been found that different impulsivity traits moderate cue-elicited craving and physiological cue reactivity in heavy and dependent alcohol drinkers and tobacco smokers (Doran, McChargue, \& Spring, 2008; Doran, Spring, \& McChargue, 2007; Franken, 2002; Kambouropoulos \& Staiger, 2001; Papachristou, Nederkoorn, Havermans, Bongers, Beunen, \& Jansen, 2013; Papachristou, Nederkoorn, Havermans, et al., 2012). In general, impulsive participants react more to cues. These findings might explain partly why highly impulsive people are found to be more prone to addiction and overconsumption of food (Dawe \& Loxton, 2004; Verdejo-Garcia, Lawrence, \& Clark, 2008). In addition, these findings imply that cue exposure with response prevention may be more beneficial for impulsive individuals who may run a higher 
risk of relapse due to their stronger cue reactivity. Finally, their strong cue-elicited responses may have more difficulty to extinguish compared to the weaker cueelicited responses of individuals low in impulsivity. Thus, extinction might prove more difficult but also more beneficial for people high in impulsivity.

Another issue is that not all conditioned responses show the same sensitivity to extinction. Evidence suggests that expectations of the reward are more sensitive to extinction compared to more hedonic responses. For example, Van Gucht, Baeyens, Vansteenwegen, Hermans, and Beckers (2010) and Van Gucht, Vansteenwegen, Beckers, and Van den Bergh (2008) have shown that although acquired expectancy for chocolate in response to a CS+ was extinguished successfully, acquired craving and liking responses were not. This differential sensitivity to extinction may indicate that different psychobiological mechanisms underlie these responses and it may also explain some of the failures of the cue exposure with response prevention interventions in addiction treatment (Van Gucht et al., 2010; Van Gucht et al., 2008).

However, there is scarcity of research regarding the involvement of impulsivity traits in the hedonic and expectancy aspects of conditioned responses. This is unfortunate because the results of this line of research could have serious implications for understanding and treating addiction and eating disorders. Assuming that cue reactivity has a learned component, impulsivity traits may influence cue reactivity by being directly involved in the learning processes, e.g., in the acquisition and extinction processes. In this case, people who are more impulsive would acquire and/or extinguish pavlovian responses differently than less impulsive people.

Traditionally, the association between pavlovian conditioning and personality has been viewed within the framework of Eysenck's and Gray's theories (Corr, Pickering, \& Gray, 1995). In Eysenck's arousal theory, it is assumed that there is a single conditionability factor hence there is no discrimination between appetitive and aversive conditioning (Corr et al., 1995). It is assumed that under conditions of moderate arousal, highly aroused people such as introverts would be more easily conditioned than people low in arousal such as extraverts, in both appetitive and aversive conditioning tasks (Zinbarg \& Mohlman, 1998). Unlike Eysenck's arousal theory, in Gray's theory, there are two distinct neuropsychological systems for appetitive and aversive conditions respectively. The Behavioral Activation System (BAS) is activated by reward signals and elicits approach behaviour. Impulsivity is associated with sensitivity of this system (Matthews \& Gilliland, 1999). On the other hand, responses to aversive stimuli are mediated by the Behavioral Inhibition System, which inhibits approach behaviour (Corr et al., 1995). Trait anxiety is associated with sensitivity of the BIS (Matthews \& Gilliland, 1999). Within Gray's theory, introverts are people high in BIS and low in BAS and extraverts are impulsive people who are low in BIS and high in BAS (Corr et al., 1995; Matthews \& Gilliland, 1999). However, the role of BAS/BIS systems in conditioning can be viewed from both a motivational and an associative point of view and different predictions can be derived from each perspective (Zinbarg \& Mohlman, 1998). From a motivational perspective, the BAS/BIS systems are not involved in the acquisition of pavlovian 
conditioning. In this view, these systems are activated by already established appetitive and aversive conditioned stimuli and their role is merely to moderate the motivational properties of these stimuli (Corr, 2001). On the other hand, an associative interpretation of the theory views cognitive mechanisms essential components of the BAS/BIS systems (Zinbarg \& Mohlman, 1998). Assuming that separate cognitive mechanisms are necessary for the development of appetitive and aversive associations, it can be predicted that the strength and number of aversive and appetitive cognitive resources that constitute these mechanisms are positively associated with BIS and BAS activity, respectively (Zinbarg \& Mohlman, 1998). In other words, it is expected that a higher BAS activity will be associated with a higher speed of acquisition in appetitive associative learning, and a higher BIS activity will be associated with a faster acquisition in aversive associative learning (Zinbarg \& Mohlman, 1998). Consistent with the associative perspective, Gray's theory, like Eysenck's theory, regards introverts as better conditioned than extraverts in aversive conditioning tasks (Corr, 2004; Corr et al., 1995). However, the two theories have different predictions for the conditionability of extraverts/introverts in appetitive conditions. In contrast to Eysenck's theory, Gray's theory predicts that regardless of arousal levels, extraverts would be more sensitive to appetitive conditioning than introverts (Corr, 2004; Corr et al., 1995).

Assuming that Gray's theory is right, the rationale for the effect of impulsivity on the acquisition phase of appetitive pavlovian learning is that following the appearance of the CS+, the presence of the appetitive US (food, drug) stimulates the impulsivity system (e.g., BAS) and as a result causes arousal and emotional changes that strengthen the CS-US bond in the working memory (Corr, 2001). Alternatively, impulsivity traits could only be involved in the motivational properties of the conditioned stimuli (CS) after pavlovian learning has been established (Corr, 2001; Matthews \& Gilliland, 1999; Zinbarg \& Mohlman, 1998). Finally, most evidence for the involvement of impulsivity traits in cue reactivity comes from studies which assess responding to stimuli that have already been conditioned in the natural environment (Doran et al., 2008; Doran et al., 2007; Papachristou et al., 2013; Papachristou, Nederkoorn, Havermans, et al., 2012; Robbins \& Ehrman, 1992). However, reactivity to naturalistic cues may also consist of unlearned components (Robbins \& Ehrman, 1992). For example, substance users and patients with eating disorders may respond more intensely to any salient/arousing stimuli than control participants and not only to substance- or food-related cues (Robbins \& Ehrman, 1992). In turn, this unlearned arousal could be misinterpreted as craving under the demand effects of their participation in a cue-reactivity study (Robbins \& Ehrman, 1992). It could be that some impulsivity traits are sensitive to these unlearned components of cue reactivity. However, it is important to emphasize that this is only a speculation and that non-specific arousal may not be a key element in all impulsivity systems. For example, unlike Eysenck's model, in Gray's model arousal in general is not a key element of sensitivity to reward (Matthews \& Gilliland, 1999). Despite these limitations, our point is that in order to know if impulsivity indeed moderates pav- 
lovian learning, there is a need to create conditioned stimuli (CS+, CS-) in the laboratory and to test this hypothesis in individuals without extensive histories with the US.

In order to gain a deeper insight into the mechanisms underlying cue reactivity, we used a pavlovian conditioning procedure similar to Van Gucht et al.'s (2010) study. The first aim of the present study was to replicate Van Gucht et al.'s (2010) findings, concerned with the acquisition and especially the differential extinction of learned subjective responses (craving, expectancy and liking). In particular, it is expected that relative to the CS-, craving for chocolate in response to the CS+ and liking for the CS+ will remain unaffected after extinction, while expectancy for chocolate in the presence of the CS+ will be extinguished.

The second aim of the present study was to investigate whether impulsivity affects the acquisition and the extinction processes in appetitive learning. However, impulsivity is a multidimensional construct measured with a variety of behavioural and self-report instruments (Dawe \& Loxton, 2004; Dom, Wilde, Hulstijn, \& Sabbe, 2007; Verdejo-Garcia et al., 2008). It also appears that there is a weak association between self-report and behavioural measures of impulsivity (Dom et al., 2007). For example, Dom et al. (2007) reported that the Sensation Seeking Scale (SSS) is not correlated with the Go/No-Go task, a behavioral measure of response inhibition, in abstinent alcohol-dependent people. The weak association between these two types of impulsivity measurement indicates that each type may assess different aspects of the construct (Dom et al., 2007). In the same vein, Dawe and Loxton (2004) report that in factor analytic studies, self-report measures of sensitivity to reward based on Gray's model load on a different factor from self-report impulsivity measures based on Zuckerman's, Cloninger's, and Eysenck's personality models. As a single measure of impulsivity cannot capture the whole spectrum of impulsive behaviour, we use multiple impulsivity measures in the present study, both behavioural and self-report, in order to explore the role of impulsivity in appetitive learning. We have chosen three impulsivity measures because each of them taps different aspects of the construct: a behavioural measure of response inhibition (stop signal task), a self-report measure of sensitivity to reward (Behavioural Activation System scale), and a short version of the SSS. Furthermore, all three measures have been implicated in substance use and misuse as well as in normal and disordered eating behaviour (.Dawe \& Loxton, 2004; Guerrieri, Nederkoorn, \& Jansen, 2008; Jansen, Klaver, Merckelbach, \& Van den Hout, 1989; Verdejo-Garcia et al., 2008). Finally, there is evidence that two of these measures, a weaker response inhibition and a stronger sensitivity to reward, are associated with a higher reactivity to alcohol cues in social heavy and dependent alcohol drinkers (Kambouropoulos \& Staiger, 2001; Papachristou et al., 2013; Papachristou et al., 2012). Since cue reactivity is considered to be a result of pavlovian learning, it is interesting to see if these specific impulsivity measures moderate the intensity of cue reactivity via an effect on pavlovian learning or via different mechanisms. 
For each of the three measures of impulsivity in the present study (sensitivity to reward, sensation seeking, response inhibition), it was hypothesized that in the acquisition phase, more vs. less impulsive people would acquire a faster and stronger craving and expectancy response for chocolate to the CS+ and a stronger liking for the $\mathrm{CS}+$, relative to the CS-. Additionally, during the extinction phase, it was hypothesized that there would be a differential extinction of these acquired subjective responses between more and less impulsive participants. More specifically, it was expected that highly impulsive participants would not extinguish their subjective CRs, while less impulsive participants would extinguish them successfully.

\section{Methods}

\section{Participants}

Fifty (39 women and 11 men) participants with a mean age of 22.58 years, (SD = 4.77) volunteered to participate in the study. All participants were recruited via advertisements in the university premises. Only participants who were able and willing to consume milk chocolate in the laboratory were allowed to take part in the study. They were rewarded for their participation in the experiment with either course credits or a gift certificate of $10 €$.

\section{Materials}

Similar to Van Gucht et al.'s (2010) study, two serving trays were used as conditional stimuli in the present experiment. The two trays differed from each other in terms of shape and colour. One tray was brown and rectangular and the other one was white and round. One of them was used as the CS+ and the other one as the CSwith the order of assignment counterbalanced across participants. At baseline, participants liked equally the two trays, t (49) $=-1.081$, ns. The unconditional stimulus (US) was milk chocolate (Bonbiance Napolitains melk). Each piece of chocolate weighed 4 grams.

\section{Measures}

Sensitivity to reward (STR): STR was measured with the BAS subscale from the BIS/BAS scale (Carver \& White, 1994; Franken, 2005). The BIS/BAS scale is a 24item self-report instrument, which assesses the sensitivity of the Behavioural Inhibition System (BIS: 7 items) and the Behavioural Approach System (BAS: 13 items) (Carver \& White, 1994). Additionally, the BAS scale is subdivided into 3 subscales: Fun Seeking (4 items), Reward Responsiveness (5 items), and Drive (4 items). In 
the present study, the Dutch version of the BIS/BAS was used (Franken, 2005). The BAS had a good internal consistency, with a Cronbach alpha coefficient of .79.

\section{Response inhibition}

The Stop Signal Task (SST) was used to assess response inhibition or the (in) ability to stop a prepotent response (Logan, Schachar, \& Tannock, 1997). The task consists of two types of trials: go trials and stop trials. Each go trial begins with a fixation cross in the centre of the screen. The fixation cross vanishes after 500ms and then a geometrical (square) pattern is displayed either on the left or the right part of the screen. Participants are asked to respond to the pattern as fast as they can by pressing either the left or right "shift" button, respectively. However, in $25 \%$ of the go trials, after the go-signal a $1000 \mathrm{~Hz}$ sound is emitted through headphones (stop signal) signifying to the participants that they have to hold back their response. Initially, the acoustic stop signal is emitted at $250 \mathrm{~ms}$ after the go signal presentation but during the task the stop signal delay varies according to participant's performance. These adjustments allow participants to successfully withhold their responses at approximately $50 \%$ of the stop trials. The dependent variable in the task is the stop signal reaction time (SSRT). A higher SSRT is taken as an index of impaired response inhibition because it indicates that more time is required for an individual to inhibit a prepotent response.

The short Sensation Seeking Scale (sSSS; Madsen, Das, Bogen, \& Grosman, 1987) The scale contains ten forced-choice items. The participant has to choose the one that best suits his/her preference. High sensation-seeking items are scored as 1 and low sensation-seeking items are scored as 0 . The total score ranges from 0 (minimum sensation seeking) to 10 (maximum sensation seeking). This scale has been shown to be a valid and reliable measure of the sensation seeking construct (Jansen et al., 1989; Madsen et al., 1987).

\section{Craving, US-expectancy and liking}

Craving, US-expectancy and liking were measured with the same $10-\mathrm{cm}$ visual analogue scales (VASs) used in Van Gucht et al.'s (2010) study. Regarding craving, participants were asked: "When presented with this tray, how strong is your craving for chocolate right now?". The VAS for craving ranged from "no craving at all" to "extremely strong craving". As regards US-expectation, the VAS scale was accompanied by the following question: "How strongly do you now expect to be invited to eat chocolate?" ranging from "certainly not" to "certainly". Finally, concerning liking, participants were asked: "To what extent do you find the white (brown) tray pleasant/unpleasant?" ranging from "very unpleasant" to "very pleasant". 


\section{Procedure}

The experiment consisted of one laboratory session lasting approximately 1 hour and arranged between $12.30 \mathrm{pm}$ and $19.00 \mathrm{pm}$. Ethical approval was obtained from the Ethical Committee of the Psychology Faculty of Maastricht University. Initially, participants had to read and sign the informed consent form and then fill out a brief demographic questionnaire. Following this, they were presented with the two personality questionnaires (the BAS/BIS and the SSS) and the SST in a counterbalanced order. Then, the craving and US-expectancy VASs were shown to them and the meaning of these concepts was clarified by the experimenter. After that, participants were given instructions similar to those in Van Gucht et al.'s (2010) (cited in p. 690) study: "Here you see two different serving trays. I will present you with those trays in a randomized order, determined beforehand on the basis of coin tosses. One tray will sometimes be followed by me asking you to eat something, the other tray not". Finally, just before the acquisition phase (baseline), participants were presented with the two trays and asked to rate their liking for each tray.

Then, the acquisition phase started. It consisted of eight trials, four (A1-A4) for the CS+ and the CS-, respectively. The two trays were presented in a random order as described in the instructions with the constraint that no more than two consecutive trials were the same. In each trial, the experimenter put the tray on participant's view for $10 \mathrm{sec}$ and asked them to concentrate on it and on their feelings and thoughts at the time of presentation (Van Gucht et al., 2010). Then, participants were required to rate their craving and expectancy for chocolate on the VASs. The VASs for craving and expectancy were administered in counterbalanced order across participants. In a CS+ trial, participants were always offered a piece of chocolate and were instructed to eat it. Following this, the tray was always placed in a shopping bag out of participant's view. In a CS- trial, no chocolate was offered and the tray was placed in the shopping bag immediately after the VASs completion. The intertrial interval was $10 \mathrm{sec}$. At the end of the acquisition phase, participants were required to fill out the liking VAS.

The extinction phase followed the acquisition phase. It consisted of 16 trials, eight (E1-E8) for the CS+ and the CS-, respectively, presented in a random order as in the acquisition phase. Extinction trials were identical to the acquisition trials except for the fact that no chocolate (and chocolate eating) was paired with the CS+. At the end of the extinction phase, participants were once more instructed to rate their liking for each tray on a VAS. After the extinction phase, participants were debriefed, thanked, and rewarded for their participation in the experiment.

\section{Statistical analysis}

The SSRTs, sSSS and BAS scores were centered and entered as covariates in the analysis. There was no significant correlation between the three impulsivity measures. Inspection of the histograms, box-plots, and tests of normality showed 
that there were no outliers and that each of three impulsivity measures was normally distributed. In order to confirm the differential acquisition of the learned responses between CS+ and CS-, a two-way 2 (Cue type: CS+ vs. CS-) by 4 (Trial: Trial A1 vs. Trial A2 vs. Trial A3 vs. Trial A4) repeated-measures ANCOVA was performed on craving and expectancy ratings, respectively. Regarding liking, a similar two-way 2 (Cue type: CS+ vs. CS-) by 2 (Phase: baseline vs. end of acquisition phase) repeated measures ANCOVA was performed. In addition, interactions with the covariates were also tested. When further analysis was required, a median split was conducted on an impulsivity measure in order to classify participants as being either high or low on this trait. Finally, to demonstrate the generalization of learning from the acquisition to the extinction phase, a 2 (Cue type: CS+ vs. CS-) by 2 (Trial: A4 vs. E1) repeated measures ANCOVA was conducted on expectancy and craving responses.

To investigate the differential extinction of the learned responses between CS+ and CS-, a 2 (Cue-type: CS+ vs. CS-) by 8 (Trial: E1 vs. E2 vs. E3 vs. E4 vs. E5 vs. E6 vs. E7 vs. E8) repeated measures ANCOVA was performed on expectancy and craving ratings, respectively. A similar 2 (Cue type: CS+ vs. CS-) by 2 (Phase: end of acquisition vs. end of extinction) repeated measures ANCOVA was performed on liking. Interactions with the covariates were also tested. When further analysis was required, a median split was performed on an impulsivity measure.

\section{Results}

Table 1 Mean, minimum, and maximum scores and standard errors on the SST, BAS, and sSSS

\begin{tabular}{lcccc}
\hline Measures of Impulsivity & Mean & SE & Minimum & Maximum \\
\hline Stop Signal Task (SSRT) & 236.81 & 5.36 & 158.16 & 314.14 \\
Behavioural Activation System (BAS) scale & 40.32 & 0.66 & 28 & 50 \\
Short Sensation Seeking Scale (sSSS) & 5.74 & 0.29 & 1 & 9 \\
\hline
\end{tabular}

Note. $n=50$ 
Table 2 Mean scores, standard errors, number of participants, t-tests, degrees of freedom, and p values for high and low scores (median split) in each impulsivity measure

\begin{tabular}{llllllll}
\hline & Mean & & SE & t-test & df & p value \\
\cline { 2 - 6 } & $\begin{array}{l}\text { High in } \\
\text { Impulsivity }\end{array}$ & $\begin{array}{l}\text { Low in } \\
\text { Impulsivity }\end{array}$ & $\begin{array}{l}\text { High in } \\
\text { Impulsivity }\end{array}$ & $\begin{array}{l}\text { Low in } \\
\text { Impulsivity }\end{array}$ & & & \\
\hline SSRT & 267.25 & 206.36 & 24.13 & 20.35 & -9.65 & 48 & P $<.001$ \\
& $\mathrm{~N}=25$ & $\mathrm{~N}=25$ & & & & & \\
BAS & 44.17 & 36.77 & 0.48 & 0.63 & -9.24 & 48 & $\mathrm{P}<.001$ \\
& $\mathrm{~N}=24$ & $\mathrm{~N}=26$ & & & & & \\
SSSS & 7.67 & 4.34 & 0.14 & 0.28 & -10.5 & 40.59 & $\mathrm{P}<.001$ \\
& $\mathrm{~N}=21$ & $\mathrm{~N}=29$ & & & & & \\
\hline
\end{tabular}

\section{Self-reported Expectancy rating}

\section{Acquisition}

The two-way interaction CS type (CS+ vs. CS-) by Trial (A1 vs. A2 vs. A3 vs. A4) on expectancy rating was significant, $F(2.61,119.86)=12.3, \mathrm{p}<.001$ (Fig. 1). Regarding the CS+, there was a statistically significant increase in expectancy during the acquisition phase, $\mathrm{F}(1,46)=35.05, \mathrm{p}<.001$. With regard to the CS-, there was a statistically significant decrease in expectancy during this phase, $F(1,46)=7.7, \mathrm{p}=$ .008. At the end of the acquisition phase (Trial A4), CS+ elicited significantly higher expectancy for chocolate than CS-, F $(1,46)=70.97, \mathrm{p}<.001$. Impulsivity traits did not affect the acquisition of the strength of the expectancy response. None of the three-way interactions on expectancy rating was statistically significant (BAS: F $(2.61,119.86)=0.48, \mathrm{~ns} ;$ SSS: $\mathrm{F}(2.61,119.86)=0.67$, ns; $\operatorname{SSRT}: \mathrm{F}(2.61,119.86)=$ $0.79, \mathrm{~ns})$.

\section{Transition from acquisition to extinction}

The two-way interaction CS type (CS+ vs. CS-) by Trial (A4 vs. E1) on expectancy was not significant, $F(1,46)=2.05$, ns. The main effect of Trial was also not significant, $\mathrm{F}(1,46)=0.55$, ns. The main effect of CS type was significant, $\mathrm{F}(1,46)=64.1$, $\mathrm{p}<.001$. In general, the CS+ elicited more expectancy for chocolate than the CS-. The results show that the acquired expectancy response was maintained from the end of the acquisition phase to the beginning of the extinction phase (Fig. 1).

\section{Extinction}

The extinction of the expectancy response was successful. The two-way interaction CS type (CS+ vs. CS-) by Trial (E1 vs. E2 vs. E3 vs. E4 vs. E5 vs. E6 vs. E7 vs. E8) on expectancy was highly significant, $F(4.16,191.36)=10.26, p<.001$ (Fig. 1). At the end of extinction (Trial E8), there was no significant difference in expectancy ratings between CS+ and CS-, F $(1,46)=0.74$, ns. Impulsivity traits did not play a role 
in the extinction of the expectancy response. None of the three-way interactions on expectancy rating was statistically significant $(B A S: F(4.16,191.36)=0.59$, ns; SSS: $\mathrm{F}(4.16,191.36)=0.48, \mathrm{~ns}$; SSRT: $\mathrm{F}(4.16,191.36)=2.03$, ns $)$. However, there was a significant two-way interaction CS type by BAS on expectancy, $F(1,46)=4.86, p=$ .032. Further analysis showed that there was no difference in the expectancy response to the CS+ between high and low sensitive to reward participants, F $(1,46)$ $=0.73$, ns. However, there was a marginally significant difference in the expectancy response to the CS- between high and low sensitive to reward participants, $F(1,46)$ $=3.83, \mathrm{p}=.056$. High BAS participants responded more strongly to the CS- than low BAS participants.

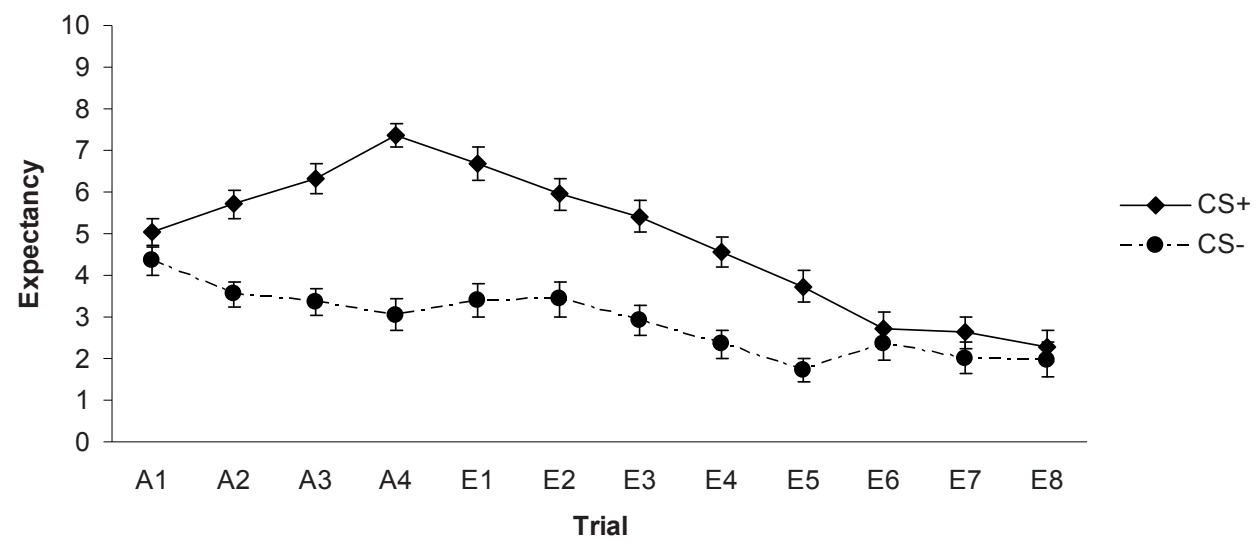

Fig. 1 Mean expectancy (for chocolate) scores and S.E.M. in response to the CS+ and CS- across the acquisition and the extinction phases

\section{Self-reported Craving rating}

\section{Acquisition}

There was a significant two-way interaction CS type (CS+ vs. CS-) by Trial (A1 vs. A2 vs. A3 vs. A4) on craving for chocolate, $F(2.17,99.92)=6.28, p=.002$ (Fig. 2). Further analysis indicated that craving in response to the CS+ increased significantly during the acquisition phase, A1 vs. A4: $\mathrm{F}(1,46)=6.79, \mathrm{p}=.012$. In contrast, CSdid not change significantly during this phase, A1 vs. A4: $F(1,46)=3.47, p=.069$. At the end of the acquisition phase (Trial A4), CS+ elicited higher craving than CS-, F $(1,46)=16.65, \mathrm{p}<.001$. Furthermore, impulsivity traits did not affect the acquisition of craving. None of the three-way interactions on craving rating was statistically significant $(B A S: F(2.17,99.92)=0.21$, ns; SSS: $F(2.17,99.92)=1.02$, ns; SSRT: $F$ $(2.17,99.92)=0.08, \mathrm{~ns})$. 
Transition from acquisition to extinction

The analysis showed that the two-way interaction CS type (CS+ vs. CS-) by Trial (A4 vs. E1) on craving was not significant, $\mathrm{F}(1,46)=.35$, ns. Additionally, there was a non-significant main effect of Trial (A4 vs. E1) on craving, F $(1,46)=1.05$, ns. Finally, there was a significant main effect of CS type (CS+ vs. CS-) on craving, F $(1,46)=$ $22.69, \mathrm{p}<.001$. Overall, the CS+ elicited higher craving than the CS-. These findings illustrate that the learned craving response did generalize to the first extinction trial (E1) (Fig. 2).

\section{Extinction}

The extinction of the learned craving response was not successful. The two-way interaction CS type (CS+ vs. CS-) by Trial (E1 vs. E2 vs. E3 vs. E4 vs. E5 vs. E6 vs. E7 vs. E8) on craving was not significant showing that the extinction phase did not reduce the acquired differentiation in craving between the CS+ and the CS-, F (2.83, 130.37) $=0.54$, ns (Fig. 2). At the end of extinction (Trial E8), there was a significant difference in craving ratings between the CS+ and the CS-, F $(1,46)=23.11, \mathrm{p}<$ .001 . Impulsivity traits did not play a role in the extinction of the craving response. None of the three-way interactions on craving was statistically significant (BAS: F $(2.83,130.37)=0.59$, ns; SSS: F $(2.83,130.37)=1.26$, ns; SSRT: F $(2.83,130.37)=$ 0.5 , ns). Nevertheless, there was a main effect of BAS on craving during this phase, $\mathrm{F}$ $(1,46)=6.1, p=.017$. In general, during extinction, participants with higher BAS scores experience higher overall craving $(\mathrm{M}=5.23, \mathrm{SE}=0.44)$ than participants with lower BAS scores $(\mathrm{M}=3.90, \mathrm{SE}=0.42)$.

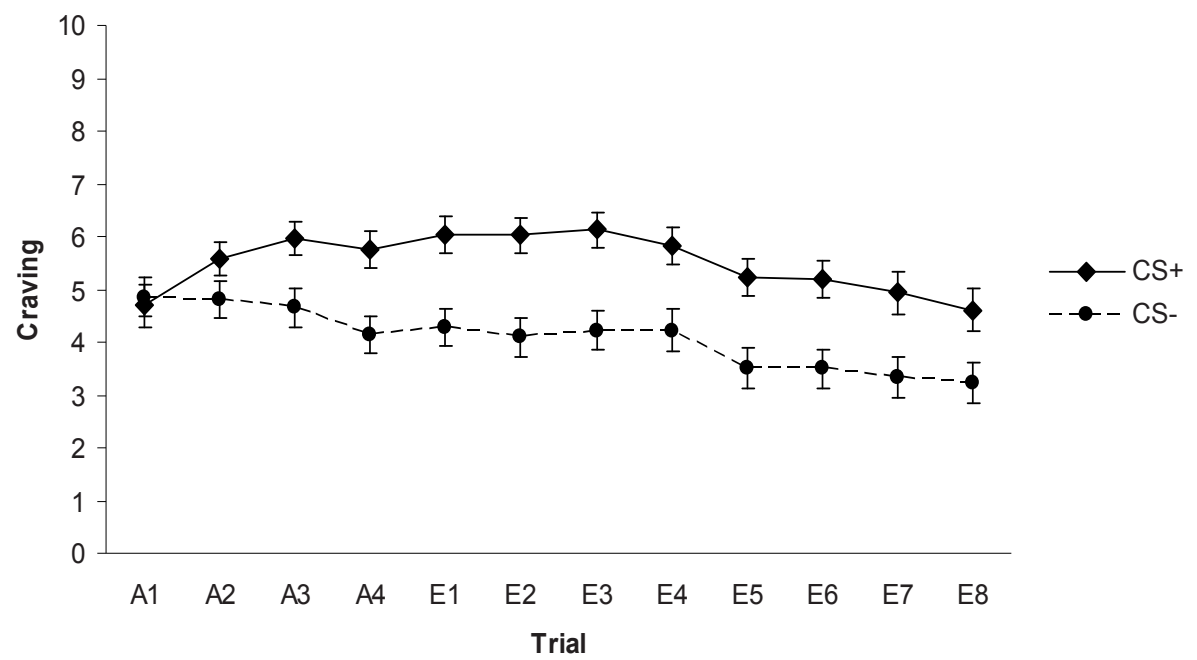

Fig. 2 Mean craving (for chocolate) scores and S.E.M. in response to the CS+ and CS- across the acquisition and the extinction phases 


\section{Self-reported Liking rating}

\section{Acquisition}

There was a significant two-way interaction CS type (CS+ vs. CS-) x Phase (Baseline vs. end of acquisition phase) on liking, $F(1,46)=36.43$, $p<.001$ (Fig. 3). Further analysis indicated that there was a slight but significant increase in liking rating for the CS+ from baseline to the end of acquisition, $F(1,46)=6.04, p=.018$. In addition, there was a significant decrease in liking rating for the CS- from baseline to the end of acquisition phase, $F(1,46)=51.35$, $p<.001$. At the end of the acquisition phase, participants liked the CS+ significantly more than the CS-, F $(1,46)=28.44$, p $<.001$. Finally, there was no significant effect of any impulsivity measure on the acquisition of the liking response (Sensation Seeking: $F(1,46)=0.17$, ns; BAS: F (1, 46) $=1.09$, ns; SSRT: F $(1,46)=0.00$, ns. $)$.

\section{Extinction}

Extinction of the liking response was not fully successful in the present experiment. Although the two-way interaction CS type (CS+ vs. CS-) by Phase (end of acquisition vs. end of extinction) on liking was significant, $F(1,46)=5.83, p=.020$, participants still liked more the CS+ than the CS- at the end of the extinction phase, F (1, $46)=13.7, p<.001$, (Fig. 3). The liking rating for the CS+ significantly decreased during extinction, $\mathrm{F}(1,46)=16.37, \mathrm{p}<.001$. On the other hand, there was no statistically significant decrease in the liking rating for the CS- during this phase, $\mathrm{F}(1,46)$ $=2.35$, ns. Finally, there was a significant two-way interaction BAS by Phase on liking rating, $\mathrm{F}(1,46)=4.26, \mathrm{p}=.045$. Additional analysis demonstrated that both high and low BAS scorers experience a decrease in liking, regardless of CS type (High BAS: $F(1,21)=12.15, p=.002$; Low BAS: $F(1,23)=5.22, p=.028)$. However, it appears that the decrease in liking is larger in high BAS scorers (end of acquisition phase: $\mathrm{M}=5.43, \mathrm{SE}=0.22$; End of extinction phase: $\mathrm{M}=4.31, \mathrm{SE}=0.33$ ) than in low BAS scorers (End of acquisition phase: $\mathrm{M}=5.58, \mathrm{SE}=0.21$; End of extinction phase: $\mathrm{M}=5.16, \mathrm{SE}=0.22$ ). 


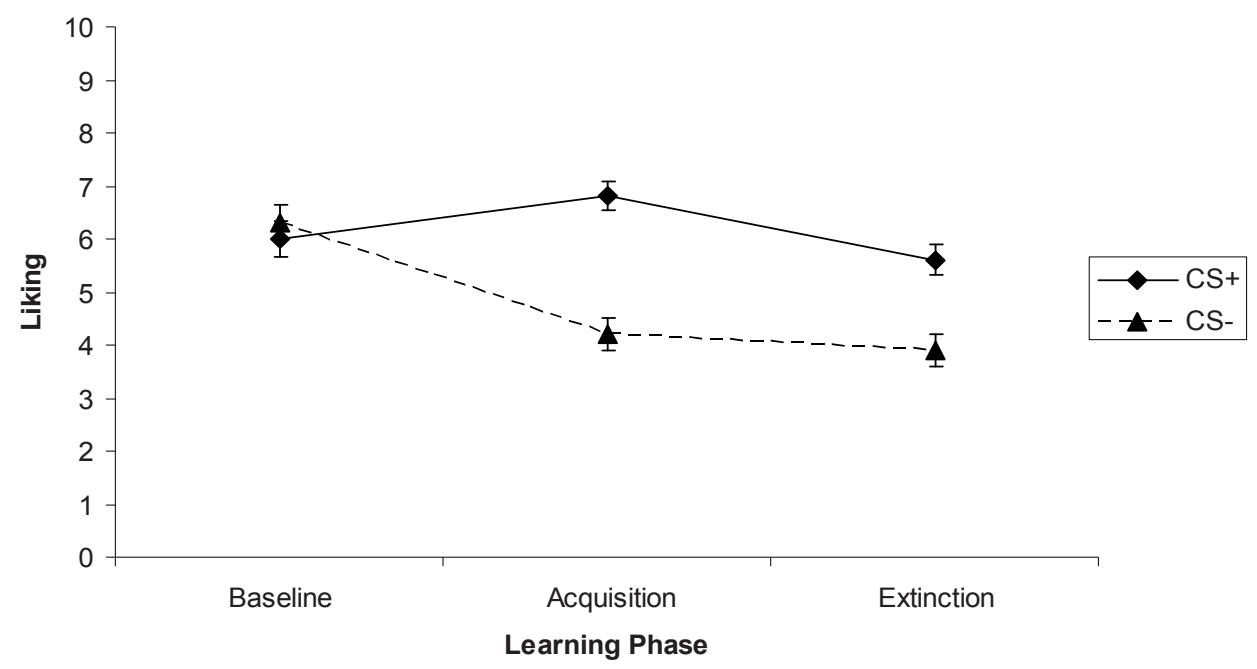

Fig. 3 Mean liking scores and S.E.M. for the CS+ and CS- across the acquisition and the extinction phases

\section{Discussion}

The purpose of the present study was i) to replicate Van Gucht et al.'s (2010) findings, concerned with the acquisition and the differential extinction of appetitive learned subjective responses (craving, expectancy and liking) and ii) to investigate the role of impulsivity traits in appetitive learning. Our findings give support to the first aim of the present study but we find no supportive evidence for the role of impulsivity traits in appetitive learning.

First of all, the differential conditioning paradigm used in the present study led to a successful acquisition of the three appetitive conditioned responses. At the end of the acquisition phase, participants showed increased craving and expectancy for chocolate in response to the CS+ and more liking for the CS+, relative to the CS-. These findings are similar to Van Gucht et al.'s (2010) and Van Gucht et al.'s (2008) findings and support the validity of the conditioning paradigm. Additionally, the present results suggest a role for conditioning in appetitive cue reactivity and are in line with the results of earlier conditioning studies in the field of substance abuse (Field \& Duka, 2001; Lazev, Herzog, \& Brandon, 1999). However, as in previous studies, our findings do not exclude other sources of cue reactivity that may not be related to associative learning (Lazev et al., 1999; Robbins \& Ehrman, 1992).

The present study also supports the differential extinction of the subjective appetitive responses. Unlike expectancy for chocolate, the acquired difference in craving was not extinguished successfully and the acquired difference in liking was only partially extinguished. At the end of the extinction phase, participants still liked the CS+ more than the CS- and craved chocolate more in response to the CS+ relative to the CS-. In general, our results provide support to Van Gucht et al.'s 
(2010) findings and illustrate a de-synchrony of these appetitive conditioned responses during extinction but not during acquisition. This desynchrony does not imply that cue-elicited craving cannot be extinguished successfully in therapy or after including more extinction trials or sessions in the procedure. Evidence from both clinical and laboratory studies suggest that cue-elicited craving can be successfully extinguished under certain conditions (Boutelle, Zucker, Peterson, Rydell, Cafri, \& Harnack, 2011; Conklin \& Tiffany, 2002; Jansen, 1998; Van Gucht et al., 2008). The present findings highlight a differential sensitivity of these appetitive responses to extinction, resulting perhaps from the different nature of these response systems. The difficulty in the extinction of cue-elicited craving resembles the difficulty in extinguishing evaluative conditioned responses that is often reported in the literature, though in the present study the acquired difference in liking was partially extinguished (De Houwer, Thomas, \& Baeyens, 2001; Van Gucht et al., 2010). On the other hand, conditioned expectancies for reward may reflect a system that prepares an individual to process a salient stimulus independent of its evaluative value (Van Gucht et al., 2008). Yet, this differential sensitivity may have important clinical implications showing that even after successful extinction of reward expectancies, cue-elicited craving and liking for the conditioned stimulus could still remain perhaps posing a potential threat for relapse (Van Gucht et al., 2010; Van Gucht et al., 2008).

In the present study, we find no supportive evidence for the role of impulsivity traits in the acquisition and extinction processes of appetitive conditioning. Our results are in agreement with the findings of another study conducted in our laboratory, which showed that trait impulsiveness is not related with the acquisition of a learned craving response for an appetitive food (milkshake) but only with overeating (Van den Akker, Jansen, Frentz, \& Havermans, 2012). It is possible that other learning mechanisms are influenced by impulsivity. Perhaps impulsive people show stronger habit learning, meaning that the CS+ has more influence on behavior, albeit not on craving. However, the role of stimulus strength may be of importance in the present study (Matthews \& Gilliand, 1999). For example, in an early conditioning study by Paisey and Mangan (1988), it was found that extraversion was negatively related to the acquisition of the electrodermal CR to weak sexual stimuli and positively related to the acquisition of the same CR to strong sexual stimuli. In the present study, the appetitive US was milk chocolate that might have been a weak arousing stimulus for the participants. It could be that a more novel or arousing US (e.g., a novel food, a substance of abuse, or even a personally relevant US such as participants' favourite brand of chocolate) may have resulted in a different outcome. This is an empirical question, however, that can be answered with further research.

Alternatively, impulsivity may be involved in the expression of the motivational properties of the conditioned stimuli (CS) after pavlovian learning has been established (Corr, 2001; Matthews \& Gilliland, 1999; Pickering \& Gray, 1999; Zinbarg \& Mohlman, 1998). This assumption fits well with the findings of cue reactivity stud- 
ies in the field of substance abuse where the substance-related cues are considered to be well-established conditioned stimuli as a result of their association with the effects of the substance prior to the experiment (Doran et al., 2008; Doran et al., 2007; Franken, 2002; Kambouropoulos \& Staiger, 2001; Papachristou et al., 2013; Papachristou, Nederkoorn, Havermans, et al., 2012). A more thorough way to test empirically this assumption would be to examine the effects of impulsivity traits on the ability of a well-established CS+ to motivate behaviour in conditioned reinforcement and pavlovian-to-instrumental paradigms (Bouton, 2007; Corr, 2001).

Finally, the effect of impulsivity on cue-reactivity may be related to unlearned components of cue reactivity. According to Robbins and Ehrman (1992), substance users may feel aroused when faced with substance-related cues because they simply find them to be disturbing. Alternatively, substance users or patients with eating disorders may in general react more strongly to any salient and arousing stimuli than control participants, independent of their conditioning history (Robbins \& Ehrman, 1992). In turn, this general arousal could be misinterpreted as craving under the demand effects of their participation in a cue-reactivity study (Robbins \& Ehrman, 1992). It could be that the increased cue-elicited craving in impulsive participants (Doran et al., 2008; Doran et al., 2007; Franken, 2002; Kambouropoulos \& Staiger, 2001; Papachristou et al., 2013; Papachristou, Nederkoorn, Havermans, et al., 2012) reflects sensitivity of some impulsivity measures to these unlearned components of cue reactivity. This means that the impulsive participants might not form stronger associations between the CS+ and the US but are more easily aroused by salient cues hence, their response is more intense. For heavy and dependent substance users, however, the presence of their substance of choice in the lab could be particularly arousing, while chocolate could be a less salient and therefore arousing stimulus for the participants of the present study.

Our analysis indicated that independent of cue type or trial, participants who were more sensitive to reward (BAS) experience stronger craving for chocolate during the extinction phase. Additionally, their liking response in general was reduced faster than the liking response of participants who were less sensitive to reward. Obviously, reward sensitive participants did not respond to the specific CS+ of the experiment but to something else. Speculating on the nature of these responses, one explanation could be that simply being informed about the nature of the experiment and expecting chocolate in the lab acted as a CS+ that activated the BAS system (Corr, 2001). The contrast between these expectations and the fact of not receiving chocolate any more during the extinction phase may have caused greater disappointment to more vs. less sensitive to reward participants, which resulted in a faster decline in their liking response and more craving.

There are several limitations in our study. For example, the cue reactivity components in the present study are subjective hence vulnerable to demand characteristics. On the other hand, our study was a replication of Van Gucht et al.'s (2010) study and the fact that we and Van Gucht et al. (2010) report similar results gives support to the findings of both studies. However, even if we assume that demand 
characteristics played a role in both studies, we would still have to explain why different appetitive conditioned responses showed a clearly different extinction pattern in both studies. Nevertheless, we believe that future research should address these questions by including both subjective and psychophysiological cue reactivity measures in the experimental design in order to minimize the influence of demand characteristics on participants' behaviour. Finally, we did not control for the effects of individual differences such as participants' BMI and of motivational states such as hunger on appetitive conditioning. For example, different BMIs could mean different histories with the US (chocolate) and as a result different cue reactivity to chocolate.

Despite the limitations, the findings of the present study offer deeper insight to the mechanisms involved in appetitive conditioning. The dissection of the appetitive response systems and their differential sensitivity to extinction appears to be a relatively robust finding that may stimulate further research in the field of appetitive learning and may enable us to understand some of the theoretical and clinical problems in the field of substance and eating disorders. Additionally, the findings that impulsivity traits are not involved in appetitive learning mechanisms are important. More research is needed to sort out how impulsivity traits influence consumptive behaviour: via different learning mechanisms or via routes unrelated to learning. Deeper understanding of the topic might prove useful for the development of more effective treatment of substance and eating disorders.

\section{References}

Birch, L. L., McPhee, L., Sulivan, S., \& Johnson, S. (1989). Conditioned meal initiation in young children. Appetite, 13, 105-113.

Boutelle, K. N., Zucker, N. L., Peterson, C. B., Rydell, S. A., Cafri, G., Harnack, L. (2011). Two novel treatments to reduce overeating in overweight children: A randomized controlled trial. Journal of consulting and clinical psychology, 79 (6), 759-771.

Bouton, M. E. (2007). Learning and Behavior: A contemporary synthesis. Sunderland, Massachusetts: Sinauer Associates, Inc.

Carter, B. L., \& Tiffany, S. T. (1999). Meta-analysis of cue-reactivity in addiction research. Addiction, 94(3), 327-340.

Carver, C. S., \& White, T. L. (1994). Behavioral inhibition, behavioral activation, and affective responses to impending reward and punishment: the BIS/BAS scales. Journal of Personality and Social Psychology, 67, 319-333.

Conklin, C. A., \& Tiffany, S. T. (2002). Applying extinction research and theory to cue-exposure addiction treatments. Addiction, 97, 155-167.

Cornell, C. E., Rodin, J., \& Weingarten, H. (1989). Stimulus-induced eating when satiated. Physiology \& Behavior, 45, 695-704.

Corr, P. J. (2001). Testing problems in J. A. Gray's personality theory: a commentary on Matthews and Gilliland (1999). Personality and Individual Differences, 30, 333-352.

Corr, P. J. (2004). Reinforcement sensitivity theory and personality. Neuroscience and Biobehavioral Reviews, 28, 317-332.

Corr, P. J., Pickering, A. D., \& Gray, J. A. (1995). Personality and reinforcement in associative and instrumental learning. Personality and Individual Differences, 19, 47-71. 
Dawe, S., \& Loxton, N. J. (2004). The role of impulsivity in the development of substance use and eating disorders. Neuroscience and Biobehavioral Reviews, 28, 343-351.

De Houwer, J., Thomas, S., \& Baeyens, F. (2001). Associative learning of likes and dislikes: A review of 25 years of research on human evaluative conditioning. Psychological Bulletin, 127, 853-869.

Dom, G., De Wilde, B., Hulstijn, W., \& Sabbe, B. (2007). Dimensions of impulsive behaviour in abstinent alcoholics. Personality and Individual Differences, 42, 465-476.

Doran, N., McChargue, D., \& Spring, B. (2008). Effect of impulsivity on cardiovascular and subjective reactivity to smoking cues. Addictive Behaviors, 33, 167-172.

Doran, N., Spring, B., \& McChargue, D. (2007). Effects of impulsivity on craving and behavioural reactivity to smoking cues. Psychopharmacology, 194, 279-288.

Drummond, D. C. (2001). Conceptualizing Addiction: Theories of drug craving, ancient and modern. Addiction, 96, 33-46.

Ferriday, D., \& Brunstrom, J. M. (2011). "I just can't help myself”: effects of food-cue exposure in overweight and lean individuals. International Journal of Obesity, 35, 142-149.

Field, M., \& Duka, T. (2001). Smoking expectancy mediates the conditioned responses to arbitrary smoking cues. Behavioural Pharmacology, 12, 183-194.

Franken, I. H. A. (2002). Behavioural approach system (BAS) predicts alcohol craving. Personality and Individual Differences, 32, 349-355.

Franken, I. H. A., Muris, P., \& Rassin, E. (2005). Psychometric properties of the Dutch BIS/BAS scales. Journal of Psychopathology and Behavioral Assessment, 27, 25-30.

Guerrieri, R., Nederkoorn, C., \& Jansen, A. (2008). The effect of an impulsive personality on overeating and obesity: Current state of affairs. Psychological Topics, 17, 265-286.

Jansen, A. (1998). A learning model of binge eating: Cue reactivity and cue exposure. Behaviour Research and Therapy, 36, 257-272.

Jansen, A., Klaver, J., Merckelbach, H., \& Van den Hout, M. (1989). Restrained eaters are rapidly habituating sensation seekers. Behaviour Research and Therapy, 27, 247-252.

Kambouropoulos, N., \& Staiger, P. K., (2001). The influence of sensitivity to reward on reactivity to alcohol-related cues. Addiction, 96, 1175-1185.

Lazev, A. B., Herzog, T. A., \& Brandon, T. H. (1999). Classical conditioning of environmental cues to cigarette smoking. Experimental and Clinical Psychopharmacology, 7, 56-63.

Logan, G. D., Schachar, R. J., \& Tannock, R. (1997). Impulsivity and inhibitory control. Psychological Science, 8(1), 60-64.

Madsen, D. B., Das, A. K., Bogen, I., \& Grosman, E. E. (1987). A short Sensation Seeking Scale. Psychological Reports, 60, 1179-1184.

Matthews, G., \& Gilliland, K. (1999). The personality theories of H. J. Eysenck and J. A. Gray: a comparative review. Personality and Individual Differences, 26, 583-626.

Paisey, T. J. H., \& Mangan, G. L. (1988). Personality and conditioning with appetitive and aversive stimuli. Personality and Individual Differences, 9, 69-78.

Papachristou, H., Nederkoorn, C., Corstjens, J., \& Jansen, A. (2012).The role of impulsivity and perceived availability on cue-elicited craving for alcohol in social drinkers. Psychopharmacology, 224, 145-153.

Papachristou, H., Nederkoorn, C., Havermans, R., Bongers, P., Beunen, S., \& Jansen, A. (2013). Higher levels of trait impulsiveness and a less effective response inhibition are linked to more intense cueelicited craving for alcohol in alcohol-dependent patients. Psychopharmacology. Advance online publication. doi: 10.1007/s00213-013-3063-3.

Papachristou, H., Nederkoorn, C., Havermans, R., van der Horst, M., \& Jansen, A. (2012). Can't stop the craving: The effect of impulsivity on cue-elicited craving for alcohol in heavy and light social drinkers. Psychopharmacology, 219, 511-518.

Pickering, A. D. \& Gray, J. A. (1999). The neuroscience of personality. In L. A. Pervin \& O. P. John (Eds.), Handbook of personality: Theory and research (pp. 277-299). New York: Guilford Press.

Robbins, S. J., \& Ehrman, R. N. (1992). Designing studies of drug conditioning in humans. Psychopharmacology, 106, 143-153.

Tetley, A., Brunstrom, J., Griffiths, P. (2009). Individual differences in food-cue reactivity. The role of BMI and everyday portion-size selections. Appetite, 52, 614-620. 
Toro, J., Cervera, M., Feliu, M. H., Garriga, N., Jou, M., Martinez, E., \& Toro, E. (2003). Cue exposure in the treatment of resistant bulimia nervosa. International Journal of Eating Disorders, 34, 227-234.

Van den Akker, K., Jansen, A., Frentz, F., \& Havermans, R. (2012). Impulsivity makes more susceptible to overeating after contextual appetitive conditioning. Manuscript submitted for publication.

Van Gucht, D., Baeyens, F., Vansteenwegen, D., Hermans, D., and Beckers, T. (2010). Counterconditioning reduces cue-induced craving and actual cue-elicited consumption. Emotion, 10, 688-695.

Van Gucht, D., Vansteenwegen, D., Beckers, T., Van den Bergh, O. (2008). Return of experimentally induced chocolate craving after extinction in a different context: Divergence between craving for and expecting to eat chocolate. Behaviour Research and Therapy, 46, 375-391.

Verdejo-Garcia, A., Lawrence, A. J., Clark, L. (2008). Impulsivity as a vulnerability marker for substanceuse disorders: Review of findings from high-risk research, problem gamblers and genetic association studies. Neuroscience and Behavioral Reviews, 32, 777-810.

Zinbarg, R. R., \& Mohlman, J. (1998). Individual differences in acquisition of affectively valenced associations. Journal of Personality and Social Psychology, 74, 1024-1040. 


\section{CHAPTER 5}

\section{Higher levels of trait impulsiveness and a less effective response inhibition are linked to more intense cue-elicited craving for alcohol in alcohol-dependent patients ${ }^{6}$}

${ }^{6}$ Papachristou, H., Nederkoorn, C., Havermans, R., Bongers, P., Beunen, S., \& Jansen, A. (2013). Higher levels of trait impulsiveness and a less effective response inhibition are linked to more intense cueelicited craving for alcohol in alcohol-dependent patients. Psychopharmacology, 228, 641-649. 


\section{Abstract}

Rationale. Cue-elicited craving is a well-researched phenomenon in alcohol literature. However, not all alcohol-dependent people display the same reactivity to alcohol cues. Personality factors such as multiple impulsivity traits may be responsible for individual differences in cue reactivity by modulating its intensity. Nevertheless, there has been a scarcity of empirical studies testing this assumption in alcohol literature.

Objectives. The aim of the present study was to investigate the effects of response inhibition and trait impulsiveness on cue-elicited craving for alcohol in alcohol-dependent drinkers.

Methods. Participants ( $\mathrm{n}=41)$ were inpatients of the private clinic U-Center, Netherlands. Alcohol exposure took place in a real bar-restaurant close to the premises of the clinic and participants were exposed to real alcohol cues. Response inhibition was assessed with the Stop Signal Task (SST) and trait impulsiveness with the Barratt Impulsivity Scale version 11 (BIS-11).

Results. The cue exposure was successful as alcohol-dependent patients experienced higher craving for alcohol when exposed to alcohol rather than to neutral cues. Additionally, both response inhibition and trait impulsiveness predicted cueelicited craving for alcohol. Trait impulsiveness predicted both the absolute craving in the bar-restaurant and the increase in cue-elicited craving during the whole alcohol cue exposure, while response inhibition predicted only the former.

Conclusions. The results clearly implicate both trait impulsiveness and response inhibition in the modulation of cue-elicited craving in alcohol dependence. Theoretical and methodological issues in the findings and their clinical implications in alcohol treatment and relapse are discussed.

Keywords: Alcohol dependence - Cue reactivity - Craving - Alcohol cue exposure · Impulsivity $\cdot$ Response Inhibition $\cdot$ Trait impulsiveness 


\section{Introduction}

In alcohol literature, cue reactivity refers to the finding that when heavy drinkers and alcohol-dependent individuals are exposed to alcohol-related cues, their craving for alcohol increases and their physiology (e.g., salivation, skin conductance response, heart rate) changes (Carter \& Tiffany, 1999; Drummond, 2000). Nevertheless, although cue reactivity is a well-researched phenomenon, there is still controversy about the factors involved in it. After all, not every alcohol-dependent individual shows the same reactivity to alcohol cues, which implies that there are other factors that moderate its intensity. Impulsivity is a possible candidate here (Papachristou, Nederkoorn, Havermans, van der Horst, \& Jansen, 2012).

In general, impulsivity is defined as the tendency to respond fast to environmental and internal stimuli without planning or consideration of the consequences of one's behaviour (Dawe \& Loxton, 2004). However, it appears that impulsivity is a multidimensional construct that consists of heterogeneous traits that reflect distinct aetiologies and psychobiological mechanisms and are assessed via different instruments and methods (Dawe \& Loxton, 2004; de Wit, 2008; Whiteside \& Lynam, 2001, 2003).

Typically, impulsivity is measured via self-report questionnaires and behavioural tasks (Verdejo-Garcia, Lawrence, \& Clark, 2008). There is evidence that these two types of measurement correlate weakly with each other and explain unique variance in problem drinking (Christiansen, Cole, Goudie, \& Field, 2012). These findings give further support to the notion that impulsivity is an umbrella construct consisting of unrelated concepts (Dick, Smith, Olausson, Mitchell, Leeman, O'Malley, \& Sher, 2010; Enticott, Ogloff, \& Bradshaw, 2006). It also seems that impulsivity is conceptualized differently in each type of measure. In self-report measures, it is regarded as a dispositional characteristic and scores represent relatively stable individual differences in perceiving and reacting to the world (de Wit, 2008; Dick et al., 2010; Verdejo-Garcia et al., 2008). On the other hand, behavioural measures assess specific cognitive processes and are more sensitive to moment-to-moment fluctuations in impulsivity levels within an individual (Christiansen et al., 2012; Verdejo-Garcia et al., 2008). Although self-report measures appear to have a better ecological validity than behavioural measures, the former are more easily influenced by social desirability bias than the latter (Enticott et al., 2006; Verdejo-Garcia et al., 2008).

Both types of measurement have been used to assess impulsivity in alcoholdependent and heavy drinkers (Christiansen et al., 2012; Verdejo-Garcia et al., 2008). Regarding self-report measures, the Barratt Impulsivity Scale version 11 is commonly used in alcohol studies as a measure of trait impulsiveness (BIS-11; Christiansen et al. 2012; Patton, Stanford, \& Barratt, 1995). For example, Von Diemen, Bassani, Fuchs, Szobot, and Pechansky (2008) have found that trait impulsiveness is strongly associated with alcohol and substance use disorders. Addition- 
ally, Dom, Hulstijn, and Sabbe (2006) reported that early-onset alcohol-dependent patients have higher BIS-11 scores than late-onset patients.

Regarding behavioural measures, behavioural inhibition tasks are frequently used in alcohol and substance abuse studies (de Wit., 2008). These tasks assess response inhibition or the ability to stop a well-learned motor response upon the appearance of new information. The stopping (in)ability can be assessed either before the initiation of the response (action restraint measured with the go/no-go task) or after the initiation of the response (action cancellation measured with the Stop Signal Task) (Eagle, Bari, \& Robbins, 2008). Nigg, Wong, Martel, Jester, Puttler, Glass, Adams, Fitzgerald, and Zucker (2006) reported that impaired response inhibition, measured with the Stop Signal Task (SST), predicts alcohol-related problems in adolescents with a vulnerability to alcohol and substance abuse disorders. In the same vein, Nederkoorn, Baltus, Guerrieri, and Wiers (2009) have demonstrated that heavy drinking is associated with less effective response inhibition (SST) in women but not in men. Finally, Rubio, Jimenez, Rodrigo-Jimenez, Martinez, Avila, and Ferre (2008) have shown that both trait impulsiveness and response inhibition (SST) are predictors of alcohol dependence in heavy drinkers in a 4-year follow-up study.

Cue elicited craving is a central characteristic of any substance dependence and the relationship between impulsivity traits and substance dependence might reflect individual differences in experienced levels of such cue reactivity. The association of either trait impulsiveness or response inhibition with cue-elicited craving for alcohol or other drugs is not well-researched in the literature, but there are two studies that show a relationship between trait impulsiveness and subjective and physiological cue reactivity in nicotine-dependent smokers (Doran, McChargue, \& Spring, 2008; Doran, Spring, \& McChargue, 2007). Further, there is one study with social drinkers that examined the role of both impulsivity dimensions on cueelicited craving for alcohol (Papachristou, Nederkoorn, Havermans, et al., 2012). It was found that response inhibition but not trait impulsiveness is associated with higher cue-elicited craving for alcohol in heavy social drinkers. However, there is no study on the effects of either trait impulsiveness or response inhibition on cueelicited craving for alcohol in alcohol-dependent people. The scarcity of research on this topic is surprising given the view that cue-elicited craving is an index of approach behaviour towards alcohol and drugs of abuse (Anton, 1999; Carter \& Tiffany, 1999). Consequently, a less effective response inhibition or higher trait impulsiveness could weaken the inhibition of approach behaviour to such cues and contribute to relapse (Dawe, Gullo, \& Loxton, 2004; Doran et al., 2007). Clearly, there is a need for more studies in the field that could shed light on this complex relationship.

The aim of the present study was to examine whether response inhibition and trait impulsiveness have an effect on cue-elicited craving for alcohol in alcoholdependent people. The participants of the present study were inpatients of the private clinic U-Center, Netherlands. Alcohol exposure took place in a real bar- 
restaurant nearby the private clinic hence participants were exposed to real alcohol cues in a real alcohol-related setting. It was hypothesized that i) alcohol-dependent people experience higher craving for alcohol when exposed to alcohol than to water cues, ii) a higher trait impulsiveness score is associated with higher cue-elicited craving for alcohol in alcohol-dependent people, and iii) a less effective response inhibition is associated with higher cue-elicited craving for alcohol in alcoholdependent people.

\section{Methods}

\section{Participants}

Forty-one patients (22 men and 19 women; Mean age $=51.15, \mathrm{SD}=10.9)$ undergoing a six-week inpatient alcohol treatment program at the private clinic, U-Center, Netherlands, were recruited for the present study. All patients had been diagnosed by the staff psychiatrists with a DSM-IV diagnosis of alcohol dependence. Thirtyone patients $(75.61 \%)$ had a multiple diagnosis (another Axis-I disorder or a combination of Axis-I and Axis-II disorders) and ten patients (24.39\%) had been diagnosed only with alcohol dependence. None of the patients had been diagnosed with either antisocial or borderline personality disorder or with attention deficit hyperactivity disorder. Four patients $(9.76 \%)$ had a second diagnosis of cannabis dependence, two patients (4.88\%) of cocaine dependence, and twenty-two patients (53.66\%) smoked more than 15 cigarettes per day.

Inclusion criterion was a diagnosis of alcohol dependence. Exclusion criteria were a history of psychosis or bipolar disorder, organic serious brain impairment, and any prescribed psychoactive medication that could interfere with craving and psychomotor performance. Participants were benzodiazepine-free at the time of testing. All participants were tested after detoxification and within the first three weeks of their treatment in the U-Center.

\section{Measures}

\section{Trait Impulsiveness}

The Dutch version of the Barratt Impulsiveness Scale version 11 (BIS-11; Patton, Stanford, \& Barratt, 1995) was used to assess trait impulsiveness. It consists of 30 items and is divided into three factors: motor (acting without thinking), attentional (not focusing on the task at hand and cognitive instability), and non-planning impulsiveness (lack of self-control and difficulty orientating to the future).

Participants had to report on a 4-point scale the extent to which a series of statements applies to them from "Rarely/Never" to "Always/Almost Always". Scores vary from 30 (low trait impulsiveness) to 120 (high trait impulsiveness). 
Previous research with clinical and non-clinical populations has demonstrated the reliability of the questionnaire with Cronbach's alpha coefficient ranging from .79 to .83 (Patton et al., 1995). In the current study, the Cronbach's alpha coefficient was .78.

\section{Response Inhibition}

The Stop-Signal Task (SST) was used to assess response inhibition (Logan, Schachar, \& Tannock, 1997). It consists of two parallel trials, a go and a stop paradigm. The task begins with a $500 \mathrm{~ms}$ fixation point in the centre of a computer screen. Next, a go trial follows. In each go trial a picture of a square pattern is displayed either on the left or the right of the centre of the screen for $1500 \mathrm{~ms}$. Participants are instructed to respond as fast as possible by pressing the right "shift" button with the right hand when the square pattern is depicted on the right part of the screen and the left "shift" button with the left hand when the square pattern is portrayed on the left part of the screen. Between trials, the screen becomes blank for $1000 \mathrm{~ms}$. However, in $25 \%$ of the go trials, an auditory stop signal is emitted through headphones after the go-signal, signaling that the participants must inhibit their response. The stop signal is a $1000 \mathrm{~Hz}$ tone lasting $100 \mathrm{~ms}$. In the beginning, the auditory stop signal occurs $250 \mathrm{~ms}$ after the go signal (stop signal delay = $250 \mathrm{~ms}$ ) but throughout the task the duration of the interval changes depending on the participant's performance. After a failure to successfully inhibit the response, the next stop signal is presented $50 \mathrm{~ms}$ earlier thus, making the task easier. Conversely, when the participant inhibits the response successfully, the next stopsignal is heard $50 \mathrm{~ms}$ later, thereby making the task more difficult. These adjustments allow participants to effectively withhold their responses roughly at $50 \%$ of the stop trials. The average percentage of correct responses in the present task was $46 \%(n=32)$.

In the present task, there are 3 practice blocks, consisting of 6,12 and 24 trials, respectively. The practice blocks are followed by 4 test blocks of 64 trials each. Between blocks, participants are permitted to have a short break. There are three dependent variables in the task: mean Go reaction time (RT), mean stop signal delay (SSD), and stop signal reaction time (SSRT). The SSRT is the difference between the mean Go RT and the mean SSD measured in milliseconds (ms). A higher SSRT indicates that a participant is slower to inhibit a prepotent response hence it is an indicator of impaired response inhibition.

\section{Craving}

Craving was assessed with two 100-mm visual analogue scales (VAS) ranging from 0 (not at all) to 100 (very much). Participants were asked to indicate (a) their desire to consume alcohol: "How much do you feel like drinking alcohol right now?", (b) their urge to drink alcohol: "How strong is your urge to drink alcohol right now?". In general, it has been shown that VASs are valid and reliable indicators of craving for alcohol (Kozlowski, Pillitteri, Sweeney, Whitfield, \& Graham, 1996). In 
the current study, the Cronbach's alpha and the correlation coefficient $r$ between the two items at each level of cue exposure was acceptable: i) water baseline: Cronbach's alpha $=.65 ; \mathrm{r}=.56, \mathrm{p}<.001$, ii) water exposure: Cronbach's alpha $=.74 ; \mathrm{r}$ $=.71, \mathrm{p}<.001$, iii) alcohol baseline: Cronbach's alpha $=.81 ; \mathrm{r}=.75, \mathrm{p}<.001$, iv) alcohol exposure: Cronbach's alpha $=.87 ; \mathrm{r}=87, \mathrm{p}<.001$.

Two types of craving scores were calculated in the present study. The first type is the change in craving during the whole cue exposure procedure after adjusting for baseline levels and exposure to neutral cues. The second type is the absolute craving score during the alcohol cue-exposure in the bar-restaurant. Both measures could be important in the daily life of alcohol-dependent people because both of them could be related to relapse. However, the latter type of craving may not be necessarily cue-specific and may also include non-associative components, such as withdrawal craving (Robbins \& Erhman, 1992; Sayette, Shiffman, Tiffany, Niaura, Martin, \& Shadel, 2000). As Sayette et al. (2000) argue, both measures could be meaningful in cue reactivity studies and the distinction between them may result in different interpretations of the data. As very little research has been conducted on the relationship between impulsivity and craving in alcohol-dependent people, it was assumed that both craving scores are of interest and should be included in the present study in order to investigate in more depth the nature of this interaction.

\section{Procedure}

Ethical approval was obtained from both the Ethics Committee of the Psychology Faculty of Maastricht University and the Ethics Committee of the U-Center. All the participants had to fill in an informed consent form in which it was explained that they would be exposed to alcohol-related cues in the nearby bar-restaurant. However, while being at the U-Center, none of the participants was informed that the goal of the study was to assess the relationship between trait impulsiveness/response inhibition and cue-elicited craving for alcohol. Participants were debriefed via mail/email after having completed their treatment program at the UCenter. All testing took place in the clinic (U-Center) and in a nearby bar-restaurant between 01.30 and 06.00 p.m. Participants took part in two individual sessions planned in the same week and always on the same days (Mondays and Wednesdays).

Before the first session, the participants had been contacted by the staff of the clinic and had been informed broadly about the study. Only those participants who showed interest in the study were invited to the first session. During the first session, the informed consent form was first administered to the patients. In the form, they were told that the study investigates reactions to alcohol cues and that they would be exposed to alcohol-related cues in a real bar-restaurant. Only after the patient agreed and signed the consent form, they were allowed to participate in the study. After signing the form, participants were presented with a brief demographic 
questionnaire and then performed the Stop Signal Task and filled out the BIS-11. The order of the task and the BIS-11 was counterbalanced between participants.

Having finished with the tasks/questionnaires, participants were exposed to water cues in the clinic. They were offered a glass filled with tap water and the experimenter instructed them to focus on the water, imagine how it tastes, pick up and hold the glass, and sniff the water in the glass. She also invited the patient to imagine a situation in which drinking water would be pleasant. During the exposure, the patients had to bring the glass close to their nose and mouth, close their eyes, and imagine that they take a sip and that the water is all over their mouth and throat. The experimenter herself modeled the instructions thus ensuring that the patient knew exactly what to do and did not feel overly self-conscious during the exposure. From time to time, the experimenter had a small chat with the patient about the type of water they drink (e.g., carbonated water), and in general about the issue of drinking water. The patient was free to express their thoughts and feelings about the topic. At other times, the patients were left alone in their thoughts while holding the glass of water and after being instructed to concentrate on its transparent texture/colour. These instructions were repeated every five minutes. After the water exposure, each patient was asked to provide information about the place, time, feelings, and people surrounding a typical alcohol drinking episode. The experimenter used this information during the alcohol exposure along with exposure to real alcohol cues.

Two days after the water exposure, the alcohol exposure session took place. Once more, the experimenter reminded the patient that the exposure would occur in a nearby bar-restaurant with real alcohol cues and that the patient was free to quit the study if they felt uncomfortable. It was also stated explicitly that drinking during the alcohol exposure was not allowed and that in case that any drinking occurred, the exposure would stop immediately. Then, the experimenter took the patient to the bar-restaurant and they sat together at a table. When the patient felt ready, both the experimenter and the patient ordered their own favourite alcoholic beverage, respectively. Following this, the experimenter gave the same instructions to the patient as she had done in the water exposure and as before she modeled the instructions. After the alcohol cue exposure, the patient was led back to the clinic by the experimenter and was explicitly told to contact the staff of the clinic in case they felt dysphoria or had any other distressing symptoms.

The two sessions were not counterbalanced in order, thus water exposure was always first and alcohol exposure was always second in order. It was thought that exposure to real alcohol cues in a real alcohol-related setting would be a stressful experience for the patients and asking them to start the study with the alcohol exposure might have resulted in high stress levels.

Baseline craving ratings were taken before the water exposure and also before the alcohol exposure while the patient was still in the clinic. During each cue exposure condition, craving was measured every five minutes. If after 15 minutes of cue exposure craving levels did not increase more or had returned back to baseline 
levels, the cue exposure was stopped. If craving did increase during cue exposure, the experimenter continued the exposure till craving returned back to baseline levels, or till the maximum time of 60 minutes was reached.

\section{Statistical analysis}

Inspection of the SSRTs showed that nine participants (almost) never inhibited their responses during the performance of the Stop Signal Task. Due to their spurious performance in the task, these participants were excluded from any response inhibition analysis, though they were included in the analysis of trait impulsiveness and cue exposure. Similar to our earlier study (Papachristou, Nederkoorn, Havermans, et al., 2012), there was no statistically significant relationship between trait impulsiveness and response inhibition, $(\mathrm{r}=-.01, \mathrm{~ns}, \mathrm{n}=32)$.

Firstly, a 2-way cue type (water vs. alcohol) x time (baseline vs. exposure) repeated-measures ANCOVA was performed to assess the effects of cue exposure on craving. Age was centered and entered as a covariate in the analysis because it correlated negatively with cue-elicited craving for alcohol in the alcohol condition ( $\mathrm{r}=$ $-.50, \mathrm{p}=.001$ ). The peak intensity of alcohol craving at baselines and during each cue exposure was the dependent variable and was calculated by averaging the maximum craving scores across the two visual analogue scales for each participant. Effect sizes were reported as eta squared $\left(\eta^{2}\right)$. Greenhouse-Geisser correction was used when Mauchly's test of sphericity was significant.

Based on the peak craving scores, a difference craving score was computed for each cue exposure condition (water: exposure-baseline; alcohol: exposurebaseline). Then, an overall difference craving score was estimated by subtracting the aforementioned differences from each other (alcohol difference-water difference). The latter difference score, a measure of the increase in craving for alcohol during exposure to alcohol cues, was the criterion variable in two hierarchical linear regression models with age and trait impulsiveness ( $1^{\text {st }}$ model) and age and response inhibition $\left(2^{\text {nd }}\right.$ model) as their predictors, respectively. Further analysis with the BIS-11 subscales was also performed. Age was entered as a predictor in the models because it correlated negatively both with craving (Trait impulsiveness model: $\mathrm{r}=-.41, \mathrm{p}<.01$; Response Inhibition model: $\mathrm{r}=-.37, \mathrm{p}<.05)$ and with the overall score in trait impulsiveness $(\mathrm{r}=-.31, \mathrm{p}<.05)$ (but not with response inhibition, $r=.28, n s$ ). No correlations with gender and impulsivity or craving were significant. In addition, the same two regression models were used to predict the absolute maximum craving for alcohol during the exposure in the bar-restaurant (craving at water/alcohol baselines and during water exposure not subtracted), in order to obtain a more clinically relevant measure of peak cue-elicited craving for alcohol. 


\section{Results}

\section{The effects of cue exposure on peak cue-elicited alcohol craving}

There was a statistically significant 2-way interaction between cue type and time on peak craving, $\mathrm{F}(1,39)=28.56, \eta^{2}=.38, \mathrm{p}<.001$. Further analysis demonstrated that during the water condition there was a slight but non-significant decrease in alcohol craving from baseline to exposure, (Mean difference $=-.59, \mathrm{~F}(1,39)=0.25$, $\left.\eta^{2}=.00, \mathrm{~ns}\right)$. On the other hand, during the alcohol condition, there was a significant increase in peak craving from baseline to exposure, (Mean difference $=10.01, \mathrm{~F}(1$, $39)=26.86, \eta^{2}=.34, p<.001$ ) (Fig. 1). Additionally, there was no statistically significant main effect of cue type on peak craving, $F(1,39)=3.42, \eta^{2}=.08$, ns (Fig. 1). Finally, a statistically significant main effect of time on peak craving was found, $\mathrm{F}$ (1, $39)=14.16, \eta^{2}=.22, p<.001$. Regardless of cue type, peak craving for alcohol was higher after cue exposure $(\mathrm{M}=12.84, \mathrm{SE}=2.41)$ than at baseline $(\mathrm{M}=8.12, \mathrm{SE}=$ 1.84) (Fig. 1).

The results also showed a significant main effect of age on peak craving, F (1, $39)=10.19, \eta^{2}=.21, p<.01$, and a significant 3 -way interaction between cue type, time, and age on peak craving, $F(1,39)=7.91, \eta^{2}=.10, p<.01$. To further analyze the effect of age on the 2-way interaction, a median split (Median $=53$ years) was performed on age and the participants in the present study were divided into two age groups: "younger" and "older". The results showed that the 2-way interaction cue type $\mathrm{x}$ time on peak craving was statistically significant for both age groups (Younger: $F(1,19)=20.93, \eta^{2}=.52, p<.001$; Older: $F(1,20)=7.63, \eta^{2}=.28, p<$ .05). Further analysis indicated that the maximum intensity of cue-elicited craving for alcohol did not change significantly during the water condition (exposurebaseline) in either age group, (Younger: $F(1,19)=0.18, \eta^{2}=.01$, ns; Older: $F(1,20)$ $=2.91, \eta^{2}=.13$, ns.). During the alcohol condition, however, both groups experienced higher peak craving after cue exposure compared to baseline but the increase in peak intensity of craving in younger participants was higher than in older participants, (Younger: Mean difference $=17.16, \mathrm{SE}=3.71, \mathrm{~F}(1,19)=21.46, \eta^{2}=$ $.53, \mathrm{p}<.001$; Older: Mean difference $=3.19, \mathrm{SE}=1.34, \mathrm{~F}(1,20)=5.70, \eta^{2}=.22, \mathrm{p}<$ $.05)$.

Finally, after inspection of the data, there were 12 participants who did not experience an increase in craving during the whole cue exposure. This number corresponds to approximately $1 / 4$ of the participants in the present study and is in agreement with the results of previous studies in the literature (Litt, Cooney, \& Morse, 2000). 


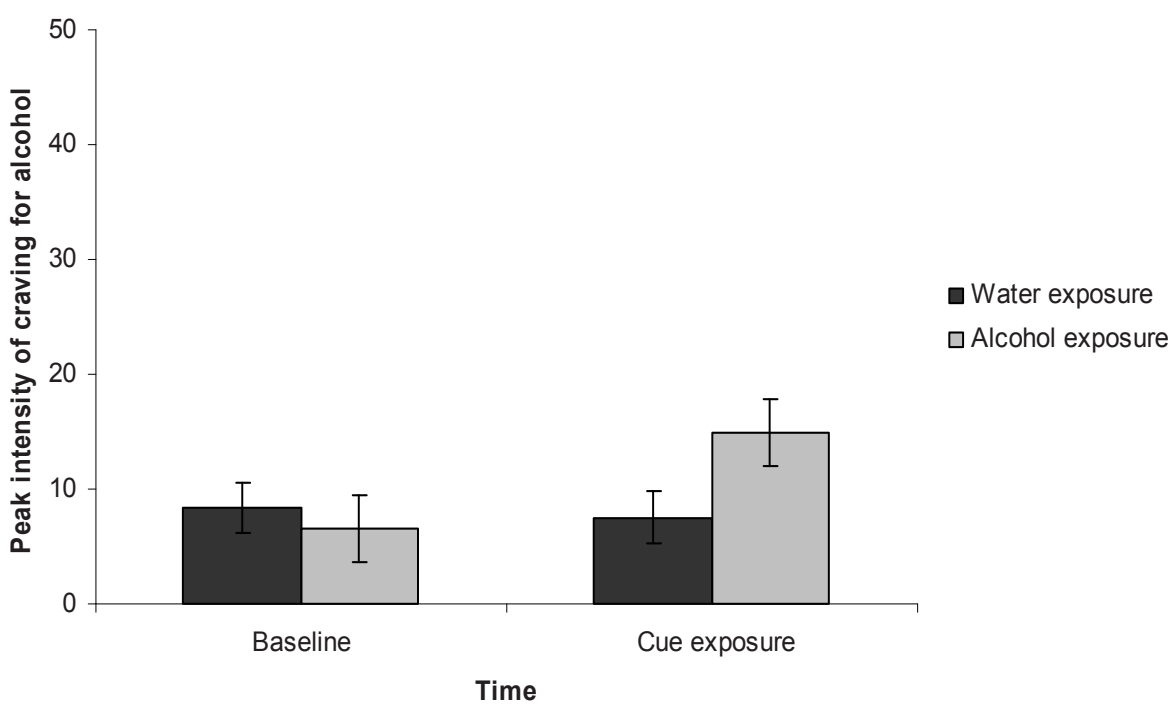

Fig. 1 Peak intensity of craving for alcohol during water and alcohol cue exposure.

\section{Trait impulsiveness and increase in craving for alcohol during alcohol cue exposure}

Hierarchical linear regression was conducted to evaluate how well trait impulsiveness predicts the increase in craving for alcohol during alcohol cue exposure, after controlling for the effects of age on craving. The increase in maximum levels of cueelicited craving for alcohol, after subtracting craving at baselines and during water exposure (see statistical analysis), was the criterion variable and trait impulsiveness and age, were the predictors. Age was entered at step 1 of the analysis, while trait impulsiveness was entered at step 2 . At step 1, age explained $17 \%$ of the variance of cue-elicited alcohol craving, $F(1,39)=7.91, p=.008$. After entry of the BIS11 at step 2, the total variance explained by the model as a whole was $26.8 \%, \mathrm{~F}$ (2, $38)=6.95, p=.003$. After controlling for age, trait impulsiveness explained approximately an additional $10 \%$ of the variance in cue-elicited craving for alcohol, $\mathrm{F}$ change $(1,38)=5.15, p=.029$ (Table 1 ). Further analysis showed that after controlling for age, the Attentional Impulsiveness and the Non-planning Impulsiveness subscales of trait impulsiveness do not predict the increase in cue-elicited craving for alcohol, (Attentional Impulsiveness: $\mathrm{F}(1,38)=1.26$, ns, $\Delta \mathrm{R}^{2}=.027$; Nonplanning Impulsiveness: $\mathrm{F}(1,38)=2.4$, ns, $\left.\Delta \mathrm{R}^{2}=.049\right)$. However, the Motor Impulsiveness subscale successfully predicts the increase in cue-elicited craving for alcohol, $\mathrm{F}(1,38)=6.14, \mathrm{p}=.018, \Delta \mathrm{R}^{2}=.12$ (Table 1$)$. The hierarchical linear regression results suggest that alcohol-dependent patients with higher levels of trait impulsiveness tend to experience a higher increase in cue-elicited craving for alcohol than alcohol-dependent patients with lower levels of trait impulsiveness. 


\section{Response inhibition and increase in craving for alcohol during alcohol cue exposure}

Hierarchical linear regression was performed to assess whether response inhibition predicts the increase in craving for alcohol during alcohol cue exposure, after controlling for the influence of age. The increase in maximum levels of cue-elicited craving for alcohol, after subtracting craving at baselines and during water exposure (see statistical analysis), was the criterion variable and SSRT and age, the predictor variables in the model. Age was entered at step1 explaining $16.1 \%$ of the variance of cue-elicited alcohol craving, $F(1,30)=5.76, p=.023$. After entry of the SSRT at step 2, the model was not significant any more, F $(2,29)=2.89$, ns (Table 1). Based on these results, response inhibition levels appear to have little predictive power over the increase in cue-elicited craving for alcohol in alcohol-dependent patients.

\section{Trait impulsiveness and absolute craving for alcohol during alcohol cue exposure}

Hierarchical linear regression was performed to examine whether trait impulsiveness predicts craving during the alcohol cue exposure, after controlling for the effects of age. The maximum absolute craving score during exposure to alcohol cues (exposure that took place in the bar-restaurant) was the criterion variable and trait impulsiveness and age, were the predictors. Age was entered at step 1 of the analysis, while trait impulsiveness was entered at step 2. At step 1, age accounted for $25.4 \%$ of the variance of cue-elicited alcohol craving, $F(1,39)=13.30, p=.001$. After entry of the BIS-11 scores at step 2, the total variance explained by the model as a whole was $42.4 \%, \mathrm{~F}(2,38)=13.96, \mathrm{p}<.001$. After controlling for age, trait impulsiveness explained approximately an additional $16.9 \%$ of the variance in peak craving for alcohol during exposure to alcohol cues, $\mathrm{F}$ change $(1,38)=11.16, \mathrm{p}=$ .002 (Table 1). Further analysis indicated that both the Attentional and Motor Impulsiveness subscales but not the Non-planning Impulsiveness subscale predict absolute craving, (Attentional Impulsiveness: $\mathrm{F}(1,38)=6.88, \mathrm{p}=.012, \Delta \mathrm{R}^{2}=.11$; Motor Impulsiveness: $F(1,38)=9.05, p=.005, \Delta R^{2}=.14$; Non-planning Impulsiveness: $\mathrm{F}(1,38)=3.21$, ns, $\Delta \mathrm{R}^{2}=.06$ ) (Table 1). These findings indicate that alcoholdependent patients with higher levels of trait impulsiveness tend to experience a higher peak craving when exposed to alcohol cues than alcohol-dependent patients with lower levels of trait impulsiveness.

\section{Response inhibition and absolute craving for alcohol during alcohol cue exposure}

Hierarchical linear regression was performed to assess whether response inhibition predicts craving during exposure to alcohol cues, after controlling for the influ- 
ence of age. The maximum absolute craving score during exposure to alcohol cues (exposure that took place in the bar-restaurant) was the criterion variable and SSRTs and age were the predictor variables in the model. Age was entered at step1 explaining $30.1 \%$ of the variance of craving during exposure to alcohol cues, F (1, $30)=12.94, p=.001$. After entry of the SSRTs at step 2 , the model was still significant, $\mathrm{F}(2,29)=11.36, \mathrm{p}<.001$. After controlling for age, response inhibition levels accounted for $13.8 \%$ of the variance in craving during the alcohol cue exposure, $\mathrm{F}$ change $(1,29)=7.13, \mathrm{p}=.012$ (Table 1 ). It seems that alcohol-dependent patients with less effective response inhibition tend to experience higher peak craving when exposed to alcohol cues than patients with more effective response inhibition.

Table 1 Linear regression analyses, with age, trait impulsiveness (total score and subscales), and response inhibition as predictors of the increase in cue-elicited craving (craving at baselines/water exposure subtracted) and absolute craving (craving at baselines/water exposure not subtracted) during alcohol cue exposure in the bar-restaurant

\begin{tabular}{|c|c|c|c|c|c|c|c|c|}
\hline \multirow[b]{2}{*}{ Predictors } & \multicolumn{4}{|c|}{ Increase in craving to alcohol cues } & \multicolumn{4}{|c|}{ Absolute craving to alcohol cues } \\
\hline & $\mathrm{B}$ & SE B & $\beta$ & $\Delta \mathrm{R}^{2}$ & $\mathrm{~B}$ & SE B & $\beta$ & $\Delta \mathrm{R}^{2}$ \\
\hline $\begin{array}{l}\text { Trait impulsiveness } \\
\text { (BIS-11) }\end{array}$ & 0.48 & 0.21 & $.33^{*}$ & .10 & 1.10 & 0.33 & $.43^{* *}$ & .17 \\
\hline $\begin{array}{l}\text { Motor impulsiveness } \\
\text { (BIS-11) }\end{array}$ & 1.23 & 0.5 & $.36^{*}$ & .12 & 2.4 & 0.8 & $.4^{* *}$ & .14 \\
\hline $\begin{array}{l}\text { Attentional impulsiveness } \\
\text { (BIS-11) }\end{array}$ & 0.61 & 0.54 & .17 & .03 & 2.21 & 0.84 & $.35^{*}$ & .11 \\
\hline $\begin{array}{l}\text { Non-planning impulsiveness } \\
\text { (BIS-11) }\end{array}$ & 0.72 & 0.46 & .23 & .05 & 1.37 & 0.76 & .24 & .06 \\
\hline $\begin{array}{l}\text { Response inhibition } \\
\text { (SSRT) }\end{array}$ & 0.02 & 0.04 & .08 & .005 & 0.16 & 0.06 & $.39 *$ & .14 \\
\hline
\end{tabular}

Note: $* \mathrm{p}<05, * * \mathrm{p}<.01$

\section{Discussion}

In the present study, it was hypothesized that i) alcohol-dependent patients experience more intense craving for alcohol when exposed to alcohol rather than to water cues, ii) higher levels of trait impulsiveness and iii) a less effective response inhibition are linked to more intense cue-elicited craving for alcohol in alcoholdependent patients.

First of all, alcohol-dependent patients experience a higher increase in alcohol craving when exposed to alcohol as compared to neutral cues. This finding confirms the first hypothesis of the present study. Knowing that cue-elicited craving for alcohol is usually weaker than cue-elicited craving for other substances of abuse, we tried to apply some fundamental guidelines in order to obtain a reliable effect 
(Carter \& Tiffany 1999; Rohsenow \& Niaura, 1999; Tiffany, Carter, \& Singleton, 2000). Therefore, great efforts were made to develop a strong cue exposure with personally relevant stimuli in a real alcohol-related environment; and to expose the patients to a combination of cues for as long as possible, while always bearing in mind that this experience was stressful for them. Although limited, the increase in cue-elicited craving for alcohol is significant and of a moderate effect size. Our finding is in line with well-established findings in the alcohol cue reactivity literature and once more it demonstrates that alcohol craving shows cue specificity (Carter \& Tiffany, 1999; Havermans, Mulkens, Nederkoorn, \& Jansen, 2007; Tiffany et al., 2000). Most important, a successful cue exposure was the cornerstone of our study because a consistent cue-elicited craving response is necessary in order to identify the factors that are involved in this phenomenon (Carter \& Tiffany, 1999).

The results also confirm the second and third hypotheses of our study. It was found that trait impulsiveness predicted both the absolute craving in the barrestaurant and the increase in cue-elicited craving during the whole alcohol cue exposure, while response inhibition predicted successfully only the former. The former type of craving is a threat for relapse in real life and it may be even more clinically relevant than the increase in cue-elicited craving in alcohol dependence. Future research should investigate whether the interaction of cue-elicited craving with impulsivity traits predicts relapse in alcohol dependence. If empirical evidence supports this assumption, then alcohol treatment and prevention programs might benefit from impulsivity interventions in combination with cue exposure with response prevention programs. .

Our findings are in line with Doran et al.'s (2007) findings who also reported that a stronger increase in cue-elicited craving for tobacco is associated with higher scores in trait impulsiveness. Furthermore, our results are partly in agreement with Papachristou, Nederkoorn, Havermans et al.'s (2012) study, in which it was found that response inhibition and not trait impulsiveness is associated with cue-elicited craving for alcohol. The discrepancy in the findings between the two studies could be due to differences in the populations studied, the type and duration of cue exposure, craving instruments, and differences in the computation of cue-elicited craving. For example, in Papachristou, Nederkoorn, Havermans et al.'s (2012) study, the sample consists of heavy social drinkers and the alcohol cue exposure lasts only three minutes and takes place in the laboratory. In the current study, the sample consists of alcohol-dependent inpatients and the cue exposure is longer and takes place in a real alcohol-related setting.

With regard to variation in determining cue-elicited craving, we have found that unlike trait impulsiveness, response inhibition only predicts absolute cueelicited craving score in the bar-restaurant and not the increase in cue-elicited craving. These two types of cue-elicited craving, craving change and absolute craving, may have fundamental differences. Regarding craving change for example, the inclusion of a baseline measurement could control for individual differences in responding, expectations, withdrawal craving, and arousal resulting from conflicting 
drinking goals that could be misinterpreted as craving (Patterson \& Newman, 1993; Robbins \& Ehrman, 1992; Sayette et al., 2000; Papachristou, Nederkoorn, Corstjens, \& Jansen, 2012). Furthermore, controlling for craving during neutral cue exposure demonstrates the cue specificity of alcohol craving (Carter \& Tiffany, 1999; Robbins \& Ehrman, 1992; Tiffany et al., 2000). The notion of cue specificity is in turn, closer to a learning explanation, although a more sophisticated experimental design is required to reach safely this conclusion (Robbins \& Ehrman, 1992). On the other hand, any of the aforementioned factors could be involved in the absolute cueelicited craving score in the bar-restaurant and could interact with response inhibition, though this assumption should be supported by future empirical evidence. Therefore, our results are consistent with the broader view that impulsivity consists of multiple dimensions that are uniquely associated with different aspects or indices of alcohol motivation and problems (Christiansen et al., 2012; Dick et al., 2010; Henges \& Marczinski, 2012; Lane, Cherek, Rhoades, Pietras, \& Tcheremissine, 2003). Alternatively, the relationship between response inhibition and increase in cue-elicited craving could be real but weak, requiring a larger number of participants to be detected statistically.

Although our study contributes to the understanding of the complex relationship between personality and cue reactivity in alcohol-dependence, it is not flawless. It should be noted that alcohol-dependent people are not a homogeneous population (Dom et al., 2006). For example, individual differences in the age of onset of alcohol problems or the presence (or absence) of comorbid antisocial personality disorder or post-traumatic stress disorder could distinguish between more homogeneous subgroups in alcohol dependence. These factors potentially added to the heterogeneity of our study sample and might have affected the extent of cueelicited craving (Coffey, Schumacher, Stasiewicz, Henslee, Baillie, \& Landy, 2010). The limited sample size precludes us to examine this, but in future research it would be interesting to investigate whether the same conclusions can be drawn in more homogeneous groups of alcohol dependent patients (Dom et al., 2006; Verdejo-Garcia et al., 2008). Furthermore, the cue-elicited craving response was reliable but small, which creates doubts about its role in relapse. This could be the result of the reluctance of our participants to admit the full scale of their craving response for reasons related to their patient status and their motivation to remain abstinent (Carter \& Tiffany, 1999; Wertz \& Sayette, 2001). Moreover, there were no measures of stress and of severity of alcohol dependence in the present study. However, the exposure to alcohol cues may have been stressful for some patients and this could have influenced their cue reactivity levels. In the same vein, a higher degree of dependence may reflect a longer learning history or changes in neural systems involved in learning, motivation and impulsivity and as a result it could also have affected cue reactivity levels in the present study (Drummond, 2000; Drummond, Litten, Lowman, \& Hunt, 2000). Additionally, the magnitude of the relationship between trait impulsiveness/response inhibition and cue-elicited craving suggests that there is still a great amount of variance in cue-elicited craving that 
must be explained by other factors. For example, our data displays that age is an important factor in the moderation of cue-elicited craving in alcohol-dependence. Speculating on the nature of this finding, it could be that older patients were more effective at hiding their craving during the cue-exposure or had higher motivation for doing so. Alternatively, it could be that as people grow older, they become less aroused by alcohol-related cues. We suggest that this finding should be the focus of future research because it may have important theoretical and clinical implications for the treatment of elderly alcohol-dependent patients. Finally, the small effect size of the relationship implies that addressing impulsive behaviour in order to prevent relapse through a reduction in cue-elicited craving may have limited therapeutic utility.

In sum, our results confirm our hypotheses that both trait impulsiveness and response inhibition influence the intensity of cue-elicited craving in alcoholdependence. If cue-elicited craving is a motivational index of alcohol-seeking and a risk factor for relapse in alcohol dependence (Drummond, 2000) then the next step is to examine whether the interaction of impulsivity traits with cue-elicited craving predicts relapse. In that case, both behavioural training and pharmacological treatment for impulsive behaviour in tandem with cue exposure with response prevention should be an option in alcohol treatment. Our findings shed some light on these complex relationships and underline the importance of doing further research on the topic.

\section{References}

Anton, R. F. (1999). What is craving? Models and implications for treatment. Alcohol Research and Health, $23,165-173$.

Carter, B. L., \& Tiffany, S. T. (1999). Meta-analysis of cue-reactivity in addiction research. Addiction, 94, 327-340.

Christiansen, P., Cole, J. C., Goudie, A. J., \& Field, M. (2012). Components of behavioural impulsivity and automatic cue approach predict unique variance in hazardous drinking. Psychopharmacology, 219, 501-510.

Coffey, S. F., Schumacher, J., Stasiewicz, P. R., Henslee, A. M., Baillie, L. E., \& Landy, N. (2010). Craving and physiological reactivity to trauma and alcohol cues in posttraumatic stress disorder and alcohol dependence. Experimental and Clinical Psychopharmacology, 18, 340-349.

Dawe, S., Gullo, M. J., Loxton, N. L. (2004). Reward drive and rash impulsiveness as dimensions of impulsivity: Implications for substance misuse. Addictive Behaviors, 29, 1389-1405.

Dawe, S., Loxton, N. J. (2004). The role of impulsivity in the development of substance use and eating disorders. Neuroscience and Biobehavioral Reviews, 28, 343-351.

De Wit, H. (2008). Impulsivity as a determinant and consequence of drug use: a review of underlying processes. Addiction Biology, 14, 22-31.

Dick, D. M., Smith, G., Olausson, O., Mitchell, S. H., Leeman, R. F., O’Malley, S. S., \& Sher, K. (2010). Understanding the construct of impulsivity and its relationship to alcohol use disorders. Addiction Biology, $15,217-226$.

Dom, G., Hulstijn, W., \& Sabbe, B. (2006). Differences in impulsivity and sensation seeking between earlyand late-onset alcoholics. Addictive behaviors, 31, 298-308. 
Doran, N., McChargue, D., \& Spring, B. (2008). Effect of impulsivity on cardiovascular and subjective reactivity to smoking cues. Addictive Behaviors, 33, 167-172.

Doran, N., Spring, B., McChargue, D. (2007). Effects of impulsivity on craving and behavioural reactivity to smoking cues. Psychopharmacology, 194, 279-288.

Drummond, D. C. (2000). Human models in craving research: What does cue-reactivity have to offer clinical research? Addiction, 95, S129-S144.

Drummond, D. C., Litten, R. X., Lowman, C., Hunt, W. A. (2000). Craving research: future directions. Addiction, 95, S247-S255.

Eagle, D. M., Bari, A., \& Robbins, T. W. (2008). The neuropsychopharmacology of action inhibition: crossspecies translation of the stop-signal and go/no-go tasks. Psychopharmacology, 199: 439-456.

Enticott, P. G., Ogloff, G. R. P., \& Bradshaw, J. L. (2006). Associations between laboratory measures of executive control and self-reported impulsivity. Personality and Individual Differences, 41, 285-294.

Havermans, R. C., Mulkens, S., Nederkoorn, C., \& Jansen, A. (2007). The efficacy of cue exposure with response prevention in extinguishing drug and alcohol cue reactivity. Behavioral Interventions, 22, 121-135.

Henges, A. L., \& Marczinski, C. A. (2012). Impulsivity and alcohol consumption in young social drinkers. Addictive Behaviors, 37, 217-220.

Kozlowski, L. T., Pillitteri, J. L., Sweeney, C. T., Whitfield, K. E., \& Graham, J. W. (1996). Asking questions about urges or craving for cigarettes. Psychology of Addictive Behaviors, 10, 248-260.

Lane, S. D., Cherek, D. R., Rhoades, H. M., Pietras, C. J., \& Tcheremissine, O. V. (2003). Relationships among laboratory and psychometric measures of impulsivity: implications in substance abuse and dependence. Addictive Disorders and Their Treatment, 2, 33-40.

Litt, M. D., Cooney, N. L., \& Morse, P. (2000). Reactivity to alcohol-related stimuli in the laboratory and in the field: predictors of craving in treated alcoholics. Addiction, 95, 889-900.

Logan, G. D., Schachar, R. J., \& Tannock, R. (1997). Impulsivity and inhibitory control. Psychological Science, 8, 60-64.

Nederkoorn, C., Baltus, M,. Guerrieri, R., \& Wiers, R. W. (2009). Heavy drinking is associated with deficient response inhibition in women but not in men. Pharmacology Biochemistry and Behavior, 93, 331-336.

Nigg, J. T., Wong, M. M., Martel, M. M., Jester, J. M., Puttler, L. I., Glass, J. M., Adams, K. M., Fitzgerald, H. E., \& Zucker, R. A. (2006). Poor response inhibition as a predictor of problem drinking and illicit drug use in adolescents at risk for alcoholism and other substance use disorders. Journal of the American Academy of Child and Adolescent Psychiatry, 45, 468-475.

Papachristou, H., Nederkoorn, C., Corstjens, J., \& Jansen, A. (2012). The role of impulsivity and perceived availability on cue-elicited craving for alcohol in social drinkers. Psychopharmacology, 224, 145-153.

Papachristou, H., Nederkoorn, C., Havermans, R., van der Horst, M., \& Jansen, A. (2012). Can't stop the craving: The effect of impulsivity on cue-elicited craving for alcohol in heavy and light social drinkers. Psychopharmacology, 219, 511-518.

Patterson, C. M., \& Newman, J. P. (1993). Reflectivity and learning from aversive events: Toward a psychological mechanism for the syndromes of disinhibition. Psychological Review, 100, 716-736.

Patton, J. H., Stanford, M. S., Barratt, E. S. (1995). Factor structure of the Barratt Impulsiveness Scale. Journal of Clinical Psycholy, 51, 768-774.

Robbins, S. J., \& Ehrman, R. N. (1992). Designing studies of drug conditioning in humans. Psychopharmacology, 106, 143-153.

Rohsenow, D. J., \& Niaura, R. S. (1999). Reflections on the state of cue-reactivity theories and research. Addiction, 94, 341-351.

Rubio, G., Jimenez, M., Rodrigo-Jimenez, R., Martinez, I., Avila, C., Ferre, F., et al. (2008). The role of behavioural impulsivity in the development of alcohol dependence: A 4-year follow-up study. Alcoholism: Clinical and Experimental Research, 32, 1681-1687.

Sayette, M. A., Shiffman, S., Tiffany, S. T., Niaura, R. S., Martin, C. S., \& Shadel, W. G. (2000). Methodological approaches to craving research: the measurement of drug craving. Addiction, 95, S189-S210.

Tiffany, S. T., Carter, B. L., \& Singleton, E. G. (2000). Challenges in the manipulation, assessment and interpretation of craving relevant variables. Addiction, 95, S177-S187. 


\section{CHAPTER 5}

Verdejo-Garcia, A., Lawrence, A. J., \& Clark, L. (2008). Impulsivity as a vulnerability marker for substance-use disorders: Review of findings from high-risk research, problem gamblers and genetic association studies. Neuroscience and Behavioral Reviews, 32, 777-810.

Von Diemen, L., Bassani, D. G., Fuchs, S. C., Szobot, C. M., \& Pechansky, F. (2008). Impulsivity, age of first alcohol use and substance use disorders among male adolescents: a population based case-control study. Addiction, 103, 1198-1205.

Wertz, J. M., Sayette, M. A. (2001). A review of the effects of perceived drug use opportunity on selfreport urge. Experimental and Clinical Psychopharmacology, 9, 3-13.

Whiteside, S. P., \& Lynam, D. R. (2001). The Five Factor Model and impulsivity: Using a structural model of personality to understand impulsivity. Personality and Individual Differences, 30, 669-689.

Whiteside, S. P., \& Lynam, D. R. (2003). Understanding the role of impulsivity and externalizing psychopathology in alcohol abuse: Application of the UPPS Impulsive Behavior Scale. Experimental and Clinical Psychopharmacology, 11, 210-217. 


\section{CHAPTER 6}

\section{Cue reactivity during treatment, and not}

impulsivity, predicts relapse after treatment in alcohol use disorders ${ }^{7}$

7 Papachristou, H., Nederkoorn, C., Giesen, J. C. A. H., \& Jansen, A. (in revision). Cue reactivity during treatment, and not impulsivity, predicts relapse after treatment in alcohol use disorders 


\begin{abstract}
Both cue-elicited craving and impulsivity have been involved in alcohol misuse. However, their role in relapse has not been very clear. In the present study, we ask whether cue-elicited craving, impulsivity, and their interaction term predict relapse in problem drinkers. Participants $(n=20)$ were former patients of the private clinic, U-Center, in the Netherlands, who had completed a six-week alcohol treatment program and had an abstinence goal. While in treatment, they underwent a cue exposure paradigm in a real alcohol-related setting and their trait impulsivity was measured with the Barratt Impulsiveness Scale version 11 (BIS-11). During the follow-up assessment, patients were contacted again and asked about their alcohol drinking behaviour during the first three months after the end of the treatment program. It was found that higher craving and lower trait impulsivity levels are associated with a higher probability of relapse.
\end{abstract}

Keywords: Alcohol misuse $\cdot$ impulsivity $\cdot$ craving $\cdot$ cue exposure $\cdot$ relapse 


\section{Introduction}

Cue reactivity is a robust phenomenon in alcohol misuse (Carter \& Tiffany, 1999). According to the conditioned incentive model, stimuli paired with the reinforcing effects of alcohol acquire incentive properties via classical conditioning. As a result, they elicit a conditioned motivational state that elicits subjective (e.g., craving), physiological (e.g., changes in heart rate), and behavioural reactivity (e.g., promote alcohol drinking) (Carter \& Tiffany, 1999; Stewart, de Wit, \& Eikelboom, 1984). According to this model, there should be at least a modest correlation between craving (subjective reactivity) and alcohol drinking (behavioural reactivity) because both responses have a common source: the motivational state elicited by the alcohol-related cues. This relationship could help both clinicians and researchers to predict relapse in former alcohol patients based on their level of cue-elicited craving. Although there is some evidence that cue-elicited craving is a predictor of relapse to heavy drinking (Drummond \& Glautier, 1994), there are also findings that do not support this prediction (Drummond, 2000).

Drummond, Litten, Lowman, and Hunt (2000) argue that there may be other factors serving as mediators/moderators of craving that could affect the predictive validity of craving in relapse. The authors argue that relapse could also be associated with the moderators/mediators themselves (Drummond et al., 2000). In support of their assumption, recent studies with social and problem drinkers show that higher impulsivity levels are linked to stronger cue-elicited craving for alcohol (Franken, 2002; Kambouropoulos \& Staiger, 2001; Papachristou, Nederkoorn, Havermans, Bongers, Beunen, \& Jansen, 2013; Papachristou, Nederkoorn, Havermans, van der Horst, Jansen, 2012). However, none of these studies has examined the potential role of both cue-elicited craving and impulsivity as well as of their interaction in relapse after treatment.

The present study aims to answer the aforementioned question. Participants were former inpatients of the private clinic U-Center, in the Netherlands, who had undertaken a six-week alcohol treatment program for problem drinking. While in the clinic they participated in a cue-reactivity study in which they were exposed in a single session to individualized alcohol cues in a real alcohol-related setting (barrestaurant). Their cue-elicited craving and impulsivity levels were measured during that study (Papachristou et al., 2013). In the present study, it was hypothesized that higher impulsivity and higher cue-elicited craving levels as well as their interaction term are associated with a higher probability of relapse in this group of problem drinkers during the first three months after the end of their inpatient treatment program. 


\section{Methods}

\section{Participants}

Participants were former patients of the private clinic U-Center, in the Netherlands, who underwent a six-week inpatient alcohol treatment program with an abstinence goal. The clinic used evidence-based treatment protocols including cognitivebehaviour therapy and motivational interviewing. Cue exposure with response prevention was not included in the treatment program. While in the first three weeks of their treatment, 47 problem drinkers (28 men and 19 women, 41 alcohol dependent and 6 alcohol abusers) underwent a cue exposure paradigm in which they were presented with their favourite alcoholic beverage in a bar-restaurant nearby the clinic (Papachristou et al., 2013). Of the 47 problem drinkers, 20 (12 men and 8 women; 19 alcohol dependent and 1 alcohol abuser) could be reached for the 3-month follow-up assessment. There were no significant gender differences between those patients who were reached for the follow-up assessment and the rest of the group $\left(\chi^{2}(1)=0.003\right.$, ns.). Similarly, there were no differences in trait impulsiveness $(\mathrm{t}(45)=0.66, \mathrm{~ns})$, in cue-elicited craving ( $\mathrm{t}(45)=-0.76$, ns.), and in age ( $\mathrm{t}(45)=-1.93$, ns) between these two groups. The mean age of the participating group was 53.25 years $(S D=10.15$, $\min =30$, $\max =67)$. Finally, among the 20 former patients who provided information about relapse, six ( 5 men and 1 woman, mean age $=49.83, \mathrm{SD}=13.93)$ relapsed and 14 (7 men and 7 women, mean age $=54.71, \mathrm{SD}=8.25$ ) did not relapse within the first 3 months after the end of the treatment program.

Ethical approval was obtained from the Ethics Committee of the Psychology Faculty of Maastricht University. All participants were diagnosed with alcohol problems by the staff psychiatrists according to DSM-IV criteria. None of the patients had been diagnosed with either antisocial or borderline personality disorder or with attention deficit hyperactivity disorder. Additionally, none of the participants had a history of psychosis or suffered from serious brain impairment.

\section{Measures}

Trait impulsiveness (BIS-11)

Trait impulsiveness was measured with the Dutch version of the Barratt impulsiveness Scale version 11 while the patients were in treatment and before their participation in the cue-exposure study (Patton, Stanford, \& Barratt, 1995). The BIS-11 consists of 30 items and each item is reported on a 4-point scale. The total score ranges from 30 (low impulsivity) to 120 (high impulsivity). It is divided into three factors: motor, attentional, and non-planning impulsiveness. Previous research in a wide range of populations has confirmed the reliability of the questionnaire with 
Cronbach's alpha coefficient ranging from .79 to .83 (Patton et al. 1995). For the present sample of problem drinkers, the Cronbach's alpha coefficient was .8.

\section{Craving}

Craving was assessed with two 100-mm visual analogue scales (VAS) ranging from 0 (not at all) to 100 (very much). Patients were asked (a) "How much do you feel like drinking alcohol right now?" and (b) "How strong is your urge to drink alcohol right now?". Craving levels were collected at baselines and during exposure to water and alcohol-related stimuli, (in fixed order) (Papachristou et al., 2013). Based on peak intensity scores averaged across the two VAS, a difference score was calculated for each condition (water condition: exposure-baseline; alcohol condition: exposure-baseline) and finally an overall difference craving score was estimated for the whole cue exposure (alcohol difference-water difference). The overall difference craving score was used as a predictor of relapse. The same variable was also the criterion variable in the original cue exposure study with alcohol dependent patients (Papachristou et al., in press). In the current study, the correlation coefficient $r$ between the two craving items at each level of cue exposure was acceptable: i) water baseline: $r=.9, p<.001$, ii) water exposure: $r=.91, p<.001$, iii) alcohol baseline: $\mathrm{r}=.94, \mathrm{p}<.001$, iv) alcohol exposure: $\mathrm{r}=.69, \mathrm{p}=.001$.

\section{Relapse}

The assessment of relapse was part of a larger follow-up research program with the purpose to assess the effectiveness of treatment. All former patients of the clinic were contacted once by mail and email and asked to fill in an online survey. They were inquired whether they had used alcohol again since they left the treatment program and if so when they used alcohol for the first time (lapse). Relapse was considered to have occurred when the patient reported using alcohol on at least two separate occasions within the first three months after leaving the U-Center. In the present study, all patients who had a single lapse repeated drinking thereafter and they were therefore considered to have relapsed. The patients of the current study were contacted at least three months ${ }^{8}$ after the end of their treatment program.

\footnotetext{
${ }^{8}$ Only one patient was contacted 63 days after the end of the treatment program but since he had relapsed within the first 3 months (21 days after leaving the program) he was included in the analysis.
} 


\section{Results}

Table 1 Trait impulsiveness (BIS-11) and craving for alcohol (difference) scores in problem drinkers (Relapse: $\mathrm{n}=6$; No relapse: $\mathrm{n}=14$ )

\begin{tabular}{lllllllllll}
\hline & \multicolumn{3}{l}{ Relapse $(\mathrm{n}=6)$} & \multicolumn{6}{l}{ No relapse $(\mathrm{n}=14)$} & \multicolumn{2}{c}{ t test } \\
\cline { 2 - 10 } & Mean & SE & Range & Mean & SE & Range & t value & df & p value \\
\hline $\begin{array}{l}\text { Increase in craving for alcohol } \\
\text { during cue exposure (100mm) }\end{array}$ & 23.42 & 9.17 & 55.5 & 7.68 & 3.52 & 44.5 & 1.6 & 6.53 & .16 \\
\begin{tabular}{l} 
Trait Impulsiveness (BIS-11) \\
\hline
\end{tabular} & 59.83 & 5.21 & 34 & 67.87 & 2.32 & 33 & -1.65 & 18 & .12 \\
\hline
\end{tabular}

Hierarchical logistic regression (Method: Enter) was conducted to assess whether trait impulsiveness (BIS-11), cue-elicited craving, and their interaction term predict probability of relapse in the group of problem drinkers. The two predictors did not correlate significantly with each other, $r=.32, p=.17$, ns. Both trait impulsiveness and craving scores were centered before being entered into the regression model. Both BIS-11 and cue-elicited craving scores were entered at Block 1 of the analysis and their interaction term, BIS-11 x cue-elicited craving, was entered at Block 2. The results suggest that higher levels of trait impulsiveness are associated with a lower probability to relapse in this group of problem drinkers. Unlike trait impulsiveness, higher levels of cue-elicited craving are associated with a higher probability of relapse within the first three months. Finally, the interaction between trait impulsiveness and cue-elicited craving for alcohol does not predict relapse in this group of problem drinkers (Table 2).

Table 2 Logistic regression model used to predict relapse in problem drinkers (Relapse: $n=6$; No relapse: $\mathrm{n}=14$ )

\begin{tabular}{lllll}
\hline & \multicolumn{4}{l}{$95 \%$ CI for Odds ratio } \\
\cline { 2 - 5 } & B(SE) & Lower & Odds ratio & Upper \\
\hline constant & -1.19 & & & \\
Cue-elicited craving & $0.11^{*}(0.05)$ & 1.005 & 1.116 & 1.238 \\
Trait impulsiveness (BIS-11) & $-0.17^{*}(0.08)$ & 0.724 & 0.848 & 0.992 \\
BIS-11 x cue-elicited craving & $-0.01(0.01)$ & 0.971 & 0.991 & 1.011 \\
\hline
\end{tabular}

Note Block $1 \mathrm{R}^{2}=.39$ (Cox \& Snell). Model $\chi^{2}(2)=10.02, \mathrm{p}=.007$; Block $2 \mathrm{R}^{2}=.43$ (Cox \& Snell). Model $\chi^{2}$ (3) $=11.24, \mathrm{p}=0.01$, ns. Block $\chi^{2}(1)=1.22, \mathrm{p}=0.27$, ns.

${ }^{*} \mathrm{p}<.05 .{ }^{* *} \mathrm{p}<.01$. 


\section{Discussion}

The present findings support our hypothesis that cue-elicited craving for alcohol predicts alcohol drinking. Our results show that higher cue-elicited craving for alcohol in a real alcohol-related setting is associated with an increased probability of relapse in problem drinkers. Although our results are based on a small sample size, they are in line with previous alcohol and nicotine cue reactivity studies in which it was also found that subjective and physiological cue reactivity predict relapse during follow-up (Abrams, Monti, Carey, Pinto, \& Jacobus, 1988; Drummond \& Glautier, 1994; Rohsenow, Monti, Rubonis, Sirota, Niaura, Colby, et al., 1994). Together, all these findings highlight the importance of including cue reactivity paradigms in clinical practice with the aim to reduce cue-elicited craving during treatment. Exposing problem drinkers to cues in a naturalistic setting could become an integral component of alcohol treatment.

In contrast to our hypotheses, the analysis shows that higher impulsivity levels are associated with a lower probability of relapse during the first three months after leaving the clinic. Additionally, the interaction between cue-elicited craving and impulsivity is not a significant predictor of relapse in the present study. Our results are in contrast to the results of a recent study which shows that the NonPlanning scale of BIS-11 is a significant predictor of relapse in alcohol-dependent patients but only indirectly via craving (Evren, Durkaya, Evren, Dalbudak, \& Cetin, 2012). On the other hand, there is also evidence that trait impulsiveness does not always predict relapse in appetitive disorders (e.g., pathological gamblers, Goudriaan, Oosterlaan, De Beurs, \& Van Den Brink, 2008). Nevertheless, we are not aware of any published study that shows a negative relationship between trait impulsiveness and relapse in appetitive disorders. Speculating on this finding, it could be that some other variable(s) interferes with the effect of impulsivity on relapse. Higher impulsivity levels could still predict relapse for some problem drinkers but not for others. Additionally, there is some evidence from research on eating behaviour showing that impulsive adolescents benefit more from weight-reduction therapy that contains behaviour modification strategies (Pauli-Pott, Albayarak, Herebrand, and Pott, 2010). Similarly, it could be that some impulsive problem drinkers might benefit more from their therapeutic program. Evidently, this unexpected finding awaits replication from future research.

Our study has several limitations. For example, our analysis is based on a small and relatively old (Mean $=53.25$ years, $\min =30$, $\max =67$ ) sample and it is possible that a larger and younger (people in their 20s) sample would show a different relationship between impulsivity and relapse. Additionally, we have used only one self-report measure of impulsivity and future studies should also include behavioural measures such as the stop signal task (Christiansen et al. 2012; VerdejoGarcia, Lawrence, \& Clark, 2008). Furthermore, the validity of the self-reported measures of abstinence was not confirmed by collateral reports and/or biological 
markers. Despite the limitations, our study is the first one which examines the role of cue-elicited craving, trait impulsivity, and their interrelationship in relapse in alcohol misuse. Our results are in line with those cue reactivity models that interpret cue-elicited craving as a motivational index of substance misuse and provide support to the clinical relevance of the cue exposure paradigm in alcohol misuse (Drummond et al., 2000). Finally, our findings highlight the importance of studying cue-elicited craving in the natural drinking environment where cue-elicited responses may have greater predictive value (Drummond et al., 2000). The role of context in cue-elicited craving may be even more important in alcohol cue reactivity studies as it has been found that alcohol-dependent drinkers experience lower levels of cue-elicited craving than other addicts (Carter \& Tiffany, 1999). Thus, overall, our findings suggest that cue reactivity is an important determinant of relapse and it might be wise to reduce cue reactivity during treatment.

\section{References}

Abrams, D. B., Monti, P. M., Carey, K. B., Pinto, R. P., \& Jacobus, S. I. (1988). Reactivity to smoking cues and relapse: tow studies of discriminant validity. Behavior Research and Therapy, 26, 225-233.

Carter, B. L., \& Tiffany, S. T. (1999). Meta-analysis of cue-reactivity in addiction research. Addiction, 94(3), 327-340.

Christiansen, P., Cole, J. C., Goudie, A. J., \& Field, M. (2012). Components of behavioural impulsivity and automatic cue approach predict unique variance in hazardous drinking. Psychopharmacology, 219, 501-510.

Drummond, D. C. (2000). Human models in craving research: What does cue-reactivity have to offer clinical research? Addiction, 95, S129-S144.

Drummond, D. C., \& Glautier, S. (1994). A controlled trial of cue exposure treatment in alcohol dependence. Journal of Consulting and Clinical psychology, 62, 809-817.

Drummond, D. C., Litten, R. Z., Lowman, C., \& Hunt, W. A. (2000). Craving research: future directions. Addiction, 62, 809-817.

Evren, C., Durkaya, M., Evren, B., Dalbudak, E., \& Cetin, R. (2012). Relationship of relapse with impulsivity, novelty seeking and craving in male alcohol-dependent inpatients. Drug and Alcohol Review, 31, 81-90.

Franken, I. H. A. (2002). Behavioural approach system (BAS) predicts alcohol craving. Personality and Individual Differences, 32, 349-355.

Goudriaan, A. E., Oosterlaan, J., De Beurs, E., \& Van Den Brink, W. (2008). The role of self-reported impulsivity and reward sensitivity versus neurocognitive measures of disinhibition and decision-making in the prediction of relapse in pathological gamblers. Psychological Medicine, 38, 41-50.

Kambouropoulos, N., \& Staiger. P. K. (2001). The influence of sensitivity to reward on reactivity to alcohol-related cues. Addiction, 96, 1175-1185.

Papachristou, H., Nederkoorn, C., Havermans, R., Bongers, P., Beunen, S., \& Jansen, A. (2013). Higher levels of trait impulsiveness and a less effective response inhibition are linked to more intense cueelicited craving for alcohol in alcohol-dependent patients. Psychopharmacology, 228, 641-649.

Papachristou, H., Nederkoorn, C., Havermans, R., van der Horst, M., Jansen, A. (2012). Can't stop the craving: The effect of impulsivity on cue-elicited craving for alcohol in heavy and light social drinkers. Psychopharmacology, 219, 511-518.

Patton, J. H., Stanford, M. S., \& Barratt, E. S. (1995). Factor structure of the Barratt Impulsiveness Scale. Journal of Clinical Psychology, 51, 768-774. 
Pauli-Pott, U., Albayrak, O., Herebrand, J., \& Pott, W. (2010). Does inhibitory control capacity in overweight and obese children and adolescents predict success in a weight-reduction program? European Child and Adolescence Psychiatry, 19, 135-141.

Rohsenow, D. J., Monti, P. M., Rubonis, A. V., Sirota, A. D., Niaura, R. S., Colby, S. M., Wunschel, S. M., \& Abrams, D. B. (1994). Cue reactivity as a predictor of drinking among male alcoholics. Journal of Consulting and Clinical Psychology, 62, 620-626.

Stewart, J., de Wit, H., \& Eikelboom, R. (1984). Role of unconditioned and conditioned drug effects in the self-administration of opiates and stimulants. Psychological Review, 91, 251-268.

Verdejo-Garcia, A., Lawrence, A. J., \& Clark, L. (2008). Impulsivity as a vulnerability marker for substance-use disorders: Review of findings from high-risk research, problem gamblers and genetic association studies. Neuroscience and Behavioral Reviews, 32, 777-810. 



\section{CHAPTER 7}

General discussion 
CHAPTER 7 
The aim of the present thesis was to investigate the role of impulsivity in appetitive learning and in cue-elicited craving for alcohol. In general, our hypothesis was that more vs. less impulsive alcohol drinkers will experience stronger cue-elicited craving. In a series of studies, we tested this hypothesis in different types of alcohol drinkers and chocolate lovers. As impulsivity is a multidimensional construct, we used a variety of impulsivity measures, both self-report and behavioural, but our main focus was on response inhibition (measured with the Stop Signal Task, SST) and trait impulsiveness (measured with the Barratt Impulsiveness Scale version 11, BIS-11). This strategy enabled us to replicate our findings but also to find subtle differences between different populations and impulsivity components. Overall, our results support our general hypothesis.

In Chapter 2, we find evidence supporting our hypothesis in heavy but not in light social drinkers. As impulsivity is a multidimensional construct, it is of interest that only response inhibition (SST) appeared to be associated with stronger cueelicited craving for alcohol, while trait impulsiveness (BIS-11) and sensitivity to reward (measured with the Card Arranging Reward Responsivity Objective Test, CARROT) were not. However, heavy drinkers in this study had higher scores on trait impulsiveness than light drinkers, while the two groups did not differ in response inhibition and reward sensitivity.

A methodological limitation of the first study was that we did not control for the perceived availability of alcohol. As previous literature has provided evidence for the importance of perceived availability of the substance in cue-elicited craving (Wertz \& Sayette, 2001), we decided to incorporate this variable in the second study (Chapter 3). By doing so, we also filled a gap in the alcohol literature because the majority of evidence for the role of perceived availability in cue reactivity comes from nicotine studies. The results of this second study indicate that response inhibition is not associated with cue-elicited craving for alcohol in moderate social drinkers, resembling the findings for the light drinkers in the first study. However, we demonstrated that perceived availability of alcohol increases craving for alcohol during the cue exposure paradigm. Most important, we offer evidence that response inhibition moderates the relationship between perceived availability and cue-elicited craving in moderate social drinkers: participants with low response inhibition who expected alcohol showed the highest craving during exposure.

In our third study (Chapter 4), we attempted to examine the mechanisms by which impulsivity influences conditional appetitive responses. One possibility is that impulsivity modulates Pavlovian learning processes. Thus, our first goal was to establish successful acquisition and extinction of appetitive conditional responses for chocolate by using a discriminative conditioning paradigm borrowed by Van Gucht, Vansteenwegen, Beckers, and Van den Bergh's (2008) study. We successfully replicated Van Gucht et al.'s (2008) main findings by demonstrating that not all appetitive responses are equally sensitive to extinction. Expectancy for chocolate in response to the CS+ extinguished successfully, while craving for chocolate in response to the CS+ and liking for the CS+ did not. Having done this, our second aim 
was to investigate whether various impulsivity traits modify the acquisition and extinction processes in appetitive learning. Our results do not confirm the latter hypothesis. Our results demonstrate that neither reward sensitivity nor response inhibition nor sensation seeking influence the speed or strength of acquisition and extinction of appetitive CRs (craving, expectancy, and liking).

The study in Chapter 5 is an extension of our hypothesis to a clinical population in a real alcohol-related context (exposure in a bar). We expected that response inhibition and trait impulsiveness would modulate cue-elicited craving for alcohol in alcohol-dependent people. Our results confirm our expectations and also illustrate that in alcohol-dependent people, trait impulsiveness plays a more important role in the modification of cue-elicited craving for alcohol than response inhibition. Higher scores in trait impulsiveness are associated with a higher increase in craving for alcohol during the whole cue-exposure paradigm (water: baseline vs. exposure; alcohol: baseline vs. exposure in the bar-restaurant) and a higher absolute craving score in the bar-restaurant. In addition, a less effective response inhibition predicts higher craving for alcohol only in the bar-restaurant (absolute score).

Finally, in our last study (Chapter 6), we followed up former inpatients of the UCenter that had participated in the cue exposure paradigm of our fourth study. One of the main findings of this study was that higher cue-elicited craving during the cue exposure paradigm is associated with higher probability of relapse in former patients. An unexpected finding was the negative relationship between trait impulsiveness and relapse: higher scores in trait impulsiveness were associated with a lower probability to relapse.

In summary, in the present thesis we provide supporting evidence for our general hypothesis. Broadly speaking, more impulsive alcohol drinkers experience stronger craving when faced with alcohol-related cues than less impulsive alcohol drinkers. However, our results highlight the fact that various aspects of impulsivity explain different components of variance in alcohol-drinking behaviour and their role may vary depending on the type of drinker (light, moderate, heavy, and dependent). For example, unlike light and moderate drinkers, in both heavy social and dependent alcohol drinkers response inhibition modulates cue-elicited craving for alcohol. On the other hand, trait impulsiveness differentiates between heavy and light social drinkers but it does not modulate cue-elicited craving in any of these groups. Nevertheless, trait impulsiveness predicts cue-elicited craving for alcohol in alcohol-dependent people better than response inhibition.

An interesting point in the above findings that deserves further attention is that the relationship between response inhibition and cue-elicited craving for alcohol in both heavy social and dependent drinkers disappears when we control for craving during exposure to neutral (water) cues. Unlike response inhibition, trait impulsiveness predicts cue-elicited craving for alcohol during the overall cue exposure paradigm (water and alcohol conditions) in dependent drinkers. Controlling for craving during neutral cue exposure demonstrates the cue specificity of alcohol craving and the notion of cue specificity is in turn closer to a learning explanation 
(Robbins \& Ehrman, 1992). Thus, speculating on the results, it is likely that response inhibition may be related to non-associative aspects of cue-elicited craving for alcohol, though we cannot exclude the role of associative factors in our measures of cue-elicited craving in any of these studies.

The results of the conditioning study in the present thesis do not support the involvement of impulsivity components in the modulation of pavlovian appetitive learning. This could mean that impulsivity traits modulate the motivational properties of the appetitive conditional stimuli after pavlovian learning has been established. Alternatively, impulsivity may be involved in other types of learning e.g., instrumental and habit learning (Hogarth, 2011). Then again, impulsivity could exert an influence on pavlovian processes depending on the discriminative classical conditioning paradigm and the intensity of the US (Matthews \& Gilliland, 1999). For example, Paisey and Mangan (1988) reported that extraversion is negatively related to the acquisition of the electrodermal CR to weak sexual stimuli but positively related to the acquisition of the same CR to strong sexual stimuli. Thus, it is important to replicate the results of the present study with a more arousing US (e.g., alcohol) and increase the number of conditioning trials or even sessions in the discriminative paradigm.

Our findings suggest that cognitions like perceived availability, which predict the rewarding properties of alcohol may act as pavlovian cues eliciting craving or may constitute integral parts of the compound alcohol-related stimulus that enhance cue reactivity. Most important, we provide evidence that at least in moderate social drinkers, response inhibition interacts with perceived availability producing higher craving for alcohol. This finding enables us to view the response inhibition results of this thesis from a different perspective. For example, some of the heavy drinkers in the first study could have perceived alcohol to be available during the experiment and responded to this cognitive cue with higher craving during the alcohol condition. A similar argument could be made for alcohol-dependent people in the fourth study. Although we had warned all patients that alcohol drinking should not occur during the experiment and although all the patients were motivated to remain abstinent, they nevertheless had the opportunity to consume alcohol while being in the bar-restaurant. For some patients, alcohol could have been perceived as being available and among these people those with more deficient response inhibition may have felt the highest craving in the bar-restaurant. We believe that future research should attempt to replicate this finding in clinical populations and settings. Despite the ethical considerations, manipulations of perceived availability of alcohol should also be included in the design of the future (clinical) experiments. Former patients with dysfunctional response inhibition who leave the clinic and perceive alcohol to be available in the environment may experience higher craving and may run a higher risk for relapse compared to patients with efficient response inhibition. As Field and Cox (2008) point out, the concept of perceived availability should be incorporated into cognitive-behavioural therapy and patients could be taught to how to cope with it. For example, while being in the clinic, pa- 
tients could be provided with a bottle of their favourite alcoholic beverage so as they could perceive alcohol to be available. Being exposed to the cue of perceived availability without drinking could help the patients to extinguish the learning to this cue hence enabling them to learn to ignore it. Of course, this intervention should be organized very carefully and should run only under continuous and strict supervision from the treatment staff that should be ready to fully support the patient at any time. Our results further suggest that this strategy might be especially important to those patients with more deficient response inhibition.

The role of impulsivity and cue-elicited craving in relapse was investigated in the follow-up study with former inpatients of the U-Center. Unfortunately, we could not examine the function of response inhibition in relapse due to missing data and the small number of participants. The small number of participants also limits the generalization of our findings. Thus, at best, the results should be interpreted very cautiously. Despite these methodological limitations, our findings give support to the predictive value of cue-elicited craving in relapse and underline the importance of designing cue exposure paradigms in naturalistic environments in order to obtain reliable indices of cue reactivity. However, the unexpected negative relationship between trait impulsiveness and relapse as well as the non-significant interaction between cue-elicited craving and trait impulsiveness on relapse puzzled us. These latter findings await replication with a bigger sample. Furthermore, other variables such as age or level of dependence could moderate the relationship between trait impulsiveness and relapse in former alcohol patients and the goal of future research should be to identify these relationships.

Overall, the findings of the present thesis support the idea that higher impulsivity is associated with higher cue-elicited craving for alcohol in both heavy and alcohol-dependent drinkers. A schematic representation of the findings of the present thesis and the main predictions that follow from these findings is illustrated in Figure 1. In general, higher levels of impulsivity are associated with higher cueelicited craving for alcohol. Furthermore, perceived availability of alcohol may serve as a component of the alcohol cue or context and could increase craving for alcohol. Additionally, there is an interaction between impulsivity and perceived availability and as a result people who are more impulsive and perceive alcohol as being available in the environment may experience stronger craving. In turn, cueelicited craving for alcohol could predict alcohol-drinking and relapse in problem drinkers but its predictive value may depend on the context in which the cues are presented. Moreover, higher impulsivity levels could be associated with a higher probability of relapse indirectly via higher levels of cue-elicited craving. Although our findings suggest a negative relationship between impulsivity and relapse, this relationship could be modulated by other factors such as age, comorbidity, severity of dependence, etc. Finally, these same factors may also affect cue-elicited craving (e.g., age) hence indirectly the probability of relapse. 


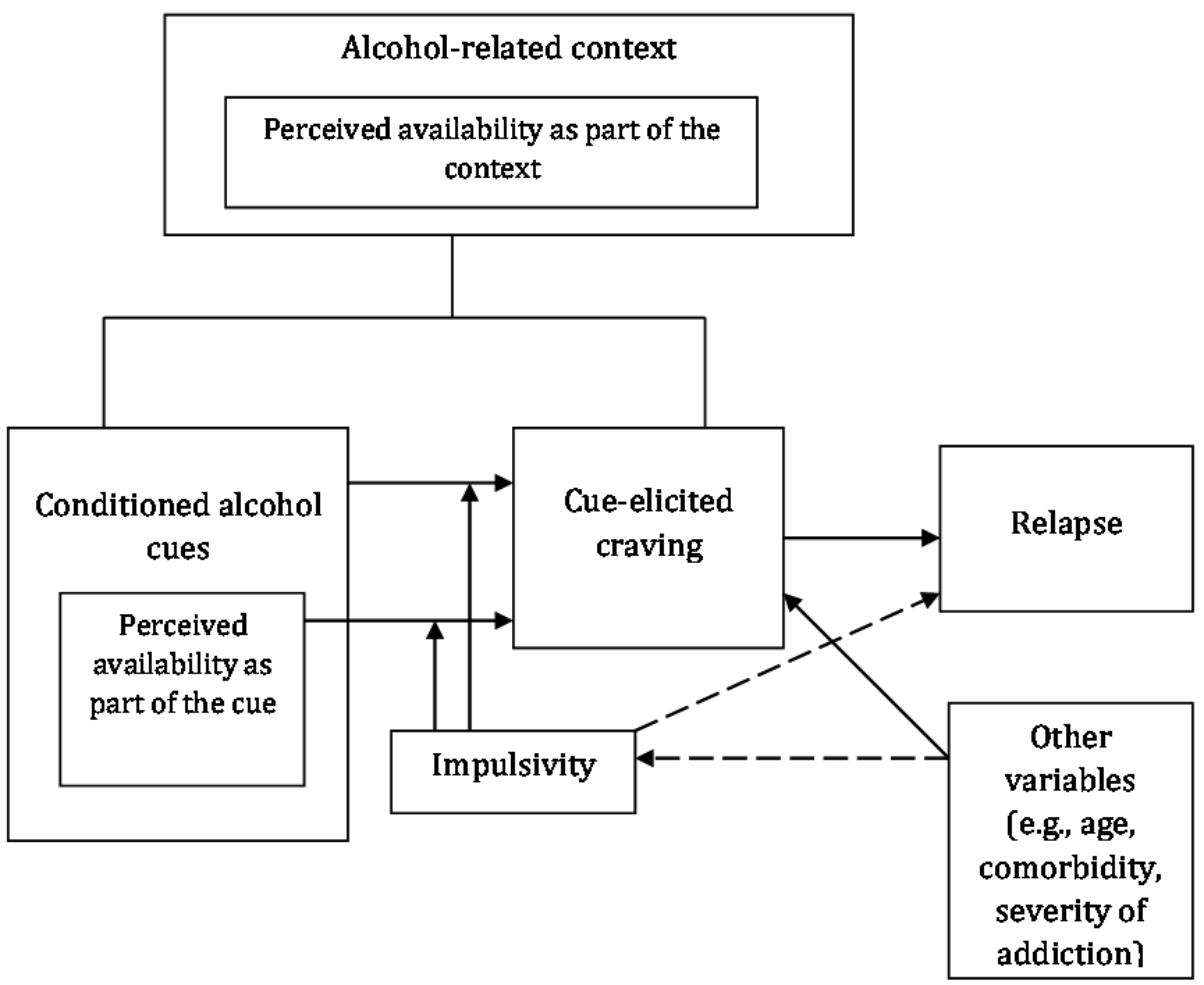

Fig. 1 Schematic overview of the main predictions derived from the findings of the present thesis. Higher impulsivity is associated with stronger cue-elicited craving for alcohol. Perceived availability of alcohol is an integral part of the cue or context and increases cue-elicited craving for alcohol. Impulsivity interacts with perceived availability and more impulsive people who perceive alcohol to be available may experience stronger craving for alcohol. Higher cue-elicited craving for alcohol may be a good predictor of relapse but its predictive value depends on the context in which the cues are presented. Impulsivity may also play a role in relapse via cue-elicited craving. Finally, there may be a direct link between impulsivity and relapse but also other variables like age, severity of dependence, and comorbidity etc. may modulate this relationship. Additionally, these same variables may modulate the strength of cue-elicited craving (e.g., age).

Craving for alcohol is often used as an index of the treatment progress of the patient and our results highlight the importance of cue-elicited craving in relapse in alcohol-dependence. Thus, we recommend that cue exposure with response prevention (CERP) interventions should be incorporated into clinical practice (Conklin \& Tiffany, 2002). However, we suggest that special effort should be made to create a naturalistic exposure environment and if possible to expose patients to the real-life alcohol setting, for example, at home or in their own favourite pub. It could also be useful for the therapist to offer online guidance of exposure sessions at home from distance, e.g., via Skype. Conklin and Tiffany (2002) argue that CERP interventions may have been ineffective in the past in addiction treatment because we have ignored fundamental learning phenomena that have been extensively discussed in 
the animal literature. One example is the renewal effect in which successfully extinguished drug-seeking CRs reappear when the animal changes context after extinction or when it returns to the environment in which the learned CR was originally acquired (Conklin \& Tiffany, 2002; Crobag, Bossert, Koya, \& Shaham, 2010). Thus, it seems that responding to a CS is context-dependent. The role of context in the renewal effect could be mediated by at least two different psychological mechanisms that may run in parallel in pavlovian learning (Crobag et al., 2010). First of all, contexts could serve as excitatory pavlovian CSs (Crobag et al., 2010). In this case, if extinction and acquisition of the CR occur in different contexts, it is likely that the acquisition context still retains its motivational properties even after extinction has occurred successfully (Crobag et al., 2010). Thus, returning to the original acquisition context would be sufficient to stimulate drug-seeking behaviour even in the absence of any discrete drug-related cues. Indeed, the results of some animal studies corroborate this idea (Crobag et al., 2010). Alternatively, contexts could serve as occasion setters modulating CS-US relationships (Bouton, 2007). Unlike an excitatory CS which signals the occurrence of the US, an occasion setter offers information about whether or not the US follows the CS perhaps by acting as a retrieval cue that disambiguates the meaning of the CS (Bouton, 2007). Evidence from animal studies has supported the role of context as occasion setter in appetitive pavlovian learning (Bouton, 2007; Crobag et al., 2010). If the context influences alcoholdrinking by serving as an occasion setter, we would expect that a successful extinction of cue-elicited craving in the clinic will not generalize in a different context. For example, in the context of the clinic, after successful extinction a discrete alcoholrelated cue (e.g., a bottle of wine) will signal the non-occurrence of alcohol and of alcohol appetitive effects. However, craving for alcohol may reappear when the patient is exposed to the same bottle of wine in his favourite pub. Finally, perceived availability is an integral component of a naturalistic environment and our findings also underline its importance in alcohol craving. Therefore, it should also be included in the CERP designs and interventions.

If cue-elicited craving predicts relapse, it is important to differentiate between patients who respond to alcohol-related cues with higher craving from those who do not because the former group is more likely to relapse than the latter group. To achieve that, impulsivity measures should be incorporated into clinical practice as a way of identifying the most vulnerable patients. Although our preliminary followup findings do not support the role of trait impulsiveness in relapse, more research should be done on the topic with bigger samples and various impulsivity components including the stop signal task and the BIS-11. Additionally, variables like age, severity of dependence, and comorbidity should be included in these designs and experimentally manipulated because they may moderate cue-reactivity and interfere with the effects of impulsivity on craving and relapse. Furthermore, we should not forget that stress and priming doses of the substance are also cues that constitute potential risks for relapse in alcohol and drug dependence and should also be included as cues in future cue-reactivity studies. In sum, the results of the present 
thesis demonstrate that higher impulsivity is associated with stronger cue-elicited craving for alcohol in heavy social and dependent alcohol drinkers and a stronger cue-elicited craving for alcohol is linked to a higher probability of relapse in problem alcohol drinkers. Finally, perceived availability increases craving for alcohol and interacts with impulsivity so as impulsive people who perceive alcohol as being available in the environment experience higher craving than less impulsive people or people who perceive alcohol to be unavailable.

\section{References}

Bouton, M. E. (2007). Learning and Behavior: A contemporary synthesis. Sunderland, Massachusetts: Sinauer Associates, Inc.

Conklin, C. A., \& Tiffany, S. T. (2002). Applying extinction research and theory to cue-exposure addiction treatments. Addiction, 97, 155-167.

Crobag, H. S., Bossert, J. M., Koya, E., \& Shaham, Y. (2010). Context-induced relapse to drug-seeking: A review. In Robbins, T. W., Everitt, B. J., \& Nutt, D. J. (2010). The Neurobiology of addiction new vistas (pp. 203-219). New York: Oxford University Press Inc.

Field, M., \& Cox, W. M. (2008). Attentional bias in addictive behaviors: A review of its development, causes, and consequences. Drug and Alcohol Dependence, 97, 1-20.

Hogarth, L. (2011). The role of impulsivity in the aetiology of drug dependence: reward sensitivity versus automaticity. Psychopharmacology, 215, 567-580.

Matthews, G., \& Gilliland, K. (1999). The personality theories of H. J. Eysenck and J. A. Gray: a comparative review. Personality and Individual Differences, 26, 583-626.

Paisey, T. J. H., \& Mangan, G. L. (1988). Personality and conditioning with appetitive and aversive stimuli. Personality and Individual Differences, 9, 69-78.

Robbins, S. J., \& Ehrman, R. N. (1992). Designing studies of drug conditioning in humans. Psychopharmacology, 106, 143-153.

Van Gucht, D., Vansteenwegen, D., Beckers, T., Van den Bergh, O. (2008). Return of experimentally induced chocolate craving after extinction in a different context: Divergence between craving for and expecting to eat chocolate. Behaviour Research and Therapy, 46, 375-391.

Wertz, J. M., Sayette, M. A. (2001). A review of the effects of perceived drug use opportunity on selfreport urge. Experimental and Clinical Psychopharmacology, 9, 3-13. 



\section{Summary}

Harmful alcohol use is associated with a wide range of social and public health problems such as cardiovascular disease, cirrhosis of the liver, cancers, violence, fatal injuries, and road traffic accidents (WHO, 2004). Research on alcohol-drinking behaviour could offer some insight into the psychological mechanisms involved in the development and maintenance of this behaviour and this knowledge in turn could help us to develop useful interventions in order to decrease alcohol-induced mortality and morbidity.

Similar to eating and drinking, alcohol-drinking behaviour cannot be explained merely by its consequences, e.g., the appetitive effects of alcohol on the central nervous system (CNS). Cues that precede alcohol drinking and are repeatedly paired with alcohol administration may become pavlovian signals that elicit physiological and subjective responses that motivate alcohol drinking (Carter \& Tiffany, 1999; Drummond, 2000; Jansen, 1998). Craving, defined as the desire for alcohol, is one type of cue-elicited response (Drummond, 2001; Kozlowski \& Wilkinson, 1987; Sayette, Shiffman, Tiffany, Niaura, Martin, \& Shadel, 2000). However, not everyone experiences cue-elicited craving in the same way and personality factors such as impulsivity could account for individual differences (Drummond et al., 2000; Litt, Cooney, \& Morse, 2000; Rees \& Heather, 1995).

In general, impulsivity is defined as the tendency to act rashly and without consideration of the consequences of one's own behaviour (Dawe \& Loxton, 2004; Evenden, 1999; Moeller, Barratt, Dougherty, Schmitz, \& Swann, 200). Nevertheless, impulsivity appears to be a multidimensional concept as the multitude of behavioural tasks and self-report impulsivity measures do not always correlate with each other. The involvement of impulsivity in cue reactivity could explain some of the variability in cue-elicited responses and enable us to identify individuals for whom cue-elicited craving is a high risk factor for relapse.

The main goal of the present thesis is to investigate the relationship between cue-elicited craving for alcohol and impulsivity in social and dependent alcohol drinkers. We expected that higher impulsivity levels would be associated with stronger craving for alcohol. In the first study (Chapter 2), we investigated this relationship in heavy and light social drinkers. Impulsivity was measured with the stop signal task (response inhibition), Card Arranging Reward Responsivity Objective Test (CARROT, sensitivity to reward), and Barratt Impulsiveness scale version 11 (BIS-11, trait impulsiveness). We found evidence supporting our main hypothesis in heavy but not in light social drinkers. Heavy social drinkers with a less effi- 
cient response inhibition experience higher cue-elicited craving for alcohol than heavy social drinkers with more effective response inhibition.

In the second study (Chapter 3), we took into account the perceived availability of alcohol as there is evidence that it may play a role in cue reactivity (Wertz \& Sayette, 2001). First of all, it was hypothesized that cue-elicited craving for alcohol is higher when people perceive alcohol as being available than as being not available in the environment. Moreover, it was expected that social drinkers with less vs. more efficient response inhibition (stop signal task) experience higher cue-elicited craving for alcohol. Finally, it was hypothesised that the effects of perceived availability on cue-elicited craving for alcohol are stronger in social drinkers with less vs. more efficient response inhibition. Our results showed that response inhibition is not associated with cue-elicited craving for alcohol in moderate social drinkers, resembling the findings for the light drinkers in the first study. As expected, perceived availability of alcohol increases craving for alcohol during the cue exposure paradigm. Finally, confirming our last hypothesis, response inhibition modulates the relationship between perceived availability and cue-elicited craving in moderate social drinkers: participants with less effective response inhibition who expected alcohol experienced the highest craving during cue exposure.

In Chapter 4, we explored the mechanisms by which impulsivity modulates conditioned appetitive responses. One possibility is that impulsivity regulates appetitive learning processes. Thus, we examined the involvement of response inhibition (stop signal task), rash impulsiveness (short SSS), and reward sensitivity (BAS) in the acquisition and extinction of subjective appetitive responses for chocolate (craving/desire, expectancy, liking) and we successfully replicated Van Gucht, Vansteenwegen, Beckers, and Van den Bergh's (2008) main findings by demonstrating that not all appetitive responses are equally sensitive to extinction. Expectancy for chocolate in response to the CS+ extinguished successfully, while craving for chocolate in response to the CS+ and liking for the CS+ did not. However, our results do not support the involvement of impulsivity in the regulation of appetitive learning processes. We demonstrated that neither reward sensitivity nor response inhibition nor sensation seeking influence the speed or strength of acquisition and extinction of appetitive CRs (craving, expectancy, and liking).

In Chapter 5, we carry on our investigation in a clinical population. Participants were alcohol-dependent inpatients of the private clinic U-Center (Epen, the Netherlands) who took part in a cue reactivity study in which they were exposed to their favourite alcoholic drink in a real alcohol setting. Two impulsivity measures were taken in that study: response inhibition (stop signal task) and trait impulsiveness (BIS-11). It was hypothesized that i) alcohol-dependent people experience stronger craving for alcohol when exposed to alcohol than to water cues, ii) a higher trait impulsiveness score is associated with higher cue-elicited craving for alcohol, and iii) a less effective response inhibition is linked to stronger cue-elicited craving for alcohol. Our findings confirmed our hypotheses. Higher scores in trait impulsiveness are associated with a higher increase in craving for alcohol during the whole 
cue-exposure paradigm (water: baseline vs. exposure; alcohol: baseline vs. exposure in the bar-restaurant) and a higher absolute craving score in the barrestaurant. In addition, a less effective response inhibition predicts higher craving for alcohol only in the bar-restaurant (absolute score).

Finally, Chapter 6 consists of a small 3-month follow-up study in which we considered the role of impulsivity and cue-elicited craving in relapse. The participants in this study were former patients of the U-Center clinic who had been treated for alcohol use disorders and had an abstinence goal. All of them had participated in the cue-reactivity study described in Chapter 4 . We tested the hypothesis that cueelicited craving for alcohol and rash impulsiveness (BIS-11) predict relapse in former patients. It was found that higher cue-elicited craving during the cue exposure paradigm is associated with higher probability of relapse in former patients. An unexpected finding was the negative relationship between trait impulsiveness and relapse: higher scores in trait impulsiveness were associated with a lower probability to relapse.

Overall, the findings of the present thesis support the idea that higher impulsivity is associated with stronger cue-elicited craving for alcohol in both heavy and alcohol-dependent drinkers. Additionally, perceived availability of alcohol may serve as a component of the alcohol cue or context and could increase craving for alcohol. Furthermore, there is an interaction between impulsivity and perceived availability and as a result people who are more impulsive and perceive alcohol as being available in the environment may experience stronger craving. In turn, cueelicited craving for alcohol could predict alcohol-drinking and relapse in problem drinkers but its predictive value may depend on the context in which the cues are presented. Moreover, higher impulsivity levels could be associated with a higher probability of relapse indirectly via higher levels of cue-elicited craving. Although our findings suggest a negative relationship between impulsivity and relapse, this relationship could be modulated by other factors such as age, comorbidity, severity of dependence, etc.

Our findings have also clinical implications. For example, manipulations of perceived availability of alcohol should be included in the design of the future (clinical) studies. For example, being exposed to the cue of perceived availability without drinking could help the patients to extinguish the learning to this cue hence enabling them to learn to ignore it. Our results indicate that this strategy might be especially important to those patients with more deficient response inhibition. Furthermore, craving for alcohol is often used as an index of the treatment progress of the patient and our results highlight the importance of cue-elicited craving in relapse in alcohol-dependence. Thus, we recommend that cue exposure with response prevention (CERP) interventions should be incorporated into clinical practice (Conklin \& Tiffany, 2002). However, we suggest that special effort should be made to expose patients to the real-life alcohol setting, for example, at home or in their own favourite pub. Finally, if cue-elicited craving predicts relapse, it is important to differentiate between patients who respond to alcohol-related cues with 
higher craving from those who do not because the former group is more likely to relapse than the latter group. To achieve that, impulsivity measures should be incorporated into clinical practice as a way of identifying the most vulnerable patients.

Taken as a whole, the results of the present thesis display that higher impulsivity is associated with stronger cue-elicited craving for alcohol in heavy social and dependent alcohol drinkers and a stronger cue-elicited craving for alcohol predicts a higher probability of relapse in problem alcohol drinkers. Finally, perceived availability increases craving for alcohol and interacts with impulsivity so as impulsive people who perceive alcohol as being available in the environment experience higher craving than less impulsive people or people who perceive alcohol to be unavailable.

\section{References}

Carter, B. L., \& Tiffany, S. T. (1999). Meta-analysis of cue-reactivity in addiction research. Addiction, 94, 327-340.

Conklin, C. A., \& Tiffany, S. T. (2002). Applying extinction research and theory to cue-exposure addiction treatments. Addiction, 97, 155-167.

Dawe, S., Loxton, N. J. (2004). The role of impulsivity in the development of substance use and eating disorders. Neuroscience and Biobehavioral Reviews, 28, 343-351.

Drummond, D. C. (2000). Human models in craving research: What does cue-reactivity have to offer clinical research? Addiction, 95, S129-S144.

Drummond, D. C. (2001). Theories of drug craving, ancient and modern. Addiction, 96, 33-46.

Evenden, J. (1999). Impulsivity: a discussion of clinical and experimental findings. Journal of Psychopharmacology, 13, 180-192.

Jansen, A. (1998). A learning model of binge eating: cue reactivity and cue exposure. Behaviour Research and Therapy, 36, 257-272.

Kozlowski, L. T., \& Wilkinson, D. A. (1987). Use and misuse of the concept of craving by alcohol, tobacco, and drug researchers. British Journal of Addiction, 82, 31-36.

Litt, M. D., Cooney, N. L., \& Morse, P. (2000). Reactivity to alcohol-related stimuli in the laboratory and in the field: predictors of craving in treated alcoholics. Addiction, 95, 889-900.

Moeller, F. G., Barratt, E. S., Dougherty, D. M., Schmitz, J. M., \& Swann, A. C. (2001). Psychiatric aspects of impulsivity. American Journal of Psychiatry, 158, 1783-1793.

Rees, V. W., \& Heather, N. (1995). Individual differences and cue reactivity. In D. C. Drummond, S. T. Tiffany, S. Glautier, \& B. Remington (Eds.), Addictive behaviour: cue exposure theory and practice (pp. 99-118). New York: John Wiley \& Sons.

Sayette, M. A., Shiffman, S., Tiffany, S. T., Niaura, R. S., Martin, C. S., \& Shadel, W. G. (2000). Methodological approaches to craving research: the measurement of drug craving. Addiction, 95, S189-S210.

Van Gucht, D., Vansteenwegen, D., Beckers, T., Van den Bergh, O. (2008). Return of experimentally induced chocolate craving after extinction in a different context: Divergence between craving for and expecting to eat chocolate. Behaviour Research and Therapy, 46, 375-391.

Wertz, J. M., Sayette, M. A. (2001). A review of the effects of perceived drug use opportunity on selfreport urge. Experimental and Clinical Psychopharmacology, 9, 3-13.

WHO (2004). Global Status Report on Alcohol. Geneva. 


\section{Acknowledgements}

First of all, I would like to thank my promotor, Professor Anita Jansen, who offered me this PhD job opportunity four years ago. I would also like to thank from the bottom of my heart my supervisor, Dr. Chantal Nederkoorn, for all her help and support and especially her patience during the last four years. One of Chantal's merits is the ability to listen carefully before speaking and this is why she could say the right thing at the right moment. She was always there for me and I felt welcome in her office and free to ask her the most naïve questions. I am grateful to both Anita and Chantal for their tolerance, valuable feedback and constant guidance throughout these four years and most of all for giving me the freedom to explore my own ideas during the project. Additionally, being close to both of them enabled me to learn more about the academic world and to understand it a bit better.

My gratitude also goes to the rest of my co-authors in my publications, Dr. Remco Havermans, Dr. Janneke Giesen, Peggy Bongers, Jan Corstjens, and Shalana Beunen. Their contribution to my work was fundamental. Special thanks to Peggy Bongers and Shalana Beunen for their help during the U-Center clinical study. Without their help, I would not have been able to finish this study. But most of all, I enjoyed working and especially talking with them because they are wonderful persons. A big thank to Karolien van den Akker for sharing her bright ideas with me. I am always curious about her new ideas and I am astonished by her ability to design elaborate experiments to test them. Most of all, I find her to be a warm and supportive person and I am happy that she is my paranymphe. Furthermore, I would like to thank the rest of the eating group Eva Antoniou, Ghislaine Schyns, Bastiaan Boh, Jessica Alleva, Jessica Werthmann, Katrijn Houben, Anne Roefs, Carolien Martijn, and Sandra Mulkens for the time they devoted to listen to my ideas and their useful feedback. A big thank to Angela Verweij, Jessie Beerthuyzen, and Truus van Uijen for their invaluable help at work but also for their willingness to help me organize my life in Maastricht during the last four years. Finally, I would like to thank the UCenter clinic for their financial support of my PhD project. I am also grateful to all the members of the U-Center who helped me organize and run my studies. Special thanks to Ingrid Weijen, director of the U-Center, who allowed me to design and run my cue exposure study with the alcohol-dependent patients. Without Ingrid's help, this study would have never been done.

I would like to thank very much Pierre and Anita Castermans. All these years, they made me feel like family and I feel always welcome in their house. Pierre is a teacher and a friend who helped me to understand a bit better the Dutch culture 
and history and tried to help me learn the Dutch language. Unfortunately, my Dutch is still poor not because Pierre is a bad teacher but because I was a bad student. Despite my bad language skills, Maastricht and the Netherlands feel a bit more like home today and this is the result of these two sweet and warm people.

Special thanks to two friends Anna Sagana and Jan Corstjens. They are highly trustworthy people and they were willing to listen and support me in every way at any time. Jan was an assistant and co-author in one of my studies and I am happy that our relationship has developed deeper roots than a simple work relationship. As for Anna, I have spent so many hours in her office talking with her about everything and distracting her from her work and despite that she is still the most productive worker I have ever seen in my life! I am deeply honoured that she has accepted to be my paranymphe.

A special mention must be made of my close friends in Greece, Giannis Papadopoulos, Antonis Vaitsopoulos, Voula Vaitsopoulou, Dimitris Koutoulas, and Vasileios Kuriakidis for their support and encouragement during these years. I have known them since my childhood and despite the physical distance between us, I always felt their presence all these years. They have always stood by me and thanks to them I felt always welcome when I returned back to Greece. Most important, they were a healthy source of distraction for me and helped me to take a break from work in order to remain productive and "sane" during the rest of the year.

One of the most important people in my life is my fiancée Ioanna Tarasidou. I am deeply grateful to her for her emotional encouragement, practical help and support, and continuous reinforcement all these years. Ioanna is the most courageous person I have ever met. She followed me here in Maastricht four years ago and she has never left my side since then. She has helped me in all possible ways, from participating in my pilot trials to enduring me mumbling about the statistical analysis and interpretation of my results. Her sense of humour and good temper cheered me up in difficult moments and motivated me to keep working. Most of all, she is still with me! I am afraid that I cannot find the words to express my gratitude to her.

Last but not least, I am grateful to my mother Maria Papachristou, my sister Afroditi Papachristou, and my brother-in-law Charis Kapetanakis for their emotional support and practical assistance all these years. I shared with them all the good and sad moments of all these four years and I knew that they were always there for me. Especially my mother spent thousand of hours talking with me on the phone, trying to learn everything about my life and work here, and supporting me in all possible ways. She was always sensitive to my needs and could sense all my feelings simply from the tone of my voice. I owe my mother and my late father, Nikolaos Papachristou, a debt of gratitude because it was them who inspired me the love for books and knowledge. It was also them who encouraged me to enter the higher education and as a result I have finished this PhD today. Once more, I am afraid that my words cannot express my gratitude to them. 


\section{About the author}

Harilaos Papachristou was born in Thessaloniki, Greece, on the $15^{\text {th }}$ of January 1973. He started his studies in psychology in 2001 in Sussex University, at Brighton, UK. In 2004, he obtained his BSc in psychology and in 2005 he finished his first MSc in psychology (with distinction) in Substance Misuse in the same university. In 2006-2007, he completed his second MSc (with distinction) in psychology in the University of Wales, Bangor, UK (Foundations of Clinical Psychology). In 2008, he completed an internship in the B' University Psychiatric Clinic of the Faculty of Medicine in Aristotle University, Thessaloniki, Greece. In 2009, he completed his second internship in the Association of Alzheimer's Disease and Related Disorders, Thessaloniki, Greece. In September 2009, he started his PhD in psychology in the Department of Clinical Psychological Science (CPS) in the Faculty of Psychology and Neuroscience, in Maastricht University (the Netherlands) in collaboration with UCenter, which he finished successfully in 2013.

\section{Publications}

Papachristou, H., Nederkoorn, C., Havermans, R., van der Horst, M., \& Jansen, A. (2012). Can't stop the craving: The effect of impulsivity on cue-elicited craving for alcohol in heavy and light social drinkers. Psychopharmacology, 219, 511518.

Papachristou, H., Nederkoorn, C., Corstjens, J., Jansen, A. (2012). The role of impulsivity and perceived availability on cue-elicited craving for alcohol in social drinkers. Psychopharmacology, 224, 145-153.

Papachristou, H., Nederkoorn, C., Beunen, S., \& Jansen, A. (2013). Dissection of appetitive conditioning: Does impulsivity play a role? Appetite, 69, 46-53.

Papachristou, H., Nederkoorn, C., Havermans, R., Bongers, P., Beunen, S., \& Jansen, A. (2013). Higher levels of trait impulsiveness and a less effective response inhibition are linked to more intense cue-elicited craving for alcohol in alcoholdependent patients. Psychopharmacology, 228, 641-649.

Papachristou, H., Nederkoorn, C., Giesen, J. C. A. H., \& Jansen, A. (in revision). Cue reactivity during treatment, and not impulsivity, predicts relapse after treatment. 
Bongers, P., Jansen, A., Papachristou, H., Nederkoorn, C., Havermans, R. (2012). Over de te vroege teloorgang van exposure therapie voor verslaafden: wat is een goede exposure? Directieve Therapie, 32, 199-211.

Kaproukanidou, D., Papachristou H., Gousopoulos, E. (2009). Molecular mechanisms of learning and memory. Scientific Annals of the Medical School of Thessaloniki, 36(1), 6-21. 